\title{
Clinical, psychosocial and therapeutic aspects of irritable bowel syndrome : results of cohort studies and aprobiotic intervention trial
}

Citation for published version (APA):

Thijssen, A. Y. (2015). Clinical, psychosocial and therapeutic aspects of irritable bowel syndrome : results of cohort studies and aprobiotic intervention trial. [Doctoral Thesis, Maastricht University]. Datawyse / Universitaire Pers Maastricht. https://doi.org/10.26481/dis.20151119at

Document status and date:

Published: 01/01/2015

DOI:

10.26481/dis.20151119at

Document Version:

Publisher's PDF, also known as Version of record

Please check the document version of this publication:

- A submitted manuscript is the version of the article upon submission and before peer-review. There can be important differences between the submitted version and the official published version of record.

People interested in the research are advised to contact the author for the final version of the publication, or visit the DOI to the publisher's website.

- The final author version and the galley proof are versions of the publication after peer review.

- The final published version features the final layout of the paper including the volume, issue and page numbers.

Link to publication

\footnotetext{
General rights rights.

- You may freely distribute the URL identifying the publication in the public portal. please follow below link for the End User Agreement:

www.umlib.nl/taverne-license

Take down policy

If you believe that this document breaches copyright please contact us at:

repository@maastrichtuniversity.nl

providing details and we will investigate your claim.
}

Copyright and moral rights for the publications made accessible in the public portal are retained by the authors and/or other copyright owners and it is a condition of accessing publications that users recognise and abide by the legal requirements associated with these

- Users may download and print one copy of any publication from the public portal for the purpose of private study or research.

- You may not further distribute the material or use it for any profit-making activity or commercial gain

If the publication is distributed under the terms of Article $25 \mathrm{fa}$ of the Dutch Copyright Act, indicated by the "Taverne" license above, 


\section{Clinical, psychosocial and therapeutic aspects of Irritable Bowel Syndrome}

-Results of cohort studies and a probiotic intervention trial- 
(C) Copyright Annemieke Thijssen, Maastricht 2015

ISBN 9789461594709

Cover design: Stefani Wiatkowski

Lay-out: Tiny Wouters

Printing: Datawyse B.V., Maastricht

The studies presented in chapter 3 and 4 of this thesis were supported by a grant of Yakult Industries.

Reproduction of this thesis was financially supported by: Yakult Industries, Nederlandse Vereniging voor Gastroenterologie, Zambon Nederland B.V., Dr. Falk Pharma Benelux B.V., Ferring B.V., Will-Pharma B.V and Maastricht Universitair Medisch Centrum+. 


\title{
Clinical, psychosocial and therapeutic aspects of Irritable Bowel Syndrome
}

-Results of cohort studies and a probiotic intervention trial-

\author{
PROEFSCHRIFT
}

ter verkrijging van de graad van doctor aan de Universiteit Maastricht, op gezag van de Rector Magnificus, Prof. dr. L.L.G. Soete volgens het besluit van het College van Decanen,

in het openbaar te verdedigen op donderdag 19 november 2015 om 12.00 uur

door

Annemieke Yvonne Thijssen

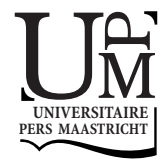




\section{Promotor}

Prof. Dr. A.A.M. Masclee

\section{Copromotoren}

Dr. C.H.M. Clemens, Alrijne Ziekenhuis Leiden

Dr. D.M.A.E. Jonkers

\section{Beoordelingscommissie}

Prof. dr. J.W.M. Muris (voorzitter)

Dr. J.J.M.H Strik

Dr. P.T.M. Weijenborg, Leids Universitair Medisch Centrum

Prof. dr. B. Witteman, Wageningen Universiteit 
The life of the dead is placed in the memory of the living. - Cicero - 



\section{Table of contents}

$\begin{array}{lll}\text { Chapter } 1 \text { General introduction } & 9\end{array}$

Chapter 2 Dysfunctional cognitions, anxiety and depression in 27 Irritable Bowel Syndrome

Chapter 3 Efficacy of Lactobacillus casei Shirota for patients with 41 Irritable Bowel Syndrome

Chapter 4 Explorative study on mechanisms contributing to beneficial effect of Lactobacillus casei Shirota probiotic treatment in Irritable Bowel Syndrome patients

Chapter 5 Plasma 5-hydroxytryptamine and 5-hydroxyindole acetic acid levels: indicators for altered serotonin metabolism in Irritable Bowel Syndrome?

Chapter 6 Gender differences in Irritable Bowel Syndrome, separate pathophysiological background?

Chapter 7 Symptoms in patients with Ulcerative Colitis in remission are associated with visceral hypersensitivity and mast cell activity

Chapter 8 General discussion

Summary

Samenvatting

Valorisation addendum

Dankwoord 



\section{CHAPTER 1}

General introduction 
Chapter 1 


\section{IRRITABLE BOWEL SYNDROME}

Irritable Bowel Syndrome (IBS) is part of the group of Functional Gastrointestinal Disorders. ${ }^{1}$ The disorder is characterized by chronic, recurrent abdominal pain or discomfort associated with alterations in the pattern of defecation, in absence of an organic cause. ${ }^{2,3}$ The prevalence of IBS among the European population ranges between $6-12 \%{ }^{4}$ and it is assumed that at least $20 \%$ of the population is affected at some time during life. ${ }^{5}$

The onset of IBS peaks between 25-55 years of age, ${ }^{4}$ with up to two-third of the patients being female. IBS patients experience a pronounced impairment in their quality of life (QoL) ${ }^{6-10}$ comparable to patients with gastro-esophageal reflux disease ${ }^{11}$ and patients with ulcerative colitis. ${ }^{12}$ This impairment in QoL leads to excessive health care seeking and consumption, ${ }^{13}$ resulting in additional costs and economic burden. ${ }^{14,15}$ It is challenging to diagnose IBS because of the lack of specific biological markers. ${ }^{16}$ In daily clinical practice, the diagnosis of IBS is symptom-based and usually confirmed after the exclusion of organic diseases. In 1978, Manning was the first to introduce diagnostic criteria for IBS. These criteria were based on symptoms of distension, relief of pain with bowel movement and more frequent and looser stools at the onset of pain. ${ }^{17}$ Since then, the diagnostic criteria have been revised by a team of experts into the Rome criteria, resulting subsequently in the Rome I, II and III criteria (Table 1.1). ${ }^{2}$ The latter are currently used, but a revision leading to the Rome IV criteria is in preparation.

Table 1.1

\begin{tabular}{ll}
\hline Rome II Criteria (1999) & Rome III Criteria (2006) \\
\hline $\begin{array}{l}\text { At least } 12 \text { weeks in the last } 12 \text { months of abdominal } \\
\text { discomfort or pain with } 2 \text { out of } 3\end{array}$ & $\begin{array}{l}\text { Recurrent abdominal pain or discomfort at least } 3 \\
\text { days/month in the last } 3 \text { months } \\
\text { of the following: }\end{array}$ \\
\begin{tabular}{ll} 
- $\quad$ Relieve of discomfort/pain by defecation & Improvement with defecation \\
- Onset associated with a change in frequency of & - Onset associated with a change in frequency of \\
stool & stool \\
- Onset associated with a change in form of stool & - Onset associated with a change in form of stool \\
& Criteria fulfilled for the last 3 months with \\
& symptom onset at least 6 months prior to diagnosis \\
\hline
\end{tabular}
\end{tabular}

Adapted from www.romecriteria.org

Adequate history taking with absence of alarm symptoms and application of the Rome criteria are the basis for diagnosing IBS. ${ }^{16,18}$ The criteria allow further subtyping based on predominant bowel habits: diarrhea predominant (IBS-D), constipation predominant (IBS-C), alternating or mixed stool pattern (IBS-M) and the undefined subtype (IBS-U). The latter category is used for patients in whom complaints of pain dominate over 
irregular defecation patterns., ${ }^{2,19}$ The Rome criteria are frequently used to select patients for inclusion in clinical trials, but clinicians do not regularly apply the Rome criteria to screen for IBS in daily practice. The criteria are not validated for daily clinical practice and do not include bloating, which is a prominent symptom of IBS. Furthermore, the presence of abdominal pain is probably linked to the amount of bloating and to what extent bowel function is altered. ${ }^{20}$

\section{Gender differences}

IBS shows a clear female predominance, with up to two-third of patients being female. ${ }^{21,22}$ Furthermore, several studies have shown that women report more intense and more frequent abdominal pain $^{23}$ and more constipation related symptoms. In addition, the IBS-C subtype is more frequent among females, while males more frequently report diarrhea related symptoms and more frequently have IBS-D subtype. ${ }^{24-27}$ Women with IBS are also more likely to report additional functional gastrointestinal (GI) conditions ${ }^{24,28}$ and many, if not all comorbid diseases associated with IBS, share the female predominance. ${ }^{29-31}$

Although female IBS patients are more likely to seek healthcare, ${ }^{23}$ the exact reasons for the gender differences in IBS remain poorly understood. Biological, behavioural, psychological and sociocultural factors might to involved. ${ }^{29}$

\section{PATHOPHYSIOLOGY}

The pathophysiology of IBS is still poorly understood, but is generally considered to be multifactorial in origin, ${ }^{32}$ including intestinal, central nervous system and psychological features. ${ }^{33}$ Many studies have focused on psychosocial factors, ${ }^{34}$ the role of serotonin metabolism, ${ }^{35}$ visceral hypersensitivity, ${ }^{36}$ altered gut permeability, ${ }^{37}$ low grade inflammation $^{38}$ and microbiota changes. ${ }^{39}$

\section{Psychosocial factors}

An association between IBS and psychosocial factors has repeatedly been described in literature. Acute and chronic stress, childhood trauma and abuse history are known to significantly affect symptom severity, illness behavior and quality of life in IBS patients. $^{34,40-42}$ Neuroticism, anxiety and depression have also been reported to be more prevalent and to influence symptom severity in IBS patients, ${ }^{6,43-45}$ for which females and younger adults were found to be most vulnerable. ${ }^{46}$ Several studies suggest that psychological comorbidity might be a risk factor for changes along the brain-gut axis leading to the onset of IBS, persistence of symptoms and abnormal illness behaviour. ${ }^{47-49}$ Guthrie et al found that $44 \%$ of IBS patients to have psychiatric co- 
morbidity, consisting mainly of depression and anxiety related mood disorders. ${ }^{50}$ The co-morbid psycho-pathology is found to have a negative impact on symptom severity, QoL, and work absenteeism in IBS. ${ }^{51}$ Furthermore, symptom severity is affected by the presence of dysfunctional cognitions. ${ }^{45,52,53}$ These cognitions are automatically occurring negative or catastrophizing thoughts induced by psychological distress and by (severe) physical symptoms. Dysfunctional cognitions scores are more prominent in a cohort of therapy refractory IBS patients. ${ }^{54}$ It remains to be established whether dysfunctional cognitions are associated with the presence of anxiety or depression and how dysfunctional cognitions influence quality of life and symptom severity in the general IBS population.

\section{Serotonin metabolism}

Nowadays, it is well accepted that IBS is associated with a dysregulation along the brain-gut axis in a bidirectional way, in which serotonin (5-hydroxytryptamine, 5-HT) is thought to play a key role. ${ }^{35,55} 5-\mathrm{HT}$ modulates an extensive range of physiological and behavioral processes in the brain ${ }^{56}$ and has a crucial role in specific brain structures regulating cognitive function and mood and is potentially relevant in the onset of anxiety and depression. ${ }^{57-59} 5-\mathrm{HT}$ is released predominantly by the enterochromaffin (EC) cells in the GI tract and is also known to regulate normal physiological functioning of the GI tract, including $\mathrm{GI}$ secretion, motility and perception. ${ }^{60}$

Previous studies have explored serotonin metabolism in IBS, but results are difficult to interpret and contradicting. Increased plasma 5-HT levels have been found in IBS, ${ }^{61-64}$ both in fasting and postprandial condition, while other did not find a difference in fasting 5-HT levels or levels were undetectable. ${ }^{62,65}$ With respect to plasma 5hydroxyindole acetic acid (5-HIAA), the degradation product of 5-HT, Atkinson et al found that 5-HIAA levels in IBS-C were slightly decreased. ${ }^{64}$ The 5-HIAA/5-HT ratio, representing turnover of 5-HT, was also found to be decreased. ${ }^{61,62}$

Overall findings regarding systemic changes in 5-HT metabolism are not consistent, partly because of the small numbers of patients studied. Data from larger wellcharacterized IBS cohorts are needed.

\section{Visceral hypersensitivity}

Visceral sensations are transmitted from the gut via afferent nerves, via the spinal cord to the brain, where painful stimuli are perceived. Visceral sensations, i.e. urge, pain and discomfort are subjective sensations resulting from central processing of visceral afferent input. These sensations are modulated by ecological factors as well as memories, emotional, motivational and cognitive factors. ${ }^{38}$ Several studies have demonstrated that patients with IBS have lower perception thresholds and increased sensations of urge, discomfort and pain during mechanical balloon distension both in 
the colon and rectum. The prevalence of visceral hypersensitivity in IBS patients varies between studies and ranges from 33 to $58 \%{ }^{38,66-70}$ Although clinical outcome in IBS patients in relation to visceral hypersensitivity is not clear, ${ }^{71}$ visceral hypersensitivity was found to be associated with more pronounced symptom severity. ${ }^{68,72}$

The mechanisms underlying visceral hypersensitivity are not fully understood, but it has been hypothesized that both peripheral and central mechanisms are involved. Visceral pain processing, by peripheral sensory input, spinal cord and supraspinal centra, all contribute to development of hypersensitivity in IBS. However, between patients, the contribution of central or peripheral factors may differ. ${ }^{73}$ In IBS-D patients a significant positive correlation has been found between increased gut permeability, visceral hypersensitivity and IBS symptom scores, suggesting a role for an impaired intestinal barrier function in visceral hypersensitivity or vice versa. ${ }^{74}$

\section{Intestinal barrier function}

The Gl tract provides a protective barrier between the outer and inner world with constant challenges and threats at the luminal side originating from microorganisms, food-derived antigens and toxic substances. A diminished function of the intestinal barrier, resulting from increased intestinal permeability, contributes to increased antigen transfer and exposure, and immune responses, which may contribute to hypersensitivity and intestinal inflammation. ${ }^{37,75,76}$ Two different routes are available for cellular transport along the intestinal barrier: the transcellular and paracellular route. The latter route is regulated by tight junctions (TJs) and adherence junctions between the epithelial cells of the intestinal mucosa. ${ }^{77}$ TJs appear as a network of sealing strands and act as a physical intercellular barrier that controls paracellular transport. ${ }^{78}$ TJs are composed of several transmembrane proteins: claudins, the integral membrane protein occludin and junction adhesion molecules. Another group of proteins are located at the cytoplasmic side, the zona occludens, i.e. ZO-1, ZO-2 and ZO3 proteins. $^{79}$ Increased intestinal permeability has been reported in IBS-D ${ }^{80,81}$ and post infectious (PI-)IBS patients, ${ }^{82,83}$ but also in a heterogeneous group of IBS patients, lower expression of ZO-1 mRNA in colonic biopsies has been reported. ${ }^{84}$

\section{Low grade inflammation}

A significant subset of IBS patients develops IBS after an episode of acute gastroenteritis, ${ }^{85-87}$ usually referred to as PI-IBS. This specific subset underlines the role of ongoing (low grade) inflammatory processes in IBS. Although routine histology does not reveal marked mucosal abnormalities, quantitative histology and immunohistochemistry point towards subtle morphologic changes in IBS patients. ${ }^{88-90}$ For example, in PI-IBS patients, serotonin containing EC cell and lamina propria T lymphocyte counts are higher in contrast to healthy volunteers. ${ }^{43}$ Furthermore, a higher 
colonic mast cell count, mast cell infiltration and increased mast cell mediator release in close proximity to mucosal nerve endings have been observed. These findings were associated with abdominal symptoms and visceral hypersensitivity in IBS patients. ${ }^{88}$ In IBS patients, a significant increase in baseline unstimulated pro-inflammatory cytokines TNF- $\alpha$, IL-1 $\beta$, IL- 6 and IL- 8 has been described, ${ }^{91,92}$ although overall increases are rather modest. In addition, O'Mahony et al. found an unfavourable significantly lower IL-10/IL-12 ratio, pointing to a pro-inflammatory state in IBS patients compared to healthy volunteers. ${ }^{93}$

In addition to $\mathrm{Gl}$ pathogens or alterations in the intestinal microbiota, the increased permeability found at least in subsets of patients, ${ }^{94}$ may contribute to low grade intestinal inflammation. How the immune activation contributes to generation of $\mathrm{Gl}$ symptoms is not completely clear, but increased mast cell counts correlate with abdominal pain and visceral hypersensitivity in IBS patients. ${ }^{88}$

A low grade inflammation with normal endoscopic findings has also been reported in patients with Ulcerative Colitis (UC) in remission. Remarkably, one third of these patients experiences symptoms that resemble IBS. Whether low grade inflammation, characterized by increased mast cell counts, and/or visceral hypersensitivity are present in UC patients in remission remains to be established.

\section{Microbiota}

The normal adult microbiome consist of over $10^{14}$ microorganisms and is crucial to the hosts' wellbeing. ${ }^{95}$ Bacterial densities are lowest in the stomach and upper small intestine, higher in the distal ileum and highest in the colon, where anaerobe bacteria predominate. ${ }^{96}$ The microbiota is composed of more than 1000 different species (i.e. phylotypes) ${ }^{97}$ and is dominated by two phyla: the Bacteroidetes and the Firmicutes. ${ }^{98}$ Important functions of the microbiota are:

- Protection against pathogens by colonisation resistance;

- Metabolism of substrates such as fermentation of non-digestible dietary residues like oligosaccharides, and proteins;

- Control of epithelial cell proliferation and differentiation, development and homeostasis of the immune system. ${ }^{99}$

Disturbances in GI microbiota composition have been reported in several Gl diseases and may have a role in the pathogenesis and clinical expression thereof. ${ }^{100}$ Studies showing associations with antibiotic use, prior gastroenteritis or presence of small bacterial overgrowth in IBS provide evidence for a role of the microbiome in the etiology of IBS. ${ }^{39,101,102}$ Differences between IBS patients and controls have been observed with respect to microbiota composition and microbial activity. While up to recently microbial analyses were culture based, at present molecular techniques have become the standard. ${ }^{103-108}$ There is general agreement that the microbiota 
composition is altered in IBS when compared to controls, but a specific microbial signature in IBS has not yet been identified. ${ }^{109}$ This might be affected by differences in methods and criteria for patient inclusion. Variations in microbial composition related to IBS subtype, gender, host genetics and presence of comorbidities have usually not been taken into account. ${ }^{20,110}$

Changes in microbiota composition and activity may result in bile acid malabsorption, altered intestinal motor and sensory function, mucosal immune activation, minimal inflammation and increased fermentation of substrates leading to excess gas production. All these factors bear relevance with respect to symptom generation in IBS. ${ }^{110,111}$ Altering the composition and/or activity of the microbiota, for example by the use of probiotics, is therefore an attractive therapeutic option in IBS. ${ }^{39}$

\section{PROBIOTICS}

Probiotics are defined as "viable mono- or mixed cultures of micro-organisms (mostly bifidobacteria and/or lactobacilli) which, when applied to humans or animals, may beneficially influence the host. ${ }^{112}$ Probiotic bacteria have to survive passage through the GI tract, including gastric, biliary and pancreatic juices. In order for probiotics to interact with the immune system, they should adhere to the intestinal mucosa, which is more likely with host-specific strains. An acceptable taste, smell and shelf-life of the probiotic product is also required. ${ }^{113}$ The main probiotic preparations currently on the market contain lactic acid bacteria (e.g. lactobacilli, streptococci, bifidobacteria), which are all normal constituents of the human GI microbiota. ${ }^{114}$

\section{Mechanisms of action}

The main mechanisms of action of probiotics depend on competition between bacteria, interactions with host immunocompetent cells of the intestinal mucosa, and secretion of bacterial products. ${ }^{114-116}$ First, an antagonistic activity against pathogenic bacteria may occur, which is probably the result of competition for adhesion sites. ${ }^{117}$ Furthermore, production of antibacterial substances such as antimicrobial peptides and hydrogen peroxide can inhibit action of pathogenic bacteria. ${ }^{118}$ Secondly, probiotics are able to stimulate and modulate the host defenses and barrier function, including the innate and the acquired immune system. ${ }^{115,117,119}$ An increase of secretory IgA production, decrease of pro-inflammatory cytokines, enhancement of antiinflammatory cytokine levels, stimulation of intestinal mucin expression and improvement of gut permeability have been reported. ${ }^{118}$ Furthermore, probiotics are able to beneficially influence phagocytosis and natural killer (NK) cell activity, and influence dendritic cell (DC) maturation. ${ }^{119}$ DCs are critical players in both innate and 
adaptive immunity because of their antigen presenting capacity, their ability to activate naïve T-cells and their pivotal role in directing helper T-cell responses. ${ }^{120}$ The third mechanism of action of a probiotic involves production of metabolites important for the host, such as short-chain fatty acids and vitamins. ${ }^{118}$ It should be noted that mechanisms differ between bacterial strains and/or species.

\section{Probiotics in IBS}

The rationale for application of probiotics in IBS is based on their potential to affect the composition and metabolic activity of the intestinal microbiota and to influence the immune system via specific receptors. ${ }^{121}$ Probiotics may induce a protective effect on intestinal barrier function, being able to restore or prevent damage to the epithelial integrity. Such evidence comes from in vitro studies with cell lines or in animal models. ${ }^{122-124}$ An example is the observation that a multispecies probiotic was able to prevent disruption of the epithelial barrier and development of visceral hypersensitivity in a mice model. ${ }^{125}$ Beneficial effects of probiotic treatment on visceral hypersensitivity have also been shown in rats. ${ }^{126-129}$

Concerning human data, the level of evidence on relevant and persistent effects of probiotics in IBS patients is moderate. A recent meta-analysis indicated that probiotics are effective as a therapy for IBS in terms of improvement of symptom scores with a number needed to treat of 7 , with only rare adverse events (number needed to harm $35){ }^{130}$ The overall benefit is generally modest. Most of those studies only assess the effect of probiotic administration on symptoms and quality of life, lacking insight into the possible mechanisms of action in the IBS pathophysiology.

Findings of individual studies are difficult to compare as different treatment strategies have been used (bacterial composition, number of bacteria, duration of treatment, control on patient compliance etc.). Potentially beneficial effects of one specific probiotic strain cannot be extrapolated to others or when combinations of strains are used. ${ }^{114}$ Even closely related bacterial strains of the same species may have different physiological effects. Further insight into the mechanisms of actions of probiotics in IBS patients, may result in more targeted interventions and improves overall outcome.

\section{Lactobacillus casei strain Shirota}

The probiotic strain Lactobacillus casei Shirota (LCS) is commercially available as Yakult . One bottle of this fermented milk drink $\left(65 \mathrm{ml}\right.$ ) contains at least $6.5 \times 10^{9} \mathrm{CFU}$ living LCS and the metabolic products of the fermentation process. LcS is known to have an adequate survival throughout the GI-tract, since it has been recovered from fecal human samples reaching levels of $10^{7} \mathrm{CFU}$ per gram of wet feces. ${ }^{112,131} \mathrm{~A}$ randomised controlled study of LCS in 70 subjects with chronic constipation found a significant improvement of bowel habits. ${ }^{132} \mathrm{~A}$ pilot study conducted by Barrett et al. ${ }^{133}$ found that 
consumption of LCS for six weeks by IBS patients, resulted in a change in early rise of breath hydrogen after lactulose intake, suggesting a decrease in small intestinal bacterial (over)growth. Effects of LCS on immune parameters have been studied extensively in animal models, in vitro, ex vivo and also in in vivo human studies. The enhancement of NK cell toxicity has been shown in several trials, an effect that even lasted after stopping consumption of LcS. ${ }^{112,134-136}$ LcS has also been shown to promote Th1 mediated responses, ${ }^{137-139}$ by an increased release of Th1 associated cytokines IL-12 and TNF- $\alpha{ }^{140}$ In line with these effects LCS suppressed allergic responses in a mice model of allergic airway disease, ${ }^{141}$ a rat model of peanut allergy ${ }^{142}$ and in human seasonal allergic rhinitis. ${ }^{143}$ However, a dextran sodium sulfate induced colitis model in mice showed that LcS was not able to prevent the induction of colitis, but anemia and bodyweight did markedly improve in the LCS treated mice compared to the control group. ${ }^{144}$ In patients with well-compensated alcoholic liver cirrhosis, LcS has been shown to normalize phagocytic capacity and IL-10 levels both of which are elevated in cirrhotic patients. ${ }^{145}$

Based on these data, a beneficial effect of LCS in IBS patients has been postulated. However, no studies have been performed on the use of LCS in IBS. 


\section{AIMS AND OUTLINE OF THE THESIS}

IBS is a highly prevalent functional GI disorder with a female predominance and heterogeneous phenotype, of which the pathophysiology remains poorly understood. In the current thesis we aim to study psychosocial, central and intestinal factors as well as patients characteristics that may affect symptom scores in patients with IBS.

Chapter 2 focuses on the impact of concurrent psychopathology on symptom severity and quality of life in IBS patients. Baseline data from several IBS intervention studies were pooled to investigate presence of anxiety, depression and dysfunctional cognitions and their influence on symptom severity and QoL in a large cohort of IBS patients. A randomized, placebo controlled and double blinded study with the probiotic LcS was then executed to assess the influence of this treatment on symptoms and quality of life in IBS patients. Results of this trial have been described in chapter 3. Chapter 4 explores possible underlying mechanisms related to various intestinal factors (i.e. intestinal inflammation, barrier function and visceral perception) contributing to a beneficial effect of the probiotic LCS in IBS patients.

Serotonin is a neurotransmitter with important functions in both the brain and the gut, which may be altered in IBS. A large, well characterized IBS patient cohort (MaastrichtIBS cohort) created the possibility to investigate serotonin metabolism and the possible impact of IBS subtype, anxiety and/or depression in IBS patients compared to healthy controls. Results of this study are presented in chapter 5 . Chapter 6 extends on the observations in chapters 3 and 5 with respect to gender differences. The Maastricht-IBS cohort was used to search for specific biomarkers related to various pathophysiological mechanisms that may contribute to differences in clinical expression and therapy response between female and male IBS patients.

Visceral hypersensitivity and increased mast cell numbers have been reported in several studies to be associated with IBS. However, it is unclear whether these factors may also contribute to IBS-like symptoms found in a large part of patients with UC in remission. Therefore, in chapter 7 we performed barostat studies, acquired rectal biopsies for mast cell counts and electron microscopy analysis in patients with UC in remission with IBS like symptomatology and healthy controls. Finally, Chapter 8 summarizes the studies presented in this thesis, discussing the results and implications for future research. 


\section{REFERENCES}

1. Drossman DA, Camilleri M, Mayer EA, Whitehead WE. AGA technical review on irritable bowel syndrome. Gastroenterology. 2002;123:2108-31.

2. Longstreth GF, Thompson WG, Chey WD, Houghton LA, Mearin F, Spiller RC. Functional bowel disorders. Gastroenterology. 2006;130:1480-91.

3. De Giorgio R, Barbara G, Stanghellini V, Cremon C, Salvioli B, De Ponti F, Corinaldesi R. Diagnosis and therapy of irritable bowel syndrome. Aliment Pharmacol Ther. 2004;20 Suppl 2:10-22.

4. Hungin AP, Whorwell PJ, Tack J, Mearin F. The prevalence, patterns and impact of irritable bowel syndrome: an international survey of 40,000 subjects. Aliment Pharmacol Ther. 2003;17:643-50.

5. Jones R, Lydeard S. Irritable bowel syndrome in the general population. BMJ (Clinical research ed. 1992;304:87-90.

6. Whitehead WE, Burnett CK, Cook EW, 3rd, Taub E. Impact of irritable bowel syndrome on quality of life. Dig Dis Sci. 1996;41:2248-53.

7. Patrick DL, Drossman DA, Frederick IO, DiCesare J, Puder KL. Quality of life in persons with irritable bowel syndrome: development and validation of a new measure. Dig Dis Sci. 1998;43:400-11.

8. Hahn BA, Kirchdoerfer L, Fullerton S, Mayer E. Evaluation of a new quality of life questionnaire for patients with irritable bowel syndrome. Aliment Pharmacol Ther. 1997;11: 547-52.

9. Luscombe FA. Health-related quality of life and associated psychosocial factors in irritable bowel syndrome: a review. Qual Life Res. 2000;9:161-76.

10. Koloski NA, Talley NJ, Boyce PM. The impact of functional gastrointestinal disorders on quality of life. Am J Gastroenterol. 2000;95:67-71.

11. Gralnek IM, Hays RD, Kilbourne A, Naliboff B, Mayer EA. The impact of irritable bowel syndrome on health-related quality of life. Gastroenterology. 2000;119:654-60.

12. Seres $G$, Kovács $Z$, Kovács $A$, Kerékgyártó $O$, Sárdi $K$, Demeter $P$, Mészáros E, Túry $F$. Different associations of health related quality of life with pain, psychological distress and coping strategies in patients with irritable bowel syndrome and inflammatory bowel disorder. J Clin Psychol Med Settings. 2008;15:287-95.

13. Creed F, Ratcliffe J, Fernandez L, Tomenson B, Palmer S, Rigby C, Guthrie E, Read N, Thompson D. Health-related quality of life and health care costs in severe, refractory irritable bowel syndrome. Ann Intern Med. 2001;134:860-8.

14. Badia X, Mearin F, Balboa A, Baró E, Caldwell E, Cucala M, Díaz-Rubio M, Fueyo A, Ponce J, Roset M, Talley NJ. Burden of illness in irritable bowel syndrome comparing Rome I and Rome II criteria. Pharmacoeconomics. 2002;20: 749-58.

15. Williams RE, Black CL, Kim HY, Andrews EB, Mangel AW, Buda JJ, Cook SF. Determinants of healthcareseeking behaviour among subjects with irritable bowel syndrome. Aliment Pharmacol Ther. 2006;23:1667-75.

16. Camilleri M, Heading RC, Thompson WG. Clinical perspectives, mechanisms, diagnosis and management of irritable bowel syndrome. Aliment Pharmacol Ther. 2002;16: 1407-30.

17. Manning AP, Thompson WG, Heaton KW, Morris AF. Towards positive diagnosis of the irritable bowel. BMJ. 1978;2:653-4.

18. Olden KW. Diagnosis of irritable bowel syndrome. Gastroenterology. 2002;122:1701-14.

19. El-Salhy M. Irritable bowel syndrome: diagnosis and pathogenesis. World J Gastroenterol. 2012;18:5151-63.

20. Pimentel M, Talley NJ, Quigley EM, Hani A, Sharara A, Mahachai V. Report from the multinational irritable bowel syndrome initiative 2012. Gastroenterology. 2013;144:e1-5.

21. Heitkemper MM, Jarrett ME. Update on irritable bowel syndrome and gender differences. Nutr Clin Pract. 2008;23:275-83.

22. Schmulson M, Adeyemo M, Gutiérrez-Reyes G, Charúa-Guindic L, Farfán-Labonne B, Ostrosky-Solis F, Díaz-Anzaldúa A, Medina L, Chang L. Differences in gastrointestinal symptoms according to gender in Rome II positive IBS and dyspepsia in a Latin American population. Am J Gastroenterol. 2010;105: 925-32. 
23. Adeyemo MA, Spiegel BM, Chang L. Meta-analysis: do irritable bowel syndrome symptoms vary between men and women? Aliment Pharmacol Ther. 2010;32:738-55.

24. Lee OY, Mayer EA, Schmulson M, Chang L, Naliboff B. Gender-related differences in IBS symptoms. Am J Gastroenterol. 2001;96:2184-93.

25. Anbardan SJ, Daryani NE, Fereshtehnejad SM, Taba Taba Vakili S, Keramati MR, Ajdarkosh H. Gender Role in Irritable Bowel Syndrome: A Comparison of Irritable Bowel Syndrome Module (ROME III) Between Male and Female Patients. J Neurogastroenterol Motil. 2012; 18:70-7.

26. Herman J, Pokkunuri V, Braham L, Pimentel M. Gender distribution in irritable bowel syndrome is proportional to the severity of constipation relative to diarrhea. Gend Med. 2010;7:240-6.

27. Thijssen AY, Jonkers DM, Leue $C$, van der Veek PP, Vidakovic-Vukic M, van Rood YR, Clemens $\mathrm{CH}$, Masclee AA. Dysfunctional cognitions, anxiety and depression in irritable bowel syndrome. J Clin Gastroenterol. 2010;44:e236-41.

28. Chang L, Toner BB, Fukudo S, Guthrie E, Locke GR, Norton NJ, Sperber AD. Gender, age, society, culture, and the patient's perspective in the functional gastrointestinal disorders. Gastroenterology. 2006; 130:1435-46.

29. Chang L, Heitkemper MM. Gender differences in irritable bowel syndrome. Gastroenterology. 2002;123:1686-701.

30. Whitehead WE, Palsson OS, Levy RR, Feld AD, Turner M, Von Korff M. Comorbidity in irritable bowel syndrome. Am J Gastroenterol. 2007;102:2767-76.

31. Meleine M, Matricon J. Gender-related differences in irritable bowel syndrome: potential mechanisms of sex hormones. World J Gastroenterol. 2014;20:6725-43.

32. Mertz HR. Irritable bowel syndrome. N Engl J Med. 2003;349:2136-46.

33. Camilleri M, Di Lorenzo C. Brain-gut axis: from basic understanding to treatment of IBS and related disorders. J Pediatr Gastroenterol Nutr. 2012;54:446-53.

34. Budavari Al, Olden KW. Psychosocial aspects of functional gastrointestinal disorders. Gastroenterol Clin North Am. 2003;32:477-506.

35. Kim DY, Camilleri M. Serotonin: a mediator of the brain-gut connection. Am J Gastroenterol. 2000;95:2698-709.

36. Bouin $M$, Plourde $V$, Boivin $M$, Riberdy $M$, Lupien $F$, Laganière $M$, Verrier $P$, Poitras $P$. Rectal distention testing in patients with irritable bowel syndrome: sensitivity, specificity, and predictive values of pain sensory thresholds. Gastroenterology. 2002;122:1771-7.

37. Barbara G. Mucosal barrier defects in irritable bowel syndrome. Who left the door open? Am J Gastroenterol. 2006;101:1295-8.

38. Azpiroz F, Bouin M, Camilleri M, Mayer EA, Poitras P, Serra J, Spiller RC. Mechanisms of hypersensitivity in IBS and functional disorders. Neurogastroenterol Motil. 2007;19:62-88.

39. Parkes GC, Brostoff J, Whelan K, Sanderson JD. Gastrointestinal microbiota in irritable bowel syndrome: their role in its pathogenesis and treatment. Am J Gastroenterol. 2008;103:1557-67.

40. Levy RL, Olden KW, Naliboff BD, Bradley LA, Francisconi C, Drossman DA, Creed F. Psychosocial aspects of the functional gastrointestinal disorders. Gastroenterology. 2006;130: 1447-58.

41. Chitkara DK, van Tilburg MA, Blois-Martin N, Whitehead WE. Early life risk factors that contribute to irritable bowel syndrome in adults: a systematic review. Am J Gastroenterol. 2008; 103:765-74; quiz 75.

42. Locke GR, 3rd, Weaver AL, Melton LJ, 3rd, Talley NJ. Psychosocial factors are linked to functional gastrointestinal disorders: a population based nested case-control study. Am J Gastroenterol. 2004; 99:350-7.

43. Dunlop SP, Jenkins D, Neal KR, Spiller RC. Relative importance of enterochromaffin cell hyperplasia, anxiety, and depression in postinfectious IBS. Gastroenterology. 2003;125: 1651-9.

44. Gwee KA, Graham JC, McKendrick MW, Collins SM, Marshall JS, Walters SJ, Read NW. Psychometric scores and persistence of irritable bowel after infectious diarrhoea. Lancet. 1996;347:150-3.

45. Kovacs Z, Kovacs F. Depressive and anxiety symptoms, dysfunctional attitudes and social aspects in irritable bowel syndrome and inflammatory bowel disease. Int J Psychiatry Med. 2007;37:245-55.

46. Spiller RC. Irritable bowel syndrome: gender, infection, lifestyle or what else? Dig Dis. 2011;29:215-21.

47. Surdea-Blaga T, Baban A, Dumitrascu DL. Psychosocial determinants of irritable bowel syndrome. World J Gastroenterol. 2012;18:616-26. 
48. Bradford K, Shih W, Videlock EJ, Presson AP, Naliboff BD, Mayer EA, Chang L. Association between early adverse life events and irritable bowel syndrome. Clin Gastroenterol Hepatol 2012;10:385-90 e1-3.

49. Sykes MA, Blanchard EB, Lackner J, Keefer L, Krasner S. Psychopathology in irritable bowel syndrome: support for a psychophysiological model. J Behav Med. 2003;26:361-72.

50. Guthrie E, Creed F, Fernandes L, Ratcliffe J, Van Der Jagt J, Martin J, Howlett S, Read N, Barlow J, Thompson D, Tomenson B. Cluster analysis of symptoms and health seeking behaviour differentiates subgroups of patients with severe irritable bowel syndrome. Gut. 2003;52:1616-22.

51. Singh P, Agnihotri A, Pathak MK, Shirazi A, Tiwari RP, Sreenivas V, Sagar R, Makharia GK. Psychiatric, somatic and other functional gastrointestinal disorders in patients with irritable bowel syndrome at a tertiary care center. J Neurogastroenterol Motil. 2012;18:324-31.

52. Gonsalkorale WM, Houghton LA, Whorwell PJ. Hypnotherapy in irritable bowel syndrome: a large-scale audit of a clinical service with examination of factors influencing responsiveness. Am J Gastroenterol. 2002;97:954-61.

53. Sugaya N, Nomura S. Relationship between cognitive appraisals of symptoms and negative mood for subtypes of irritable bowel syndrome. BioPsychoSocial medicine. 2008;2:9.

54. Gonsalkorale WM, Toner BB, Whorwell PJ. Cognitive change in patients undergoing hypnotherapy for irritable bowel syndrome. J Psychosom Res. 2004;56:271-8.

55. Berger M, Gray JA, Roth BL. The expanded biology of serotonin. Annu Rev Med. 2009;60: 355-66.

56. Cremon C, Carini G, Wang B, Vasina V, Cogliandro RF, De Giorgio R, Stanghellini V, Grundy D, Tonini M, De Ponti F, Corinaldesi R, Barbara G. Intestinal serotonin release, sensory neuron activation, and abdominal pain in irritable bowel syndrome. Am J Gastroenterol. 2011;106:1290-8.

57. Kim JJ. Serotonin, stress, and conditioning. Biol Psychiatry. 2008;63:819-20.

58. Gao HQ, Zhu HY, Zhang YQ, Wang LX. Reduction of cerebrospinal fluid and plasma serotonin in patients with post-stroke depression: A preliminary report. Clin Invest Med. 2008;31:E351-6.

59. Stasi C, Bellini M, Costa F, Mumolo MG, Ricchiuti A, Grosso M, Duranti E, Metelli MR, Gambaccini D, Bianchi L, Di Tanna GL, Laffi G, Taddei S, Marchi S. Neuroendocrine markers and psychological features in patients with irritable bowel syndrome. International journal of colorectal disease. 2013;28:1203-8.

60. Gershon MD. Review article: serotonin receptors and transporters -- roles in normal and abnormal gastrointestinal motility. Aliment Pharmacol Ther. 2004;20 Suppl 7:3-14.

61. Houghton LA, Atkinson W, Whitaker RP, Whorwell PJ, Rimmer MJ. Increased platelet depleted plasma 5-hydroxytryptamine concentration following meal ingestion in symptomatic female subjects with diarrhoea predominant irritable bowel syndrome. Gut. 2003;52:663-70.

62. Bearcroft CP, Perrett D, Farthing MJ. Postprandial plasma 5-hydroxytryptamine in diarrhoea predominant irritable bowel syndrome: a pilot study. Gut. 1998;42:42-6.

63. Dunlop SP, Coleman NS, Blackshaw E, Perkins AC, Singh G, Marsden CA, Spiller RC. Abnormalities of 5hydroxytryptamine metabolism in irritable bowel syndrome. Clin Gastroenterol Hepatol. 2005;3: 34957.

64. Atkinson W, Lockhart S, Whorwell PJ, Keevil B, Houghton LA. Altered 5-hydroxytryptamine signaling in patients with constipation- and diarrhea-predominant irritable bowel syndrome. Gastroenterology. 2006;130:34-43.

65. Kilkens TO, Honig A, Fekkes D, Brummer RJ. The effects of an acute serotonergic challenge on brain-gut responses in irritable bowel syndrome patients and controls. Aliment Pharmacol Ther. 2005;22:865-74.

66. Kuiken SD, Lindeboom R, Tytgat GN, Boeckxstaens GE. Relationship between symptoms and hypersensitivity to rectal distension in patients with irritable bowel syndrome. Aliment Pharmacol Ther. 2005;22:157-64.

67. Kanazawa M, Palsson OS, Thiwan SI, Turner MJ, van Tilburg MA, Gangarosa LM, Chitkara DK, Fukudo S, Drossman DA, Whitehead WE. Contributions of pain sensitivity and colonic motility to IBS symptom severity and predominant bowel habits. Am J Gastroenterol. 2008; 103:2550-61.

68. van der Veek PP, Van Rood YR, Masclee AA. Symptom severity but not psychopathology predicts visceral hypersensitivity in irritable bowel syndrome. Clin Gastroenterol Hepatol. 2008; 6:321-8.

69. Ludidi S, Conchillo JM, Keszthelyi D, Van Avesaat M, Kruimel JW, Jonkers DM, Masclee AA. Rectal hypersensitivity as hallmark for irritable bowel syndrome: defining the optimal cutoff. Neurogastroenterol Motil. 2012;24:729-33, e345-6. 
70. Ludidi S, Mujagic Z, Jonkers D, Keszthelyi D, Hesselink M, Kruimel J, Conchillo J, Masclee A. Markers for visceral hypersensitivity in patients with irritable bowel syndrome. Neurogastroenterol Motil. 2014;26: 1104-11.

71. Piche $\mathrm{M}$, Arsenault $\mathrm{M}$, Poitras $\mathrm{P}$, Rainville $\mathrm{P}$, Bouin $\mathrm{M}$. Widespread hypersensitivity is related to altered pain inhibition processes in irritable bowel syndrome. Pain. 2010;148:49-58.

72. Posserud I, Syrous A, Lindstrom L, Tack J, Abrahamsson H, Simren M. Altered rectal perception in irritable bowel syndrome is associated with symptom severity. Gastroenterology. 2007;133:1113-23.

73. Keszthelyi D, Troost FJ, Simrén M, Ludidi S, Kruimel JW, Conchillo JM, Masclee AA. Revisiting concepts of visceral nociception in irritable bowel syndrome. Eur J Pain. 2012;16:1444-54.

74. Zhou Q, Zhang B, Nicholas Verne G. Intestinal membrane permeability and hypersensitivity in the irritable bowel syndrome. Pain. 2009;146:41-6.

75. Travis S, Menzies I. Intestinal permeability: functional assessment and significance. Clin Sci (Lond). 1992;82:471-88.

76. Matricon J, Meleine M, Gelot A, Piche T, Dapoigny M, Muller E, Ardid D. Review article: Associations between immune activation, intestinal permeability and the irritable bowel syndrome. Aliment Pharmacol Ther. 2012;36:1009-31.

77. Van Itallie CM, Anderson JM. The molecular physiology of tight junction pores. Physiology (Bethesda). 2004;19:331-8.

78. Rao RK, Seth A, Sheth P. Recent Advances in Alcoholic Liver Disease I. Role of intestinal permeability and endotoxemia in alcoholic liver disease. Am J Physiol. 2004;286:G881-4.

79. Ma TY, Nguyen D, Bui V, Nguyen H, Hoa N. Ethanol modulation of intestinal epithelial tight junction barrier. Am J Physiol. 1999;276:G965-74.

80. Dunlop SP, Hebden J, Campbell E, Naesdal J, Olbe L, Perkins AC, Spiller RC. Abnormal intestinal permeability in subgroups of diarrhea-predominant irritable bowel syndromes. Am J Gastroenterol. 2006;101:1288-94.

81. Bertiaux-Vandaële $N$, Youmba SB, Belmonte L, Lecleire $S$, Antonietti $M$, Gourcerol G, Leroi AM, Déchelotte $P$, Ménard JF, Ducrotté $P$, Coëffier $M$. The expression and the cellular distribution of the tight junction proteins are altered in irritable bowel syndrome patients with differences according to the disease subtype. Am J Gastroenterol. 2011;106:2165-73.

82. Marshall JK, Thabane M, Garg AX, Clark W, Meddings J, Collins SM. Intestinal permeability in patients with irritable bowel syndrome after a waterborne outbreak of acute gastroenteritis in Walkerton, Ontario. Aliment Pharmacol Ther. 2004;20:1317-22.

83. Spiller RC, Jenkins D, Thornley JP, Hebden JM, Wright T, Skinner M, Neal KR. Increased rectal mucosal enteroendocrine cells, $T$ lymphocytes, and increased gut permeability following acute Campylobacter enteritis and in post-dysenteric irritable bowel syndrome. Gut. 2000;47: 804-11.

84. Piche T, Barbara G, Aubert P, Bruley des Varannes S, Dainese R, Nano JL, Cremon C, Stanghellini V, De Giorgio R, Galmiche JP, Neunlist M. Impaired intestinal barrier integrity in the colon of irritable bowel syndrome patients: involvement of soluble mediators. Gut. 2009;58:196-201..

85. Parry S, Forgacs I. Intestinal infection and irritable bowel syndrome. Eur J Gastroenterol Hepatol. 2005;17:5-9.

86. Rodriguez LA, Ruigomez A. Increased risk of irritable bowel syndrome after bacterial gastroenteritis: cohort study. BMJ. 1999;318:565-6.

87. Spiller RC. Postinfectious irritable bowel syndrome. Gastroenterology. 2003;124:1662-71.

88. Barbara G, Stanghellini V, De Giorgio R, Cremon C, Cottrell GS, Santini D, Pasquinelli G, Morselli-Labate AM, Grady EF, Bunnett NW, Collins SM, Corinaldesi R. Activated mast cells in proximity to colonic nerves correlate with abdominal pain in irritable bowel syndrome. Gastroenterology. 2004;126: 693-702.

89. Barbara G, Wang B, Stanghellini V, de Giorgio R, Cremon C, Di Nardo G, Trevisani M, Campi B, Geppetti P, Tonini M, Bunnett NW, Grundy D, Corinaldesi R. Mast cell-dependent excitation of visceralnociceptive sensory neurons in irritable bowel syndrome. Gastroenterology. 2007;132:26-37.

90. Dunlop SP, Jenkins D, Spiller RC. Distinctive clinical, psychological, and histological features of postinfective irritable bowel syndrome. Am J Gastroenterol. 2003;98:1578-83. 
91. Liebregts T, Adam B, Bredack C, Röth A, Heinzel S, Lester S, Downie-Doyle S, Smith E, Drew P, Talley NJ, Holtmann G. Immune activation in patients with irritable bowel syndrome. Gastroenterology. 2007;132:913-20.

92. Dinan TG, Quigley EM, Ahmed SM, Scully P, O'Brien S, O'Mahony L, O'Mahony S, Shanahan F, Keeling PW. Hypothalamic-pituitary-gut axis dysregulation in irritable bowel syndrome: plasma cytokines as a potential biomarker? Gastroenterology. 2006;130:304-11.

93. O'Mahony L, McCarthy J, Kelly P, Hurley G, Luo F, Chen K, O'Sullivan GC, Kiely B, Collins JK, Shanahan F, Quigley EM. Lactobacillus and bifidobacterium in irritable bowel syndrome: symptom responses and relationship to cytokine profiles. Gastroenterology. 2005;128:541-51.

94. Wilcz-Villega EM, McClean S, O'Sullivan MA. Mast cell tryptase reduces junctional adhesion molecule-A (JAM-A) expression in intestinal epithelial cells: implications for the mechanisms of barrier dysfunction in irritable bowel syndrome. Am J Gastroenterol. 2013;108:1140-51.

95. Nicholson JK, Holmes E, Wilson ID. Gut microorganisms, mammalian metabolism and personalized health care. Nat Rev Microbiol. 2005;3:431-8.

96. Macpherson AJ, Harris NL. Interactions between commensal intestinal bacteria and the immune system. Nat Rev Immunol. 2004;4:478-85.

97. Rajilic-Stojanovic M, Smidt $\mathrm{H}$, de Vos WM. Diversity of the human gastrointestinal tract microbiota revisited. Environ Microbiol. 2007;9:2125-36.

98. Dethlefsen L, Eckburg PB, Bik EM, Relman DA. Assembly of the human intestinal microbiota. Trends Ecol Evol. 2006;21:517-23.

99. Guarner F, Malagelada JR. Gut flora in health and disease. Lancet. 2003;361:512-9.

100. Round JL, Mazmanian SK. The gut microbiota shapes intestinal immune responses during health and disease. Nat Rev Immunol. 2009;9:313-23.

101. Quigley EM, Flourie B. Probiotics and irritable bowel syndrome: a rationale for their use and an assessment of the evidence to date. Neurogastroenterol Motil. 2007;19:166-72.

102. Spiller R, Garsed K. Postinfectious irritable bowel syndrome. Gastroenterology. 2009;136: 1979-88.

103. Balsari A, Ceccarelli A, Dubini F, Fesce E, Poli G. The fecal microbial population in the irritable bowel syndrome. Microbiologica. 1982;5:185-94.

104. Mättö J, Maunuksela L, Kajander K, Palva A, Korpela R, Kassinen A, Saarela M. Composition and temporal stability of gastrointestinal microbiota in irritable bowel syndrome--a longitudinal study in IBS and control subjects. FEMS Immunol Med Microbiol. 2005;43:213-22.

105. Maukonen J, Satokari R, Matto J, Soderlund H, Mattila-Sandholm T, Saarela M. Prevalence and temporal stability of selected clostridial groups in irritable bowel syndrome in relation to predominant faecal bacteria. J Med Microbiol. 2006;55:625-33.

106. Codling C, O'Mahony L, Shanahan F, Quigley EM, Marchesi JR. A Molecular Analysis of Fecal and Mucosal Bacterial Communities in Irritable Bowel Syndrome. Dig Dis Sci. 2010;55:392-7.

107. Malinen E, Rinttilä T, Kajander K, Mättö J, Kassinen A, Krogius L, Saarela M, Korpela R, Palva A. Analysis of the fecal microbiota of irritable bowel syndrome patients and healthy controls with real-time PCR. Am J Gastroenterol. 2005;100:373-82.

108. Jalanka-Tuovinen J, Salojärvi J, Salonen A, Immonen O, Garsed K, Kelly FM, Zaitoun A, Palva A, Spiller RC, de Vos WM. Faecal microbiota composition and host-microbe cross-talk following gastroenteritis and in postinfectious irritable bowel syndrome. Gut. 2014;63:1737-45.

109. Rajilić-Stojanović M, Jonkers DM, Salonen A, Hanevik K, Raes J, Jalanka J, de Vos WM, Manichanh C, Golic N, Enck P, Philippou E, Iraqi FA, Clarke G, Spiller RC, Penders J. Intestinal Microbiota And Diet in IBS: Causes, Consequences, or Epiphenomena? Am J Gastroenterol. 2015;110:278-87.

110. Kennedy PJ, Cryan JF, Dinan TG, Clarke G. Irritable bowel syndrome: a microbiome-gut-brain axis disorder? World J Gastroenterol. 2014;20:14105-25.

111. Barbara G, Stanghellini V, Cremon C, De Giorgio R, Gargano L, Cogliandro R, Pallotti F, Corinaldesi R. Probiotics and irritable bowel syndrome: rationale and clinical evidence for their use. J Clin Gastroenterol. 2008;42 Suppl 3 Pt 2:S214-7.

112. Spanhaak S, Havenaar R, Schaafsma G. The effect of consumption of milk fermented by Lactobacillus casei strain Shirota on the intestinal microflora and immune parameters in humans. Eur J Clin Nutr. 1998;52:899-907. 
113. Jonkers D, Stockbrugger R. Review article: Probiotics in gastrointestinal and liver diseases. Aliment Pharmacol Ther. 2007;26 Suppl 2:133-48.

114. Penner R, Fedorak RN, Madsen KL. Probiotics and nutraceuticals: non-medicinal treatments of gastrointestinal diseases. Curr Opin Pharmacol. 2005;5:596-603.

115. Shida K, Nanno M. Probiotics and immunology: separating the wheat from the chaff. Trends Immunol. 2008;29:565-73.

116. de Vrese M, Marteau PR. Probiotics and prebiotics: effects on diarrhea. J Nutr. 2007;137(3 Suppl 2):803S-11S.

117. Oelschlaeger TA. Mechanisms of probiotic actions - A review. Int J Med Microbiol. 2010;300:57-62..

118. Gionchetti P, Rizzello F, Campieri M. Probiotics in gastroenterology. Curr Opin Gastroenterol. 2002;18:235-9.

119. Delcenserie V, Martel D, Lamoureux M, Amiot J, Boutin Y, Roy D. Immunomodulatory effects of probiotics in the intestinal tract. Curr Issues Mol Biol. 2008;10:37-54.

120. Borchers AT, Selmi C, Meyers FJ, Keen CL, Gershwin ME. Probiotics and immunity. J Gastroenterol. 2009;44:26-46.

121. Camilleri M. Probiotics and irritable bowel syndrome: rationale, putative mechanisms, and evidence of clinical efficacy. J Clin Gastroenterol. 2006;40:264-9.

122. Qin H, Zhang Z, Hang X, Jiang Y. L. plantarum prevents enteroinvasive Escherichia coli-induced tight junction proteins changes in intestinal epithelial cells. BMC microbiology. 2009;9:63.

123. Mennigen R, Nolte K, Rijcken E, Utech M, Loeffler B, Senninger N, Bruewer M. Probiotic mixture VSL\#3 protects the epithelial barrier by maintaining tight junction protein expression and preventing apoptosis in a murine model of colitis. Am J physiol. 2009;296:G1140-9.

124. Laval L, Martin R, Natividad J, Chain F, Miquel S, de Maredsous CD, Capronnier S, Sokol H, Verdu E, van Hylckama Vlieg J, Bermúdez-Humarán L, Smokvina T, Langella P. Lactobacillus rhamnosus CNCM I-3690 and the commensal bacterium Faecalibacterium prausnitzii A2-165 exhibit similar protective effects to induced barrier hyper-permeability in mice. Gut Microbes. 2015;6:1-9..

125. Nébot-Vivinus M, Harkat C, Bzioueche H, Cartier C, Plichon-Dainese R, Moussa L, Eutamene H, Pishvaie D, Holowacz S, Seyrig C, Piche T, Theodorou V. Multispecies probiotic protects gut barrier function in experimental models. World J Gastroenterol. 2014;20:6832-43.

126. Eutamene H, Lamine F, Chabo C, Theodorou V, Rochat F, Bergonzelli GE, Corthésy-Theulaz I, Fioramonti J, Bueno L. Synergy between Lactobacillus paracasei and its bacterial products to counteract stressinduced gut permeability and sensitivity increase in rats. J Nutr. 2007;137:1901-7.

127. Verdú EF, Bercik P, Verma-Gandhu M, Huang XX, Blennerhassett $P$, Jackson W, Mao Y, Wang L, Rochat $\mathrm{F}$, Collins SM. Specific probiotic therapy attenuates antibiotic induced visceral hypersensitivity in mice. Gut. 2006;55:182-90.

128. Ait-Belgnaoui A, Han W, Lamine F, Eutamene H, Fioramonti J, Bueno L, Theodorou V. Lactobacillus farciminis treatment suppresses stress induced visceral hypersensitivity: a possible action through interaction with epithelial cell cytoskeleton contraction. Gut. 2006;55: 1090-4.

129. Agostini $S$, Goubern $M$, Tondereau V, Salvador-Cartier $C$, Bezirard $V$, Lévèque $M$, Keränen $H$, Theodorou V, Bourdu-Naturel S, Goupil-Feuillerat N, Legrain-Raspaud S, Eutamene H. A marketed fermented dairy product containing Bifidobacterium lactis CNCM I-2494 suppresses gut hypersensitivity and colonic barrier disruption induced by acute stress in rats. Neurogastroenterol Motil. 2012;24:376-e172.

130. Ford AC, Quigley EM, Lacy BE, Lembo AJ, Saito YA, Schiller LR, Soffer EE, Spiegel BM, Moayyedi P. Efficacy of prebiotics, probiotics, and synbiotics in irritable bowel syndrome and chronic idiopathic constipation: systematic review and meta-analysis. Am J Gastroenterol. 2014;109:1547-61.

131. Tuohy KM, Pinart-Gilberga M, Jones M, Hoyles L, McCartney AL, Gibson GR. Survivability of a probiotic Lactobacillus casei in the gastrointestinal tract of healthy human volunteers and its impact on the faecal microflora. J Appl Microbiol. 2007;102:1026-32.

132. Koebnick C, Wagner I, Leitzmann P, Stern U, Zunft HJ. Probiotic beverage containing Lactobacillus casei Shirota improves gastrointestinal symptoms in patients with chronic constipation. Can J Gastroenterol. 2003;17:655-9.

133. Barrett JS, Canale KE, Gearry RB, Irving PM, Gibson PR. Probiotic effects on intestinal fermentation patterns in patients with irritable bowel syndrome. World J Gastroenterol. 2008;14:5020-4. 
134. Takeda K, Okumura K. Effects of a fermented milk drink containing Lactobacillus casei strain Shirota on the human NK-cell activity. J Nutr. 2007;137:791S-3S.

135. Nagao F, Nakayama M, Muto T, Okumura K. Effects of a fermented milk drink containing Lactobacillus casei strain Shirota on the immune system in healthy human subjects. Biosci Biotechnol Biochem. 2000;64:2706-8.

136. Takeda K, Suzuki T, Shimada SI, Shida K, Nanno M, Okumura K. Interleukin-12 is involved in the enhancement of human natural killer cell activity by Lactobacillus casei Shirota. Clin Exp Immunol. 2006;146:109-15.

137. de Waard R, Garssen J, Bokken GC, Vos JG. Antagonistic activity of Lactobacillus casei strain shirota against gastrointestinal Listeria monocytogenes infection in rats. Int J Food Microbiol. 2002;73:93-100.

138. Ezendam J, van Loveren $\mathrm{H}$. Lactobacillus casei Shirota administered during lactation increases the duration of autoimmunity in rats and enhances lung inflammation in mice. Br J Nutr. 2008;99:83-90.

139. Baken KA, Ezendam J, Gremmer ER, de Klerk A, Pennings JL, Matthee B, Peijnenburg AA, van Loveren $\mathrm{H}$. Evaluation of immunomodulation by Lactobacillus casei Shirota: immune function, autoimmunity and gene expression. Int J Food Microbiol. 2006;112:8-18.

140. Shida K, Suzuki T, Kiyoshima-Shibata J, Shimada S, Nanno M. Essential roles of monocytes in stimulating human peripheral blood mononuclear cells with Lactobacillus casei to produce cytokines and augment natural killer cell activity. Clin Vaccine Immunol. 2006;13:997-1003.

141. Lim LH, Li HY, Huang CH, Lee BW, Lee YK, Chua KY. The effects of heat-killed wild-type Lactobacillus casei Shirota on allergic immune responses in an allergy mouse model. Int Arch Allergy Immunol. 2009;148:297-304.

142. de Jonge JD, Ezendam J, Knippels LM, Penninks AH, Pieters R, van Loveren H. Lactobacillus casei Shirota does not decrease the food allergic response to peanut extract in Brown Norway rats. Toxicology. 2008;249:140-5.

143. Ivory K, Chambers SJ, Pin C, Prieto E, Arques JL, Nicoletti C. Oral delivery of Lactobacillus casei Shirota modifies allergen-induced immune responses in allergic rhinitis. Clin Exp Allergy. 2008;38:1282-9.

144. Herias MV, Koninkx JF, Vos JG, Huis in't Veld JH, van Dijk JE. Probiotic effects of Lactobacillus casei on DSS-induced ulcerative colitis in mice. Int J Food Microbiol. 2005;103:143-55.

145. Stadlbauer V, Mookerjee RP, Hodges S, Wright GA, Davies NA, Jalan R. Effect of probiotic treatment on deranged neutrophil function and cytokine responses in patients with compensated alcoholic cirrhosis. J Hepatol. 2008;48:945-51. 


\section{CHAPTER 2}

Dysfunctional cognitions, anxiety and depression in Irritable Bowel Syndrome

A.Y. Thijssen, D.M.A.E. Jonkers, C. Leue, P.P.J. van der Veek, M. Vidakovic-Vukic, Y.R. van Rood, C.H.M. Clemens, A.A.M. Masclee

J Clin Gastroenterol 2010;44:e236-41 


\section{ABSTRACT}

\section{Background \& Aims}

Patients with Irritable Bowel Syndrome (IBS) have significantly impaired quality of life (QoL). We investigated the presence of dysfunctional cognitions, anxiety and depression symptoms and their impact on daily symptoms and QoL in a large IBS cohort.

\section{Methods}

A total of 268 IBS patients (Rome II criteria, age 18-65 years) were included. Patients completed a 2-week daily symptom diary. The SF-36 was used to score QoL. The 31items Cognitive Scale for Functional Bowel Disorders (CSFBD) and the Hospital Anxiety and Depression Scale (HADS) were used to analyze the psychological factors.

\section{Results}

Possible anxiety and depression disorders were present in $30 \%$ and $22 \%$ of IBS patients respectively. Patients with anxiety and depression had significantly higher mean symptom scores, impaired QoL and higher CSFBD scores $(p<0.01)$. Physical QoL and mental QoL were both affected by depression (HADS-D) and dysfunctional cognitions $(p<0.01)$. Only physical QoL, not mental QoL, was affected by referral type (hospital setting vs. community based; $p<0.01$ ). Only mental QoL was affected by anxiety (HADSA) $(p<0.01)$. Dysfunctional cognitions independently of anxiety and depression influenced QoL and IBS symptoms.

\section{Conclusion}

In this IBS cohort, dysfunctional cognitions independently influence physical and mental QoL and symptom severity. Presence of possible anxiety and depression disorders resulted in higher symptom, lower QoL and higher CSFBD scores. The results point towards an important role of psychological factors, especially dysfunctional cognitions on QoL and symptom scores in IBS patients. 


\section{INTRODUCTION}

Irritable Bowel Syndrome (IBS) is a functional gastrointestinal (GI) disorder characterized by abdominal discomfort or pain, bloating and altered bowel habits. ${ }^{1}$ The prevalence in the European population is $6-12 \%^{2}$ and at least $20 \%$ of the population is affected some time during life. ${ }^{3}$ Patients experience a significant impairment in quality of life $(\mathrm{QoL}){ }^{4-8}$ resulting in an important burden on health care and costs. ${ }^{9-11}$ Treatment of IBS is usually directed against symptoms, since the pathophysiology of IBS is still poorly understood. Recent studies provide evidence for both genetic and environmental etiological factors such as chronic inflammation and altered gut microbiota. ${ }^{12,13}$

IBS is associated with psychosocial factors. Acute and chronic stress, childhood trauma and abuse history were found to significantly affect symptom severity, illness behaviour and quality of life in IBS patients. ${ }^{14-16}$

Neuroticism, anxiety, depression and dysfunctional cognitions have been reported to be more prevalent in IBS. ${ }^{4,13-16}$ Guthrie et al. found that $44 \%$ of IBS patients had psychiatric comorbidity, consisting mainly of depression and anxiety related conditions. ${ }^{17}$ The bidirectional association with affective symptoms suggests a common pathway in patients with functional bowel complaints and affective comorbidity. ${ }^{18}$ An important factor with regard to treatment success in IBS, is the presence of dysfunctional cognitions. These cognitions are best described as automatically occurring thoughts induced by psychological distress and by (severe) physical symptoms. ${ }^{19}$ Physical symptoms increase due to dysfunctional cognitions such as the presence of the negative thought "I feel something is seriously wrong with me". Worsening of physical symptoms gives rise to more negative thoughts creating a vicious circle. It has been documented that dysfunctional cognitions contribute to symptom generation and persistence of symptoms in posttraumatic stress disorder ${ }^{20}$ and chronic low back pain. ${ }^{21}$ Toner et al. developed the Cognitive Scale for Functional Bowel Disorders (CSFBD) in 1998. ${ }^{22}$ The CSFBD consists of 31 statements reflecting a range of cognitions and has recently been used for follow-up of intervention strategies in an IBS cohort. In that study, dysfunctional cognitions correlated with severity of symptoms and were found to improve after hypnotherapy. ${ }^{19}$

Findings on the impact of various psychological factors on QoL in IBS are based on studies that incorporated small groups of patients or selected cases. The impact of various psychological factors on QoL and symptom severity needs confirmation in a larger and preferably heterogeneous cohort of IBS patients, furthermore dysfunctional cognitions should be taken into account. Our aim was to explore the relevance of psychological factors including dysfunctional cognitions on QoL and symptom severity in a large heterogeneous IBS cohort. 


\section{METHODS}

Data from a group of 268 IBS patients, originating from primary, secondary and tertiary care settings, were used for analysis. Patients had participated in three different intervention studies initiated by our research group between 2002 and 2008. Patients visiting the outpatient clinic of 4 different hospitals were invited to participate in the studies. In addition, patients were recruited via advertisements in local media. Patients between 18 and 65 years were included and had to fulfil the Rome II criteria for IBS. Exclusion criteria were major abdominal surgery, presence of organic disease (including GI diseases), pregnancy and dependence on pain medication. All studies used the same questionnaires at baseline. Data of these baseline questionnaires were combined for the present evaluation. All patients completed a symptom diary during a 2 week period, rating the severity of symptoms in a 5-point Likertscale on a daily basis ranging from no (0) to very severe symptoms (4). Symptoms included discomfort, pain, constipation, diarrhea, bloating, flatulence, ructus, nausea, defecation frequency and an overall score for that day. In addition, a mean symptom score (MSS, ranging from 0-20), based on the sum of mean discomfort, pain, constipation, diarrhea and bloating scores during the 2 week period, was calculated.

IBS subtypes (diarrhea, constipation, alternating, undefined) were defined based on these symptom diaries and/or assessed by the research physician. The IBS-undefined (IBS-U) classification was used for patients with a symptom diary that was not conclusive for one of the other 3 subtypes and showed mainly complaints of bloating and/or pain instead of irregular defecation patterns.

The RAND-36, the validated Dutch version of the Medical Outcomes Study (MOS) 36-item Short Form Health Survey (SF-36) (New England Medical Centre Hospitals, 1991), was used to measure generic health-related QoL. ${ }^{23}$ This SF-36 consists of eight domains with an outcome between 0 and 100, including physical functioning (PF), role limitations due to physical (RP) and to emotional problems (RE), social functioning (SF), bodily pain (BP), mental health (MH), vitality (VT), and general health perception (GH). High scores indicate a high quality of life. From the 8 domains, a physical (PCS) and mental (MCS) composite score can be derived and used as a general indicator for QoL. ${ }^{11,24}$

The validated Hospital Anxiety and Depression Scale (HADS) was used to score symptoms of anxiety and depression. The questionnaire consists of two 7- item scales, one for anxiety and one for depression, each with a score ranging from $0-21$. A score $\geq 8$ on the anxiety or depression sub-scale shows the presence of anxiety or depressive symptoms with the most optimal balance between sensitivity and specificity, ${ }^{25}$ thereby indicating a mood disturbance. ${ }^{26}$ The mean scores for anxiety and depression were also assessed. 
The CSFBD was used rate dysfunctional cognitions in IBS. ${ }^{22}$ This instrument consists of 31 statements on thoughts about bowel function and personality features like "I often worry there might not be a toilet available when I need it", "I often feel this abdominal pain will never go away and "I am constantly frustrated by my bowel symptoms". The CSFBD is scored ranging from "does not apply to me at all" (1) to "does apply to me totally"(7). A total score ranging from 31 (best) to 217 (worst) was calculated. A higher score indicates more dysfunctional cognitions.

\section{Statistical analysis}

All statistical analyses were performed with SPSS for Windows, version 15 (SPSS inc, Chicago II.). Scores of the questionnaires were given as mean \pm SD. Prevalences between subgroups were compared with $\mathrm{Chi} 2$ and continuous variables were compared with the independent student T-test or ANOVA with post-hoc Bonferroni test when appropriate. Continuous variables were compared in linear regression model. The level of significance was set at $p<0.05$ using two-sided tests.

\section{Ethical considerations}

Two intervention studies of which baseline data were used in this trial were approved by the Leiden University Medical Center Ethics Committee (Leiden, The Netherlands) and one intervention study was approved by the Slotervaart Hospital Medical Ethics Committee (Amsterdam, The Netherlands). They were conducted in full accordance with the principles of the 'Declaration of Helsinki' (52nd WMA General Assembly, Edinburgh, Scotland, Oct 2000). All patients gave their written informed consent prior to participation.

\section{RESULTS}

\section{Subject characteristics}

A total of 268 IBS patients were included, with a female:male ratio of 2.6:1. The mean age $\pm S D$ was $41.6 \pm 12.7$ years. All patients fulfilled the Rome II criteria. Symptom diaries, SF-36, HADS and CSFBD questionnaires were completed by 268 (100\%), 263 (99\%), $230(86 \%)$ and 261 (97\%) patients, respectively.

\section{Symptoms}

Results of the symptom diary are shown in Table 2.1. The MSS in this cohort was $7.2 \pm 4.1$. With respect to gender, only defecation frequency and stool consistency were 
different between men and women. Men had significantly lower scores for constipation and a significantly higher defecation frequency.

Table $2.1 \quad$ Symptom scores

\begin{tabular}{lccc}
\hline Symptom & $\begin{array}{c}\text { Males } \\
\mathbf{n = 7 4}\end{array}$ & $\begin{array}{c}\text { Females } \\
\mathbf{n = 1 9 4}\end{array}$ & $\begin{array}{c}\text { Total cohort } \\
\mathbf{n = 2 6 8}\end{array}$ \\
\hline Discomfort & $2.0 \pm 1.0$ & $1.9 \pm 0.9$ & $1.9 \pm 1.0$ \\
Pain & $1.7 \pm 1.2$ & $1.7 \pm 1.0$ & $1.7 \pm 1.1$ \\
Constipation & $0.8 \pm 0.8$ & $1.1 \pm 0.9 *$ & $1.0 \pm 0.9$ \\
Diarrhea & $1.1 \pm 0.9$ & $0.9 \pm 0.8$ & $0.9 \pm 0.9$ \\
Bloating & $1.7 \pm 1.0$ & $1.8 \pm 1.1$ & $1.8 \pm 1.1$ \\
Flatulence & $1.7 \pm 0.9$ & $1.7 \pm 1.1$ & $1.7 \pm 1.0$ \\
Ructus & $0.9 \pm 0.8$ & $1.0 \pm 0.9$ & $1.0 \pm 0.9$ \\
Nausea & $0.7 \pm 0.9$ & $0.9 \pm 0.8$ & $0.8 \pm 0.9$ \\
Defecation Frequency & $2.4 \pm 1.7$ & $1.7 \pm 1.1 *$ & $1.9 \pm 1.3$ \\
Total day score & $2.0 \pm 1.0$ & $1.9 \pm 1.0$ & $1.9 \pm 1.0$ \\
MSS & $7.1 \pm 4.2$ & $7.2 \pm 4.1$ & $7.2 \pm 4.1$ \\
\hline
\end{tabular}

This table shows the symptom scores (mean \pm SD) from a 2-week diary for males, females and the total group. The range of individual symptoms is $0-4$, and for the mean symptom score (MSS) $0-20$. Note the significant difference between males and females with respect to constipation and defecation frequency.

${ }^{*}$ male $<$ female $(p<0.05)$.

\section{Quality of Life}

The results of the SF-36 scores for Quality of Life are shown in Table 2.2.

Table 2.2 Quality of Life

\begin{tabular}{llcc}
\hline Domain & $\begin{array}{c}\text { Male } \\
\mathbf{n = 7 3}\end{array}$ & $\begin{array}{c}\text { Female } \\
\mathbf{n = 1 9 0}\end{array}$ & $\begin{array}{c}\text { Total } \\
\mathbf{n = 2 6 3}\end{array}$ \\
\hline 1 Physical functioning (PF) & $79 \pm 23$ & $80 \pm 23$ & $80 \pm 23$ \\
2 Social functioning (SF) & $67 \pm 26$ & $65 \pm 26$ & $65 \pm 26$ \\
1 Role limitations physical (RP) & $48 \pm 42$ & $54 \pm 43$ & $52 \pm 42$ \\
2 Role limitations emotional (RE) & $74 \pm 37$ & $72 \pm 42$ & $73 \pm 41$ \\
1 Bodily pain (BP) & $60 \pm 22$ & $56 \pm 20$ & $57 \pm 21$ \\
2 Mental health (MH) & $69 \pm 18$ & $68 \pm 19$ & $68 \pm 19$ \\
2 Vitality (VT) & $53 \pm 18$ & $51 \pm 19$ & $52 \pm 19$ \\
General health perception (GH) & $55 \pm 21$ & $53 \pm 22$ & $54 \pm 22$ \\
Physical composite score (PCS) & $43 \pm 10$ & $43 \pm 10$ & $43 \pm 10$ \\
Mental composite score (MCS) & $47 \pm 11$ & $46 \pm 11$ & $46 \pm 11$ \\
\hline
\end{tabular}

${ }^{1}$ scores combined in formula to calculate PCS.

2 scores combined in formula to calculate MCS.

This table shows the Quality of life scores (mean \pm SD) from the SF-36 per domain and composite scores for males, females and the total group. Note that there are no significant differences between males and females. 


\section{HADS and CSFBD}

Considering the HADS-depression subscale (HADS-D), males scored significantly higher than females. No gender differences were found for the mean HADS-anxiety subscale (HADS-A) nor for the CSFBD (Table 2.3).

Table 2.3 Scores from hospital anxiety and depression scale and cognitive scale for functional bowel disorders

\begin{tabular}{llccc}
\hline Scores & & Male & Female & Total cohort \\
\hline HADS-A & $(n=229)$ & $5.9 \pm 3.5$ & $5.9 \pm 3.8$ & $5.9 \pm 3.7$ \\
HADS-D & $(n=230)$ & $5.5 \pm 3.8^{*}$ & $4.4 \pm 3.3$ & $4.6 \pm 3.5$ \\
CSFBD & $(n=261)$ & $115 \pm 35$ & $111 \pm 38$ & $112 \pm 37$ \\
\hline
\end{tabular}

This table shows the scores (mean \pm SD) from the HADS and the CSFBD for males, females and the total group. Note the significant difference between males and females with respect to the HADS-depression score.

${ }^{*}$ male $>$ female $(p<0.05)$.

Regarding the HADS-A, 70 patients out of the total of $230(30 \%)$ had scores $\geq 8$, indicating the presence of a possible anxiety disorder. Of the total male and female population $24 \%$ and $32 \%$, respectively, fulfilled the HADS-A score $\geq 8$.

Regarding the HADS-D, 50 patients $(22 \%)$ had scores $\geq 8$, indicating the presence of a possible depression. Of the total male and female population $35 \%$ and $18 \%$, respectively, fulfilled the HADS-D score $\geq 8$, pointing to a significant gender difference $(p<0.01)$. Of all patients fulfilling the criteria for either a possible anxiety disorder or a possible depression ( $n=120,45 \%), 32$ patients ( $14 \%$ of the total study cohort) were suffering from both disorders.

\section{Referral and IBS}

Patients were recruited community based (50\%) (via advertisement) or via hospital care settings (50\%). The latter group consisted of patients from secondary (37\%) or tertiary (13\%) referral centres. Age and gender did not differ between referral types. Regarding questionnaires, only symptom severity (MSS) and physical composite score of QoL (QoL-PCS) differed significantly between community and hospital care patients, as shown in Table 2.4 . 
Table $2.4 \quad$ Scores per referral type

\begin{tabular}{lcccc}
\hline Questionnaire & \multicolumn{2}{c}{ Community } & Hospital care & \\
\hline MSS & $6.3 \pm 4.0$ & $(n=127)$ & $7.9 \pm 4.0 \quad(n=127)^{\#}$ \\
QoL-PCS & $45 \pm 9$ & $(n=125)$ & $40 \pm 10$ & $(n=114)^{*}$ \\
QoL-MCS & $47 \pm 11$ & $(n=125)$ & $47 \pm 11$ & $(n=114)$ \\
HADS-A & $5.8 \pm 3.6$ & $(n=112)$ & $5.9 \pm 3.6 \quad(n=106)$ \\
HADS-D & $4.3 \pm 3.6$ & $(n=112)$ & $4.8 \pm 3.1$ & $(n=106)$ \\
CSFBD & $114 \pm 37$ & $(n=127)$ & $109 \pm 37$ & $(n=124)$ \\
\hline
\end{tabular}

This table shows the difference in scores between the referral type. Scores are given as mean \pm SD for physical symptom severity (MSS), physical Quality of Life (QoL-PCS), mental QoL (QoL-MCS), HADS-anxiety, HADSdepression and CSFBD. Note the significant difference between community and hospital care patients with respect to MSS and QoL-PCS.

\# community $<$ hospital care $(p<0.01)$.

* community $>$ hospital care $(p<0.01)$.

\section{IBS subtypes}

Distribution of IBS subtypes is shown in Table 2.5. IBS subtypes differed between males and females. The IBS-D or IBS-U subtype was more prevalent in men, whereas females more frequently had IBS-C or IBS-A as subtype classification. The scores of MSS, physical and mental QoL, HADS and CSFBD were not different between IBS subtypes, as was the prevalence of possible anxiety and depression disorders (data not shown).

Table 2.5 IBS subtypes

\begin{tabular}{lccc}
\hline IBS subtype & \% males & \% females & \% (n) total cohort \\
\hline IBS diarrhea (IBS-D) & $38 \%$ & $16 \%$ & $23 \%(58)$ \\
IBS constipation (IBS-C) & $14 \%$ & $33 \%$ & $27 \%(70)$ \\
IBS alternating (IBS-A) & $16 \%$ & $32 \%$ & $28 \%(71)$ \\
IBS undefined (IBS-U) & $32 \%$ & $19 \%$ & $22 \%(57)$ \\
Total & $100 \%$ & $100 \%$ & $100 \%(256)$ \\
\hline
\end{tabular}

Table 2.5 shows the frequency of the IBS subtypes, IBS-diarrhea (IBS-D), IBS-constipation (IBS-C), IBSalternating (IBS-A) and IBS-undefined (IBS-U). Note that the subtypes are not equally divided over males and females.

$\mathrm{Chi}^{2}$, male $<$ female $(p<0.001)$.

\section{Influence of anxiety and depression}

Comparing patients with anxiety versus those without anxiety and patients with depression versus those without depression, significant higher MSS and CSFBD and lower QoL scores were found in subjects with one or both mood disturbances present (Table 2.6). Those subjects with both anxiety and depression had a significantly lower QoL-MCS compared to subjects with anxiety or depression only. Furthermore, CSFBD scores significantly correlated with HADS-A and HADS-D scores $(R=0.53, p<0.01$ for both). 
Table 2.6 Differences in anxiety and depression affected patients

\begin{tabular}{lccccc}
\hline $\begin{array}{l}\text { Scores } \\
\text { \% subjects }\end{array}$ & $\begin{array}{c}\text { No anxiety } \\
\mathbf{7 0 \%}\end{array}$ & $\begin{array}{c}\text { Anxiety } \\
\mathbf{3 0 \%}\end{array}$ & $\begin{array}{c}\text { No depression } \\
\mathbf{7 8 \%}\end{array}$ & $\begin{array}{c}\text { Depression } \\
\mathbf{2 2 \%}\end{array}$ & $\begin{array}{c}\text { Anxiety and depression } \\
\text { 14\% of total cohort }\end{array}$ \\
\hline MSS & $7.0 \pm 4.2$ & $8.8 \pm 4.1^{*}$ & $7.1 \pm 4.2$ & $9.0 \pm 4.1^{\#}$ & $9.0 \pm 4.3^{j}$ \\
QoL-PCS & $43 \pm 10$ & $40 \pm 8^{*}$ & $44 \pm 10$ & $37 \pm 10^{\#}$ & $38 \pm 8^{j}$ \\
QoL-MCS & $50 \pm 9$ & $38 \pm 10^{*}$ & $49 \pm 9$ & $36 \pm 9^{\#}$ & $32 \pm 7^{j, * *}$ \\
CSFBD & $104 \pm 32$ & $140 \pm 35^{*}$ & $108 \pm 34$ & $140 \pm 35^{\#}$ & $146 \pm 38^{j}$ \\
HADS-A & NA & NA & $5.0 \pm 3.1$ & $9.3 \pm 3.9^{\#}$ & NA \\
HADS-D & $3.5 \pm 2.9$ & $7.3 \pm 3.2^{*}$ & NA & NA & NA \\
\hline
\end{tabular}

Table 2.6 shows the differences between patients affected with a possible anxiety disorder and/ or a possible depression and patients without. Scores are given as mean \pm SD for physical symptom severity (MSS), QoLPCS, HADS-A, HADS-D and CSFBD. Note the significant differences for each variable between affected and not affected subjects for both anxiety as well as depression disorders.

* anxiety vs. no anxiety $(p<0.01) ;{ }^{*}$ depression vs. no depression $(p<0.01) ;{ }^{j}$ both anxiety and depression affected vs. no affective disorders $(p<0.05) ;{ }^{* *}$ both anxiety and depression affected vs. either anxiety or depression affected $(p<0.01) . N A=$ not applicable.

\section{Influence of psychological factors on Quality of Life and symptom severity}

A linear regression analysis has been performed to identify variables influencing QoLPCS, and symptom severity (MSS).

Table 2.7 shows the regression analysis for different outcome parameters. QoL-PCS is significantly affected by recruitment type (in which patients recruited from hospital care have a lower PCS), MSS, QoL-MCS, HADS-D and CSFBD, but not by HADS-A scores. The model with QoL-MCS as an outcome parameter identifies significant influences of QoL-PCS, HADS-A, HADS-D and CSFBD. Taking MSS as an outcome parameter, QoL-PCS and CSFBD have a significant influence. All three outcome parameters (QoL-PCS, QoLMCS and MSS) had in common that they were significantly influenced by the level of dysfunctional cognitions, independent from the other variables. 
Table $2.7 \quad$ Linear regression analysis

\begin{tabular}{lccc}
\hline Factor & $\begin{array}{c}\text { p-value outcome } \\
\text { parameter QoL-PCS }\end{array}$ & $\begin{array}{c}\text { p-value outcome } \\
\text { parameter QoL-MCS }\end{array}$ & $\begin{array}{c}\text { p-value outcome } \\
\text { parameter MSS }\end{array}$ \\
\hline Sex & 0.08 & 0.19 & 0.84 \\
Age & 0.11 & 0.5 & 0.12 \\
Referral type & $0.00^{*}$ & 0.19 & 0.06 \\
MSS & $0.01^{*}$ & 0.49 & $\mathrm{NA}$ \\
QoL-PCS & $\mathrm{NA}$ & $0.00^{*}$ & $0.01^{*}$ \\
QoL-MCS & $0.00^{*}$ & $\mathrm{NA}$ & 0.5 \\
HADS-A & 0.95 & $0.00^{*}$ & 0.72 \\
HADS-D & $0.00^{*}$ & $0.00^{*}$ & 0.12 \\
CSFBD & $0.00^{*}$ & $0.03^{*}$ & $0.00^{*}$ \\
R value & $0.62, \mathrm{p}<0.01$ & $0.75, \mathrm{p}<0.01$ & $0.50, \mathrm{p}<0.01$ \\
\hline
\end{tabular}

This table shows the data from the regression analysis, performed to assess which factors influence the outcome parameters QoL-PCS, QoL-MCS and symptom severity (MSS). P values are given for each factor. Please note the significant impact of referral type, MSS, QoL-MCS, HADS-D and CSFBD on QoL-PCS. Also note the significant influence of QoL-PCS, HADS-A, HADS-D and CSFBD on QoL-MCS and the significant influence of QoL-PCS and CSFBD scores on MSS. The R value of the 3 models are also given, an $R$ of 1 represents a perfect model.

* significant predictor outcome parameter in regression model. NA= not applicable.

\section{DISCUSSION}

The main findings of our study are the importance of anxiety, depression and dysfunctional cognitions on QoL and symptom severity in IBS patients. IBS patients with a possible anxiety disorder or depression had more severe symptoms, a worse physical and mental QoL score and higher levels of dysfunctional cognitions. Dysfunctional cognitions are an important variable that significantly affected physical and mental QoL as well as symptom severity in a regression model.

Patients were recruited community based (via advertisement) and from hospital setting, aiming to represent the broad spectrum of the IBS population. There was a difference in symptom severity and physical QoL between the groups, in favour of the community group. However, no differences in levels of anxiety, depression and dysfunctional cognitions were found between the two referral types. This outcome suggests that referral to secondary or tertiary care is mainly based on physical symptoms of IBS. However, we cannot exclude that patients recruited via the advertisement have consulted a physician for their IBS symptoms in the past.

The prevalence of possible anxiety disorders $(30 \%)$ or symptoms of a possible depression (22\%) in our cohort is comparable to IBS patients reported in the literature. ${ }^{27}$ The prevalence of affective symptoms in total is $45 \%$. Presence of a possible depression as well as a higher mean level of depression symptoms were more 
frequent in males than females, although Cain et al. ${ }^{28}$ found no gender differences with regard to depression symptoms in IBS patients. However, the higher prevalence of depressive symptoms in males was in line with findings by Sugaya et al.. ${ }^{29}$ Possible anxiety disorders showed a trend to be more prevalent in female patients in our cohort. However, the mean level of anxiety symptoms was not different between males and females. The presence of possible anxiety disorders and/or depression resulted in more severe symptoms, more impaired QoL and higher dysfunctional cognition scores. The direct relation between dysfunctional cognitions and presence of a possible anxiety disorder and depression in IBS patients has not been described before.

Only few studies have reported on dysfunctional cognitions in IBS patients. Kovacs et al. ${ }^{30}$ scored 'dysfunctional attitudes' in 46 IBS patients with the Dysfunctional Attitudes Scale (DAS) and found higher scores in 4 out of 10 attitudes. These results are difficult to compare with ours, since the used questionnaire was different. Gonsalkorale et al. did use the CSFBD to score dysfunctional cognitions and found a mean score of 151 in 78 IBS patients refractory to regular treatment. ${ }^{19}$ The mean score of dysfunctional cognitions in our study was 112 , without any difference regarding gender or IBS subtype. Our cohort consisted of a large mixed IBS population instead of a population refractory to standard IBS treatment, which may explain the lower score. Dysfunctional cognition scores from a large control population are not yet available. Van der Veek et al. evaluated dysfunctional cognitions in 38 healthy volunteers and found a mean score of $86 .{ }^{31}$ Although the CSFBD was designed for IBS and has been used successfully for follow up of IBS patients after a therapeutic intervention, this instrument needs further validation with regard to defining normal and (mildly to severely) increased scores. In addition, implications of high scores for disease management have to be further defined. From our data, it has become obvious that the level of dysfunctional cognitions influences physical and mental QoL as well as symptom severity. These observations emphasize the importance of assessing dysfunctional cognitions when considering treatment strategies.

Regarding both physical and mental QoL, the scores in IBS patients were impaired compared to previously published data of the Dutch population and are comparable with scores of migraine patients and cancer patients. ${ }^{32}$ Both dysfunctional cognitions and symptom severity influenced physical QoL. Furthermore, there was also a significant influence of depression scores on physical QoL. Surprisingly, we found no influence of anxiety scores on physical QoL. Creed et al. also showed the negative influence of depression on physical QoL, but mental QoL was not assessed in that study. ${ }^{11}$ Mental QoL in our study was significantly affected by depression, anxiety and dysfunctional cognition scores, but not by symptom severity. These findings clearly 
stress the impact of dysfunctional cognitions on QoL in IBS patients, together with other psychological factors, like the presence of anxiety and depression disorders.

Several authors have put emphasis on psychological assessment in patients with functional bowel disorders, ${ }^{1,14,15,33}$ since different studies have shown that almost twothird of all patients with self-reported depressive symptoms are not identified by the attending physician as suffering from psychiatric problems. ${ }^{34,35}$ Similarly, physicians detect only one third of all cases in somatoform disorders. ${ }^{36}$ Therefore, separate psychological assessment is mandatory. Screening of patients for QoL, anxiety, depression and dysfunctional cognitions can be performed easily through patient questionnaires and is the basis and justification for additional therapeutic interventions, which have been proven to be effective. ${ }^{37-39}$

At the present time, treatment of IBS patients in GI practices focuses on physical symptom relieve. The efficacy of various medical and dietary treatments has not been established, ${ }^{33,40}$ in contrast to the efficacy of various psychological interventions. Recently, Zijdenbos et al. concluded that psychological inter-ventions are superior to standard care focused on improvement of symptoms. ${ }^{39}$ Ford et al. found the same results for intervention with antidepressants. ${ }^{37}$

A possible limitation of this study is the recruitment of patient data from three different intervention trials. However, this is not expected to affect the outcome as these were baseline data from three studies by the same research group, using exactly the same inclusion criteria, procedures and questionnaires. Also, demographic data of the three populations did not differ. Summarizing, we found that in IBS patients, psychological factors influence symptom severity and QoL. Patients who suffer from possible anxiety disorders or depression had more severe symptoms, a worse physical and mental QoL and higher dysfunctional cognition scores. Suffering from a possible anxiety disorder independently influences mental QoL in IBS patients, whereas a possible depression influences mental as well as physical QoL. Dysfunctional cognitions independently influence physical and mental QoL, but also have a significant impact on symptom severity. No differences in psychological factors and dysfunctional cognitions were found between primary and hospital care patients.

In conclusion, recognizing possible anxiety and depression disorders as well as dysfunctional cognitions in IBS patients can be an important step in symptom relieve and improving QoL in this difficult to treat patient group, and may help to reduce the burden for health care and economic costs. 


\section{REFERENCES}

1. Longstreth GF, Thompson WG, Chey WD, Houghton LA, Mearin F, Spiller RC. Functional bowel disorders. Gastroenterology 2006;130:1480-91.

2. Hungin AP, Whorwell PJ, Tack J, Mearin F. The prevalence, patterns and impact of irritable bowel syndrome: an international survey of 40,000 subjects. Aliment Pharmacol Ther 2003;17:643-50.

3. Jones R, Lydeard S. Irritable bowel syndrome in the general population. Bmj 1992;304:87-90.

4. Whitehead WE, Burnett CK, Cook EW 3rd, Taub E. Impact of irritable bowel syndrome on quality of life. Dig Dis Sci 1996;41:2248-53.

5. Patrick DL, Drossman DA, Frederick IO, DiCesare J, Puder KL. Quality of life in persons with irritable bowel syndrome: development and validation of a new measure. Dig Dis Sci 1998;43:400-11.

6. Hahn BA, Kirchdoerfer $U$, Fullerton S, Mayer E. Evaluation of a new quality of life questionnaire for patients with irritable bowel syndrome. Aliment Pharmacol Ther 1997;11:547-52.

7. Luscombe FA. Health-related quality of life and associated psychosocial factors in irritable bowel syndrome: a review. Qual Life Res 2000;9:161-76.

8. Koloski NA, Talley NJ, Boyce PM. The impact of functional gastrointestinal disorders on quality of life. Am J Gastroenterol 2000;95:67-71.

9. Williams RE, Black CL, Kim HY, Andrews EB, Mangel AW, Buda JJ, Cook SF. Determinants of healthcareseeking behaviour among subjects with irritable bowel syndrome. Aliment Pharmacol Ther 2006;23:1667-75.

10. Badia X, Mearin F, Balboa A, Baró E, Caldwell E, Cucala M, Díaz-Rubio M, Fueyo A, Ponce J, Roset M, Talley NJ. Burden of illness in irritable bowel syndrome comparing Rome I and Rome II criteria. Pharmacoeconomics 2002;20:749-58.

11. Creed F, Ratcliffe J, Fernandez L, Tomenson B, Palmer S, Rigby C, Guthrie E, Read N, Thompson D. Health-related quality of life and health care costs in severe, refractory irritable bowel syndrome. Ann Intern Med 2001;134:860-8.

12. Farthing MJ. Irritable bowel, irritable body, or irritable brain? Bmj 1995;310:171-5.

13. Gonsalkorale WM, Perrey C, Pravica V, Whorwell PJ, Hutchinson IV. Interleukin 10 genotypes in irritable bowel syndrome: evidence for an inflammatory component? Gut 2003;52:91-3.

14. Budavari Al, Olden KW. Psychosocial aspects of functional gastrointestinal disorders. Gastroenterol Clin North Am 2003;32:477-506.

15. Levy RL, Olden KW, Naliboff BD, Bradley LA, Francisconi C, Drossman DA, Creed F. Psychosocial aspects of the functional gastrointestinal disorders. Gastroenterology 2006;130:1447-58.

16. Chitkara DK, van Tilburg MA, Blois-Martin N, Whitehead WE. Early life risk factors that contribute to irritable bowel syndrome in adults: a systematic review. Am J Gastroenterol 2008;103:765-74; quiz 775.

17. Guthrie E, Creed F, Fernandes L, Ratcliffe J, Van Der Jagt J, Martin J, Howlett S, Read N, Barlow J, Thompson D, Tomenson B. Cluster analysis of symptoms and health seeking behaviour differentiates subgroups of patients with severe irritable bowel syndrome. Gut 2003;52:1616-22.

18. Leue C, van Os J, Neeleman J, de Graaf R, Vollebergh W, Stockbrügger RW. Bidirectional associations between depression/anxiety and bowel disease in a population based cohort. J Epidemiol Community Health 2005;59:434.

19. Gonsalkorale WM, Toner BB, Whorwell PJ. Cognitive change in patients undergoing hypnotherapy for irritable bowel syndrome. J Psychosom Res 2004;56:271-8.

20. Dunmore E, Clark DM, Ehlers A. Cognitive factors involved in the onset and maintenance of posttraumatic stress disorder (PTSD) after physical or sexual assault. Behav Res Ther 1999;37:809-29.

21. Goubert L, Crombez G, Danneels L. The reluctance to generalize corrective experiences in chronic low back pain patients: a questionnaire study of dysfunctional cognitions. Behav Res Ther 2005;43:1055-67.

22. Toner BB, Stuckless N, Ali A, Downie F, Emmott S, Akman D. The development of a cognitive scale for functional bowel disorders. Psychosom Med 1998;60:492-7.

23. van der Zee KI SR. Het meten van de algemene gezonsheidstoestand met de RAND-36, een handleiding. [Assessment of general health status with the RAND-36; guidebook]; 1993. 
24. Farivar SS, Cunningham WE, Hays RD. Correlated physical and mental health summary scores for the SF-36 and SF-12 Health Survey, V.I. Health Qual Life Outcomes 2007;5:54.

25. Bjelland I, Dahl AA, Haug TT, Neckelmann D. The validity of the Hospital Anxiety and Depression Scale. An updated literature review. J Psychosom Res 2002;52:69-77.

26. Zigmond AS, Snaith RP. The hospital anxiety and depression scale. Acta Psychiatr Scand 1983;67: 361-70.

27. Mayer EA, Craske M, Naliboff BD. Depression, anxiety, and the gastrointestinal system. J Clin Psychiatry 2001;62 Suppl 8:28-36; discussion 37.

28. Cain KC, Jarrett ME, Burr RL, Rosen S, Hertig VL, Heitkemper MM. Gender differences in gastrointestinal, psychological, and somatic symptoms in irritable bowel syndrome. Dig Dis Sci 2009;54:1542-9.

29. Sugaya N, Nomura S. Relationship between cognitive appraisals of symptoms and negative mood for subtypes of irritable bowel syndrome. Biopsychosoc Med 2008;2:9.

30. Kovacs Z, Kovacs F. Depressive and anxiety symptoms, dysfunctional attitudes and social aspects in irritable bowel syndrome and inflammatory bowel disease. Int J Psychiatry Med 2007;37:245-55.

31. van der Veek PP, van Rood YR, Masclee AA. Clinical trial: short- and long-term benefit of relaxation training for irritable bowel syndrome. Aliment Pharmacol Ther 2007;26:943-52.

32. Aaronson NK, Muller M, Cohen PD, Essink-Bot ML, Fekkes M, Sanderman R, Sprangers MA, te Velde A, Verrips E. Translation, validation, and norming of the Dutch language version of the SF-36 Health Survey in community and chronic disease populations. J Clin Epidemiol 1998;51:1055-68.

33. Spiller R, Aziz Q, Creed F, Emmanuel A, Houghton L, Hungin P, Jones R, Kumar D, Rubin G, Trudgill N, Whorwell P; Clinical Services Committee of The British Society of Gastroenterology. Guidelines on the irritable bowel syndrome: mechanisms and practical management. Gut 2007;56:1770-98.

34. Meyer T, Klemme H, Herrmann C. Depression but not anxiety is a significant predictor of physicians' assessments of medical status in physically ill patients. Psychother Psychosom 2000;69:147-54.

35. Kroenke K, Jackson JL, Chamberlin J. Depressive and anxiety disorders in patients presenting with physical complaints: clinical predictors and outcome. Am J Med 1997;103:339-47.

36. Fink $P$, Hansen MS, Oxhoj ML. The prevalence of somatoform disorders among internal medical inpatients. J Psychosom Res 2004;56:413-8.

37. Ford AC, Talley NJ, Schoenfeld PS, Quigley EM, Moayyedi P. Efficacy of antidepressants and psychological therapies in irritable bowel syndrome: Systematic review and meta-analysis. Gut 2009;58:367-78.

38. Pae CU, Masand PS, Ajwani N, Lee C, Patkar AA. Irritable bowel syndrome in psychiatric perspectives: a comprehensive review. Int J Clin Pract 2007;61:1708-18.

39. Zijdenbos IL, de Wit NJ, van der Heijden GJ, Rubin G, Quartero AO. Psychological treatments for the management of irritable bowel syndrome. Cochrane Database Syst Rev 2009:CD006442.

40. Tack J, Fried M, Houghton LA, Spicak J, Fisher G. Systematic review: the efficacy of treatments for irritable bowel syndrome--a European perspective. Aliment Pharmacol Ther 2006;24:183-205. 


\section{CHAPTER 3}

Efficacy of Lactobacillus casei Shirota for patients with Irritable Bowel Syndrome

A.Y. Thijssen, C.H.M. Clemens, V. Vankerckhoven, H. Goossens, D.M.A.E. Jonkers, A.A.M. Masclee

Part of this chapter has been accepted for publication in the European Journal of Gastroenterology and Hepatology 


\section{ABSTRACT}

\section{Background \& Aims}

Meta-analyses point to a modest but significant effect of probiotics on symptoms in Irritable Bowel Syndrome (IBS). We aimed to assess the effect of the probiotic Lactobacillus casei Shirota (LCS) on symptoms and quality of life (QoL) in IBS patients in a randomised, double-blind, placebo-controlled intervention study.

\section{Methods}

IBS patients (Rome II) between 18 and 65 years of age were included. The study consisted of an eight-week intervention period in which subjects received probiotic (LCS) or placebo twice daily, followed by an eight-week follow-up period. Symptom diaries and QoL were scored at weeks 0,8 and 16 . The primary outcome parameter was a decrease of $\geq 30 \%$ in a composite mean symptom score (MSS) at week 8 based on intention-to-treat analysis.

\section{Results}

39 subjects ( $67 \%$ female) were included in the probiotic group and 41 ( $71 \%$ female) in the placebo group. After the intervention period, the mean relative improvement did not reach $30 \%$ for MSS or any individual symptom score. After follow-up (week 16) a mean improvement of $\geq 30 \%$ was reached for MSS in the probiotic group, but no significant difference between both treatment groups (mean \pm SD: $34 \pm 7 \% ; 13 \pm 8 \%$, $\mathrm{p}=0.06$ ) was found. At week 16 , in the probiotic treatment group a significantly more pronounced improvement of MSS and of all individual symptom variables was seen compared to placebo treatment (all $p<0.05$ ) in the male population.

\section{Conclusion}

After probiotic treatment with LCS no $30 \%$ improvement in mean symptom scores was observed. 


\section{INTRODUCTION}

Irritable Bowel Syndrome (IBS) is a functional gastrointestinal (GI) disorder characterised by abdominal discomfort and pain, bloating and altered bowel habits. ${ }^{1}$ The prevalence in the European population varies from $6-12 \%^{2}$ with a female predominance. In addition to abdominal symptoms, IBS patients experience significant impairment in quality of life $(\mathrm{QoL}) .^{3}$ The effects of symptoms on QoL create a large burden on health care and costs. ${ }^{4}$ Treatment of IBS is usually directed against symptoms since its pathophysiology is poorly understood. Recent studies point to the influence of environmental factors such as the presence of low grade intestinal inflammation, changes in gut permeability and alterations in gut microbiota composition and/or activity. ${ }^{5}$ Changes in fecal microbiota composition point to a decrease in coliform bacteria, lactobacilli and bifidobacteria ${ }^{6}$ and a less stable total microbiota composition. ${ }^{7}$ These changes may affect fermentation of food and gas production, mucosal immune activation and gut sensory-motor function. ${ }^{8}$

Probiotics affect intestinal microbiota and immune function by interacting with host immune competent cells of the intestinal mucosa, secreting bacterial products and competing with other bacteria. ${ }^{9}$ Probiotics have been suggested as a treatment for IBS and several studies point to a beneficial result. A recent meta-analysis of placebocontrolled trials found that probiotic use has significant benefits, ${ }^{10,11}$ however, the overall effects are only modest. ${ }^{12}$ Several other studies found no beneficial effect ${ }^{13-16}$ or even a worsening of symptoms after probiotic treatment. ${ }^{17}$ Unfortunately, results from the various studies are difficult to compare as different treatment strategies have been used (e.g. different strains, mono- or multispecies, differences in treatment duration). ${ }^{12,18,19}$ Furthermore, many studies report a high number of drop-outs after randomisation and data analyses are not always based on an intention-to-treat principle.

The probiotic strain Lactobacillus casei Shirota (LCS) is known to adequately survive throughout the GI tract and intake of LCS by healthy volunteers resulted in an increase in fecal lactobacilli and bifidobacteria. ${ }^{20} \mathrm{~A}$ randomised controlled study of LCS in 70 subjects with chronic constipation found a significant improvement of bowel habits. ${ }^{21} \mathrm{~A}$ pilot study conducted by Barrett et $a{ }^{22}{ }^{22}$ found that after IBS patients consumed LCS for six weeks, there was a change in early rise of breath hydrogen after lactulose intake, suggesting a decrease in small intestinal bacterial overgrowth. Furthermore, beneficial effects of LcS have been reported on inflammatory parameters both in vitro and in vivo. ${ }^{23}$

Based on these data, we assume that LCS has a potential beneficial effect for IBS patients. However, no studies have been performed about the use of LcS to treat IBS patients. This study aimed to assess the effect of using a probiotic product containing 
LCS on the symptoms and QoL of patients with IBS in a randomised double-blind placebo-controlled study.

\section{MATERIALS AND METHODS}

\section{Subjects}

This study, conducted between 2007 and 2009, included IBS patients between 18 and 65 years of age who fulfilled the Rome II criteria. The Rome II criteria were used in the trial protocol, which originated in 2005. Subjects were solicited via the outpatient clinics of four hospitals (three secondary hospitals and one tertiary centre) and via local advertisements. We defined IBS subtypes (i.e. diarrhea, constipation, alternating, and undefined) based on symptom diaries kept during the run-in period.

Exclusion criteria included a history of major abdominal surgery (excluding appendectomy, cholecystectomy, ovariectomy and hysterectomy), intake of more than $500 \mathrm{ml}$ of yoghurt per day, lactose intolerance, pregnancy, lactation, unstable organic disease and a history of drug or alcohol abuse. Subjects were not allowed to use laxatives, bulking agents, anti-diarrheals and/or pain medication during the study period. Only occasional use of paracetamol or non-steroidal anti-inflammatory drugs for pain relief (related to IBS or other causes) was permitted. Subjects were not allowed to use antibiotics, prebiotics or probiotics for four weeks before and during the study. Subjects were instructed to maintain their usual dietary habits throughout the entire study protocol. All concurrent medication use was recorded at inclusion and the use had to remain stable during the study.

\section{Study design}

The study was performed with patients recruited via the four hospitals according to a randomised, double-blind, placebo-controlled, parallel-grouped design. The study lasted 22 weeks and consisted of three periods: four to six weeks of run-in, an eightweek intervention and an additional eight-week follow-up period. Subjects filled out a daily symptom diary (for two weeks), a QoL questionnaire and a questionnaire assessing dysfunctional cognitions at three time points: before the start of the intervention (week -2/0), at the end of the intervention (week 6/8) and at the end of follow-up (week 14/16). All subjects who completed the protocol visited the hospital five times and had one consultation by phone (week 12), all conducted by the same research physician (AT). 


\section{Probiotic product}

Both the probiotic and placebo were provided by Yakult Europe (Almere, the Netherlands). Patients had to take one bottle of probiotic dairy product or placebo twice a day, at breakfast and dinner time. The probiotic dairy product was a fermented milk drink (one bottle $=65 \mathrm{ml}$ ) that contained at least $6.5 \times 10^{9} \mathrm{CFU}$ living LCS. The placebo was a milk drink with exactly the same composition as the probiotic drink, except for the LCS bacteria. The placebo and probiotic drinks were indistinguishable in terms of taste, smell and colour.

\section{Compliance}

Compliance with treatment was checked during each visit by counting the number of bottles remaining and asking whether subjects had forgotten to consume bottles. Further confirmation of probiotic use was performed by checking for the presence of LcS in fecal samples at the end of the intervention period. Patients were asked to fill a tube containing $6 \mathrm{ml}$ of anaerobic transport medium with a spoonful of feces. A tenfold dilution series $\left(10^{-1}\right.$ to $\left.10^{-7}\right)$ of each fecal sample was made within 48 hours after defecation using an anaerobic dilution buffer, after which fecal dilutions were incubated on Lactitol-LBS-Vancomycin medium agar plates. Large, white, grazed and dome-shaped colonies were formed by LCS after four days of incubation at $37^{\circ} \mathrm{C}$ under aerobic conditions. Ten typical colonies were checked by ELISA using a monoclonal antibody against LCS (L8, Yakult Central Institute for Microbiological Research, Tokyo, Japan). ${ }^{24}$

\section{Symptom diary}

The symptom diary, which was used in a previous Dutch trial, ${ }^{25}$ rated the severity of IBS-related symptoms using a 5-point Likert scale ranging from 0 (no symptoms) to 4 (very severe symptoms) for discomfort, pain, constipation, diarrhea, bloating, flatulence, defecation frequency and an overall score for that day (i.e. total). In addition, a mean symptom score (MSS; ranging from 0-20) was calculated based on the sum of mean discomfort, pain, constipation, diarrhea and bloating scores during the two-week period. During run-in, subjects were required to have a MSS $\geq 2$ to be included in the protocol. The MSS was defined as the primary outcome parameter. The number of symptom-free days per 2 weeks (range 0-14) was also calculated, based on the number of days with a total overall score of 0 .

\section{Quality of Life}

We used the RAND-36 survey (the validated Dutch version of the MOS 36-item Short Form Health Survey) to measure generic health-related QoL. ${ }^{26}$ The RAND-36 consists of 
eight domains with an outcome between 0 and 100: physical functioning, role limitations due to physical and emotional problems, social functioning, bodily pain, mental health, vitality and general health perception. High scores indicate a high QoL. Physical and mental composite scores can be derived from the eight domains and used as a general QoL indicator. ${ }^{4,27}$

\section{Cognitive scale of functional bowel disorders (CSFBD)}

Both symptom severity and QoL in IBS patients can be further affected by the presence of dysfunctional cognitions: automatically occurring negative or catastrophizing thoughts induced by psychological distress and (severe) physical symptoms. ${ }^{28,29} \mathrm{We}$ used the $\mathrm{CSFBD}^{29}$ to score the presence of dysfunctional cognitions. It can also be used as a follow-up tool for IBS intervention strategies. ${ }^{28}$ The CSFBD includes 31 statements on thoughts about bowel function and personality features; scores range from 1 (does not apply to me at all) to 7 (fully applies to me). A total score between 31 and 217 can be calculated. Higher scores indicate more dysfunctional cognitions.

\section{Outcome variables}

The mean symptom score (MSS) was defined as the primary outcome parameter, with a $\geq 30 \%$ improvement after the intervention period (week 8) as the target. The secondary outcome parameters were percentage improvement of individual symptom scores and number of symptom-free days, QoL and dysfunctional cognition scores. Furthermore, gender-based differences regarding the treatment effect were assessed for all outcome variables since the prevalence of IBS is different for men and women. Finally, responders were defined as subjects with $\geq 30 \%$ improvement in symptoms. Subjects who did not reach the $30 \%$ improvement and subjects for whom one or more of the follow-up data were missing or who did not complete the trial were considered non-responders.

\section{Statistical analysis}

The power calculation was based on a previous study that reported a $30 \%$ decrease in IBS symptoms after patients received psychological treatment; this study used the same symptom questionnaire. ${ }^{25}$ That decrease was considered to be clinically relevant and has proven to be a feasible target. With an $\alpha$ of 0.05 , an $1-\beta$ of 0.80 and a $\sigma$ of $39 \%$, 27 subjects should be included per group to detect this difference with an independentsamples t-test. Expecting a $25 \%$ drop-out rate, 40 subjects should be included in each group.

All statistical analyses were performed using SPSS for Windows, version 15 (SPSS inc, Chicago II.). Differences in prevalences between groups were compared with the Chi- 
square test using a Fisher exact test when necessary, while continuous variables (percentage decrease/increase from baseline regarding symptoms) were compared between groups using the independent-samples t-test or by the Mann-Whitney $U$ test when necessary. No centre effect was expected since same physician (AT) and same randomisation protocol was used.

Linear mixed model analysis was used to assess the effect of treatment over time on QoL and CSFBD scores, with treatment, time and treatment*time as fixed effects. In case of unstructured data covariance was used for repeated measures.

The level of significance was set at $p \leq 0.05$ using two-sided tests. Data about all patients, randomised to the probiotic or placebo treatment, in the analysis (i.e. intention-to-treat analysis). Data are expressed as mean $\pm \mathrm{SD}$, unless stated otherwise.

\section{Ethical considerations}

This human intervention study was approved by the Leiden University Medical Center Ethics Committee (Leiden, The Netherlands), and conducted in full accordance with the principles of the Declaration of Helsinki (52nd WMA General Assembly, Edinburgh, Scotland, Oct 2000). All patients gave their written informed consent prior to participation. This trial was registered in the Dutch Trial Registration (www.trialregister.nl), TC number 1235.

\section{RESULTS}

\section{Subjects}

A total of 338 prospective subjects received trial information after expressing interest to participate. Initially, 107 of them were willing to participate in the trial. During the run-in period, 27 did not meet the inclusion criteria or refused further participation. Eventually, 80 subjects were randomised and included in the intention-to-treat analyses.

Eight subjects were not compliant with the study protocol: two had to undergo a surgical intervention during the follow-up period, four refused further participation and two had no accurate intake of the product due to side effects. These side effects consisted of an increase in symptoms (i.e. bloating, nausea), resulting in cessation of intake of the product and involvement in the study. Both subjects were randomised in the probiotic group. No further side effects were reported.

Another eight subjects received antibiotics either during the intervention $(n=5)$ or during follow-up $(n=3)$ and were excluded from further participation but were included in the intention-to-treat analyses. 


\section{Demographics}

Table 3.1 shows the demographic data and IBS subtypes of the subjects in the probiotic $(n=39)$ and placebo group $(n=41)$. No significant differences were observed between the groups (all $p>0.10$ ). The medical histories and the use of medication at inclusion were also not significantly different between the two treatment groups $(p=0.88$ and $p=0.84$, respectively; data not shown).

Table 3.1 Demographics and IBS subtypes of subjects treated with a probiotic or placebo

\begin{tabular}{|c|c|c|}
\hline Parameter & Probiotic $(n=39)$ & Placebo $(n=41)$ \\
\hline Male/female & $13(33 \%) / 26(67 \%)$ & $12(29 \%) / 29(71 \%)$ \\
\hline $\operatorname{Age}^{\jmath}(y r s)$ & $41.1 \pm 14.8$ & $42.4 \pm 13.5$ \\
\hline Years symptoms ${ }^{\jmath}$ (yrs) & $12.5 \pm 12.9$ & $15.4 \pm 13.3$ \\
\hline Smoker & $8(21 \%)$ & $9(22 \%)$ \\
\hline Alcohol consumption' (units/week) & $4.9 \pm 5.9$ & $4.8 \pm 7.7$ \\
\hline BMI males $^{f}\left(\mathrm{~kg} / \mathrm{m}^{2}\right)$ & $27.1 \pm 4.5$ & $24.7 \pm 4.4$ \\
\hline BMI females $\left(\mathrm{kg} / \mathrm{m}^{2}\right)$ & $24.6 \pm 4.4$ & $23.8 \pm 3.6$ \\
\hline Recruitment via advertisement/hospital & $16 / 23$ & $11 / 30$ \\
\hline \multicolumn{3}{|l|}{ IBS subtypes } \\
\hline Diarrhea & $13(33 \%)$ & $11(27 \%)$ \\
\hline Constipation & $8(21 \%)$ & $12(29 \%)$ \\
\hline Alternating & $9(23 \%)$ & $14(34 \%)$ \\
\hline Undefined & $9(23 \%)$ & $4(10 \%)$ \\
\hline
\end{tabular}

${ }^{\int}$ Continuous data are expressed as mean \pm SD

\section{Compliance}

Subjects in the probiotic and placebo group reported that they had consumed at least $95 \%$ of the bottles during the intervention period. For an objective compliance measurement, the presence of LCS bacteria was analysed in subjects' fecal samples during the last week of the intervention (week 8). In the probiotic group, LcS bacteria were not detected in three patients (8\%); in the placebo group, LcS bacteria were recovered from one patient (2\%).

\section{Response to treatment}

Figure 3.1 shows the relative changes during and after treatment for MSS (primary outcome parameter) and for individual symptoms: discomfort, pain, bloating, flatulence and total (overall day score). After intervention (week 8), the mean relative improvement did not reach $30 \%$ for any of the outcome parameters and no significant differences were found between the probiotic and placebo group ( $p>0.10$; Figure 3.1A). 
Week 8

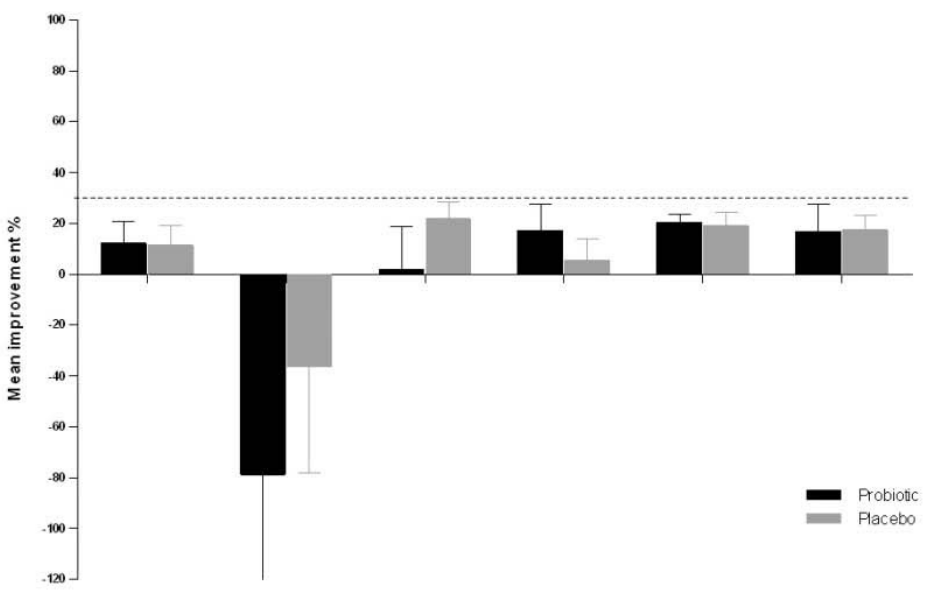

$\begin{array}{lllll}\text { Discomfort } & \text { Pain } & \text { Bloating } & \text { Flatulence } & \text { Total }\end{array}$

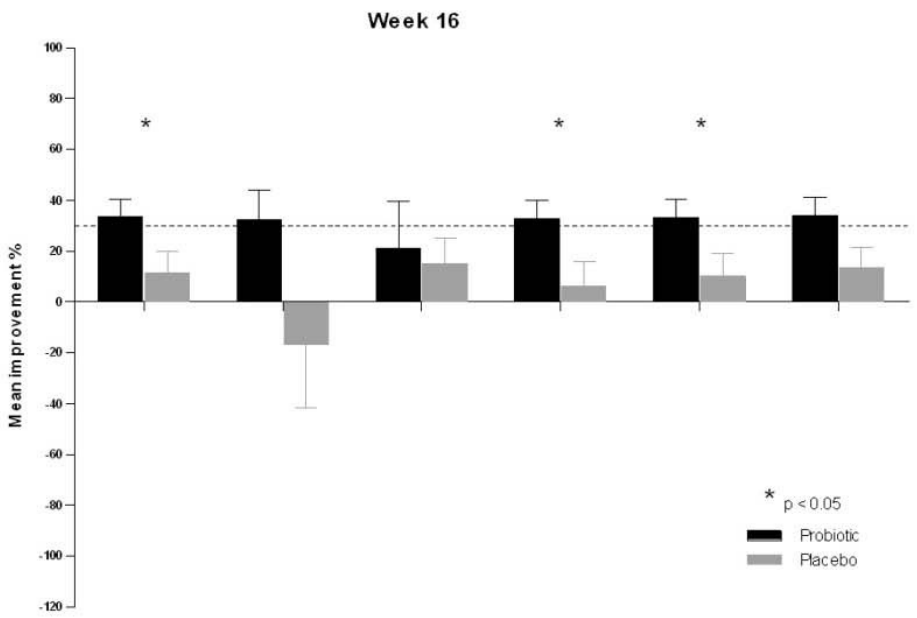

$\begin{array}{lllll}\text { Discomfort } & \text { Pain } & \text { Bloating } & \text { Flatulence } & \text { Total }\end{array}$

Figure 3.1 A. Relative improvement (given as a mean percentage \pm SEM) of each symptom variable at week 8 and week 16 for both treatment groups.

B. At week 16 , a mean improvement $\geq 30 \%$ was reached for all symptoms apart from bloating in the probiotic group, but for none of the symptoms in the placebo group 
Pain scores showed a trend towards worsening during treatment, but the range of change in individual pain scores was very wide. However, after follow-up (week 16), a mean improvement $\geq 30 \%$ was reached for MSS and individual symptoms, apart from bloating, in the probiotic group but for none of the symptoms in the placebo group. The improvement percentages were not significant for MSS $(p=0.06)$ and pain $(p=0.10)$, but improvement scores for discomfort, flatulence and total (overall day score) (all $p \leq 0.05$ ) were significantly higher in the probiotic group (Figure 3.1B). The number of symptomfree days did not differ significantly between the groups at weeks 8 and $16(2.6 \pm 3.5$ vs. $2.8 \pm 4.3, p=0.83$ and $4.0 \pm 4.6$ vs. $2.6 \pm 3.8, p=0.17$ respectively).

Table 3.2 shows the QoL and dysfunctional cognition scores.

Table 3.2 Quality of Life and cognitive scale of functional bowel disorders scores during the study period in subjects treated with probiotics $(n=39)$ or placebo $(n=41)$

\begin{tabular}{|c|c|c|c|c|}
\hline Variable & Treatment & $\begin{array}{c}\text { Week } 0 \\
\text { (before intervention) }\end{array}$ & $\begin{array}{c}\text { Week } 8 \\
\text { (after intervention) }\end{array}$ & $\begin{array}{c}\text { Week } 16 \\
\text { (after follow-up) }\end{array}$ \\
\hline QoL Physical & Probiotic & $\mathrm{n}=31$ & $n=31$ & $n=26$ \\
\hline \multirow[t]{3}{*}{ Composite Score } & & $44 \pm 4$ & $43 \pm 4$ & $43 \pm 4$ \\
\hline & Placebo & $n=37$ & $n=35$ & $n=31$ \\
\hline & & $43 \pm 5$ & $43 \pm 4$ & $43 \pm 4$ \\
\hline QoL Mental & Probiotic & $n=31$ & $n=31$ & $n=26$ \\
\hline \multirow[t]{3}{*}{ Composite Score } & & $41 \pm 6$ & $43 \pm 5$ & $44 \pm 4$ \\
\hline & Placebo & $n=37$ & $n=35$ & $n=31$ \\
\hline & & $39 \pm 7$ & $42 \pm 6$ & $41 \pm 6$ \\
\hline Cognitive Scale & Probiotic & $n=39$ & $n=33$ & $n=28$ \\
\hline forFunctional Bowel & & $90 \pm 36$ & $85 \pm 33$ & $82 \pm 37$ \\
\hline \multirow[t]{2}{*}{ Disorders } & Placebo & $\mathrm{n}=41$ & $n=36$ & $n=33$ \\
\hline & & $102 \pm 38$ & $91 \pm 40$ & $90 \pm 39$ \\
\hline
\end{tabular}

Data expressed as mean \pm SD. No significant differences in any of the items were found between the groups or within the groups over time (QoL-PCS $p=0.81$, QoL-MCS $p=0.80$ and CSFBD $p=0.23$ ).

\section{Subgroup analysis by gender}

There were no significant differences at week 8 between treatment response in the male vs. the female population (data not shown). In Figure 3.2 we show the response to treatment at week 16 for men (13 in probiotic group, 12 in placebo group) and women (26 in probiotic group, 29 in placebo group). In the male population, the probiotic treatment resulted in a significantly higher improvement of symptom scores compared to placebo treatment for MSS and each individual symptom variable (all $p<0.05$ ). In the female population, the probiotic and placebo treatment did not differ for MSS and any of the individual symptom variables (all $\mathrm{p}>0.10$ ). Regarding symptom-free days, only the men significantly benefited from probiotic treatment at week 8 and week 16 (Figure 3.3). A significantly higher placebo response was found for discomfort, bloating, 
total (overall day score) and MSS (all $p<0.05$ ) in the female versus the male population. No such differences were observed at week 8.
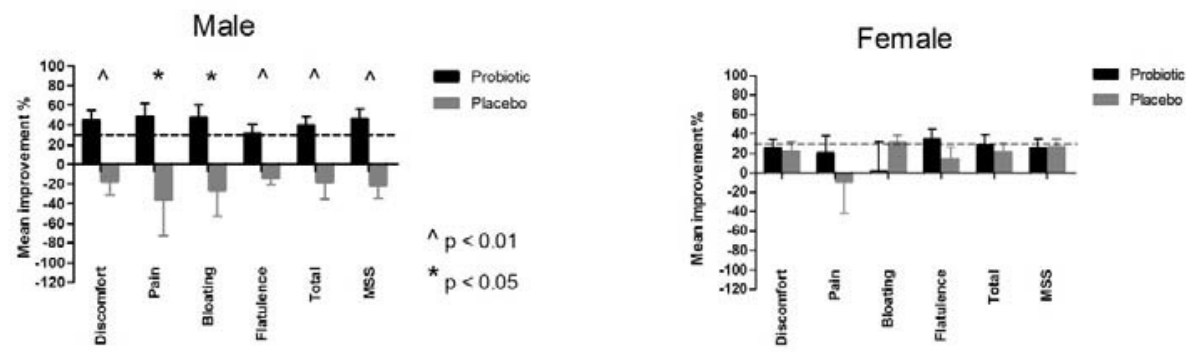

Figure 3.2 Change of symptoms at week 16 male vs. female. Mean improvement (given as a percentage \pm SEM) of symptoms after treatment at week 16 for men (13 probiotic/12 placebo) and women (26 probiotic/29 placebo) separately.

$\wedge p<0.01$ probiotic vs. placebo treatment.

* $p<0.05$ probiotic vs. placebo treatment.

For men, the QoL mental composite scores increased significantly over time in the

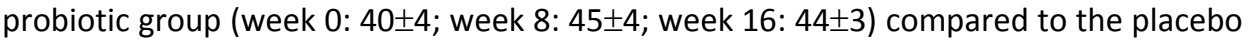

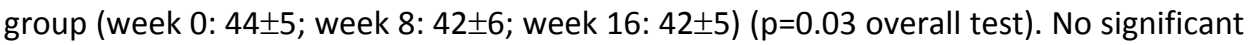
difference in the QoL mental composite scores between the treatment groups was

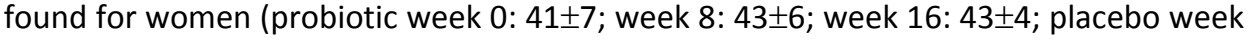
0: $37 \pm 7$; week 8: $41 \pm 6$; week 16: 40 \pm 6$)(p=0.48)$. No significant differences in treatment effect on QoL physical composite scores were detected between men and women ( $p>0.10$; data not shown).

\section{Male}

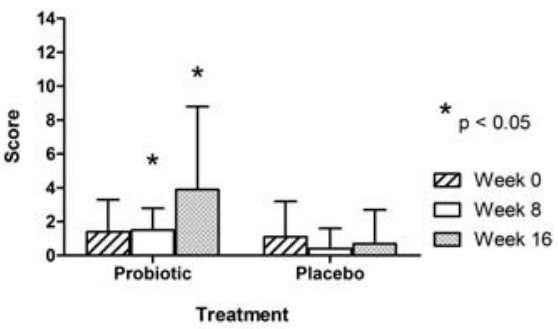

Female

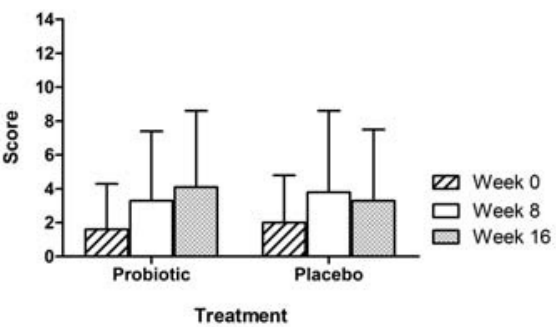

Figure 3.3 Symptoms free days (range 0-14). Change in symptom-free days, for men (13 probiotic/ 12 placebo) and women ( 26 probiotic/29 placebo) separately.

* $p<0.05$ probiotic vs. placebo treatment at week 8 and week 16 . 


\section{Responders versus non-responders}

Subjects with an MSS decrease $\geq 30 \%$ at weeks 8 or 16 were defined as responders. Of the 80 subjects, $14(36 \%)$ in the probiotic group responded and $12(29 \%)$ in the placebo group responded, which was not significantly different $(p=0.53)$. Response rates were then analysed separately for men and women. The number of male responders with respect to MSS was 7 out of 13 (54\%) for the probiotic group and 1 out of 12 (8\%) for the placebo group $(p=0.02)$. The number of female responders was 7 out of $26(27 \%)$ in the probiotic group and 11 out of $29(38 \%)$ in the placebo group $(p=0.39)$. The response rate in the probiotic group was significantly higher among men (54\% vs. $27 \%$; male vs. female) whereas the placebo group response rate was significantly higher among women ( $8 \%$ vs. $38 \%$; male vs. female) $(p=0.02)$.

\section{DISCUSSION}

We did not observe significant differences in symptom scores between probiotic LcS and placebo treatment at the end of the intervention period (week 8). However, we found a significant difference in several individual symptom scores and in the total day score in favour of the probiotic treatment group after subjects had finished both the intervention and the follow-up period (week 16). This improvement in the LcS treated subjects was more pronounced in the male compared to the female population.

In line with previous recommendations, a clinically relevant change in the patientreported symptoms score was the primary outcome measure in our trial. ${ }^{30-32}$ An improvement $\geq 30 \%$ (i.e. main outcome parameter) in MSS was considered a clinically relevant and feasible target. ${ }^{25}$ MSS is a composite score including constipation and diarrhea. The decrease in this score showed a non-significant difference $(p=0.06)$ between probiotic and placebo treatment at the end of follow-up. The score might have been confounded by the inclusion of both constipation and diarrhea scores, since significant improvement was found for most individual symptoms and the total score at the end of follow-up.

An improvement $\geq 30 \%$ was not found at week 8 for any of the symptom variables, and there was no difference in improvement between probiotic and placebo treatment at week 8. As probiotic products are known to disappear from the intestinal microbiota within one to two weeks after cessation of consumption, ${ }^{20,31,33}$ we did not anticipate that an improvement in symptoms would be observed beyond week 8 , especially not after an eight-week follow-up period, without consumption of the probiotic product. Only a few studies of IBS have assessed the duration of effect of a probiotic intervention that lasted beyond the end of intake of the product. 
A study by Simren et al. ${ }^{15}$ of a multispecies probiotic could not detect significant differences in symptom scores or responder rates between the groups treated with a probiotic or placebo after eight weeks of treatment, nor after an additional eight-week follow-up. However, researchers in that study observed a decrease in symptoms in both groups during treatment and further follow-up. ${ }^{15} \mathrm{~A}$ different trial, assessing the effect of an eight-week treatment with another multispecies probiotic and a two-week additional follow-up period in IBS patients, found no significant differences in symptom severity scores reported by probiotic- and placebo-treated patients at two weeks postintervention, although a significant beneficial effect was seen during the intervention. ${ }^{34}$ In both those studies a multispecies probiotic was used, in contrast to our product.

Kajander et al. $^{35}$ performed a probiotic trial in IBS patients with a five-month intervention period followed by a three-week follow-up. They showed an improvement in QoL that persisted up to the end of the follow-up phase. Unfortunately, these authors did not report on changes in symptoms or on microbiota composition after follow-up. ${ }^{35}$ A recent trial by Guglielmetti et al. ${ }^{36}$ found a persistent improvement after a four-week intervention period that lasted during the following two-week washout period. Unfortunately, both the treatment and the washout periods were short and therefore not comparable. In general, reports on persisting beneficial results after a follow-up period are limited and studies are difficult to compare as they have evaluated a wide variety of different probiotic products. The late onset improvement in symptoms we observed at week 16 may result from various factors. First, it may result from gradually occurring and longer-lasting changes in microbiota composition induced by LcS. Unfortunately, no data have been published about the effects of LcS on microbiota composition after cessation of treatment with the probiotic. Second, the improvement in symptoms beyond the end of intake may be related to immunological changes induced by LCS or microbiota. In IBS, especially post-infectious IBS, a low grade intestinal inflammation is known to be present. This ongoing low grade inflammation may trigger the release of mediators from mast cells and contribute to symptom generation in IBS. ${ }^{37}$ Any beneficial effect of probiotics on the inflammatory response may take weeks or months. Studies of the use probiotics by IBS patients have assessed immunological or inflammatory parameters, but only up to the end of therapy. ${ }^{38}$ However, prolonged changes in inflammatory parameters have been observed in healthy subjects, pointing to an ongoing effect of the probiotic on the intestinal immune response. A three-week consumption of LcS was found to cause a marked increase in natural killer-cell activity that lasted for an additional three weeks after stopping consumption ${ }^{39}$ and an increase of serum IgA was demonstrated to last for at least seven weeks. ${ }^{40}$ 
Psychological factors that may contribute to a more prolonged beneficial effect should also be taken into account. Participation in a clinical trial usually results in more frequent visits and more intense patient-physician contact compared to regular care. In addition, subjects may have higher expectations about therapeutic efficacy and more disease awareness when participating in a trial. ${ }^{41}$ Since our study was placebocontrolled and double-blind, any possible psychological factor should have equally affected all subjects and is not likely to account for the observed response only after LCS. On the other hand, we cannot rule out the possibility that the natural progression of IBS symptoms, which are known to fluctuate over time, caused part of the observed symptom decrease in the follow-up period.

Although our study was not powered to perform subgroup analyses, after repeating analyses by gender, we found a significant probiotic effect on symptoms, symptom-free days and mental QoL for male subjects but not for female subjects. The responder rate, defined as subjects with a relative improvement in MSS $\geq 30 \%$, also differed by gender: a significantly higher percentage of men were responders to LCS while a significantly higher percentage of women were responders to the placebo.

The observed gender differences may be accidental, but other researchers have also reported gender differences on various outcome parameters related to IBS patients. For example, differences in autonomic nervous system responses and brain activation patterns in response to visceral stimuli have been found. ${ }^{42}$ Other therapeutic intervention trials (i.e. with Alosetron) reported gender differences with regard to symptom outcome, but only found a significant beneficial effect for female subjects. ${ }^{43}$ Another IBS trial showed gender differences in response to probiotic therapy, which also favoured a female response rate to treatment in general, without a difference between probiotic or placebo treatment. ${ }^{44}$

The underlying mechanisms for the gender differences observed in this study are unclear. Up to now, no differences in the effect on microbiota composition and immune responses between men and women have been reported. Our findings might have been affected by the placebo response, which was found to be more pronounced in the female than male subjects. High placebo responses have been reported in many IBS trials and may vary between $16 \%$ and $71 \% .{ }^{45}$ Placebo responses cannot be avoided ${ }^{30}$ and should be taken into account when determining a study's sample size. A recent study examining the placebo effect in IBS found that the treating physician's warmth and empathy, combined with the duration of the interaction and the communication of positive expectations, might significantly affect the placebo response. ${ }^{46}$ Literature data regarding factors that affect the placebo response (i.e. the frequency of intervention, the number of trial visits and the type of treatment given) are indecisive. ${ }^{45,47,48}$ These 
studies point to an increase in the magnitude of the placebo effect caused by higher frequency of visits and longer duration of the intervention. Known placebo treatment also creates a placebo response. Furthermore, it is not known whether women are more receptive than men to a positive patient-physician relationship. Literature data regarding the influence of gender on placebo response are inconsistent. ${ }^{43,49-52}$

All the subjects in our study were seen by the same physician, according to a standardised scheme. We did not assess psychological factors in detail but we evaluated QoL and dysfunctional cognitions. Only mental QoL was significantly different in men after probiotic treatment. However, we cannot provide a full explanation for the influence of psychological factors on the observed placebo response.

This study was performed according to a double-blind, randomised, placebo-controlled parallel design, in which use of other pre-/probiotics was prohibited and medication use was only permitted at a stable dosage, thereby reducing some known potential confounding factors. ${ }^{19}$ The analyses were performed using an intention-to-treat principle. Per-protocol analyses revealed the same results (data not shown). Drop-outs were mainly caused by protocol violations: only two subjects in the probiotic group refused to continue participation due to the supposed side effects of the treatment given.

Compliance with the therapy was checked by assessing the presence of LcS in fecal samples at the end of the intervention. The patients' self-reported compliance was very high. LcS could not be detected in the samples from three patients in the probiotic group (i.e. it was below the detection limit of the ELISA method used). LcS was detected in the fecal sample from one patient in the placebo group, which cannot be explained. This study used the Rome II criteria for subject inclusion, as the protocol originated from 2005 and patient recruitment started in 2006. However, retrospective analyses indicated that all subjects also fulfilled the Rome III criteria. ${ }^{53} \mathrm{~A}$ further limitation of this trial is the use of a Dutch symptom questionnaire, although it has been used in a previous psychological intervention trial of IBS patients ${ }^{25}$ and found to provide reliable and reproducible data.

IBS is a heterogeneous condition with a complex multifactorial pathophysiology. This study included IBS patients from daily clinical practice without any selection related to factors such as specific symptoms, recruitment type or age. A suggestion for future therapeutic trials would be to select specific IBS subgroups, either based on predominant bowel habits or a pathophysiological feature, to enhance treatment efficacy. 
The fact that an effect of LcS was observed at week 16 but not at week 8 indicates that not only the duration of the intervention period is important, but also the duration of follow-up after the intervention. An argument in favour of prolonging the intervention period is that the placebo response declines after $6-8$ weeks of treatment. ${ }^{54}$

In conclusion, we observed an improvement in IBS symptoms after the use of the probiotic LCS by a male population. The effect on symptoms was significantly higher in the probiotic group versus the placebo group at the end of the follow-up period (week 16) though not immediately after the intervention period (week 8). 


\section{REFERENCES}

1 Longstreth GF, Thompson WG, Chey WD, Houghton LA, Mearin F, Spiller RC. Functional bowel disorders. Gastroenterology 2006;130:1480-91.

2 Hungin AP, Whorwell PJ, Tack J, Mearin F. The prevalence, patterns and impact of irritable bowel syndrome: an international survey of 40,000 subjects. Aliment Pharmacol Ther. 2003; 17:643-50.

3 Whitehead WE, Burnett CK, Cook EW, 3rd, Taub E. Impact of irritable bowel syndrome on quality of life. Dig Dis Sci. 1996;41:2248-53.

4 Creed F, Ratcliffe J, Fernandez L, Tomenson B, Palmer S, Rigby C, Guthrie E, Read N, Thompson D. Health-related quality of life and health care costs in severe, refractory irritable bowel syndrome. Ann Intern Med. 2001;134:860-8.

5 Barbara G, De Giorgio R, Stanghellini V, Cremon C, Salvioli B, Corinaldesi R. New pathophysiological mechanisms in irritable bowel syndrome. Aliment Pharmacol Ther. 2004;20 Suppl 2:1-9.

6 Balsari A, Ceccarelli A, Dubini F, Fesce E, Poli G. The fecal microbial population in the irritable bowel syndrome. Microbiologica 1982;5:185-94.

7 Matto J, Maunuksela L, Kajander K, Palva A, Korpela R, Kassinen A, Saarela M. Composition and temporal stability of gastrointestinal microbiota in irritable bowel syndrome--a longitudinal study in IBS and control subjects. FEMS Immunol Med Microbiol 2005;43:213-22.

8 Barbara G, Stanghellini V, Cremon C, De Giorgio R, Gargano L, Cogliandro R, Pallotti F, Corinaldesi R. Probiotics and irritable bowel syndrome: rationale and clinical evidence for their use. J Clin Gastroenterol 2008;42 Suppl 3 Pt 2:S214-7.

9 Shida K, Nanno M. Probiotics and immunology: separating the wheat from the chaff. Trends Immunol. 2008;29:565-73.

10 Moayyedi P, Ford AC, Talley NJ, Cremonini F, Foxx-Orenstein A, Brandt L, Quigley E. The efficacy of probiotics in the therapy of irritable bowel syndrome: a systematic review. Gut 2010;59:325-32.

11 Whelan K. Probiotics and prebiotics in the management of irritable bowel syndrome: a review of recent clinical trials and systematic reviews. Curr Opin Clin Nutr Metab Care. 2011;14:581-7.

12 Brenner DM, Moeller MJ, Chey WD, Schoenfeld PS. The Utility of Probiotics in the Treatment of Irritable Bowel Syndrome: A Systematic Review. Am J Gastroenterol. 2009;104:1033-49.

13 Niv E, Naftali T, Hallak R, Vaisman N. The efficacy of Lactobacillus reuteri ATCC 55730 in the treatment of patients with irritable bowel syndrome--a double blind, placebo-controlled, randomized study. Clin Nutr. 2005;24:925-31.

14 O'Sullivan MA, O'Morain CA. Bacterial supplementation in the irritable bowel syndrome. A randomised double-blind placebo-controlled crossover study. Dig Liver Dis. 2000;32:294-301.

15 Simren M, Ohman L, Olsson J, Svensson U, Ohlson K, Posserud I, Strid H. Clinical trial: the effect of a fermented milk containing three probiotic bacteria in patients with irritable bowel syndrome (IBS) - a randomized, double-blind, controlled study. Aliment Pharmacol Ther. 2010;31:218-27.

16 Roberts LM, McCahon D, Holder R, Wilson S, Hobbs FR. A randomised controlled trial of a probiotic 'functional food' in the management of irritable bowel syndrome. BMC Gastroenterol. 2013;13:45.

17 Ligaarden SC, Axelsson L, Naterstad K, Lydersen S, Farup PG. A candidate probiotic with unfavourable effects in subjects with irritable bowel syndrome: a randomised controlled trial. BMC Gastroenterol. 2010;10:16.

18 Rogers NJ, Mousa SA. The shortcomings of clinical trials assessing the efficacy of probiotics in irritable bowel syndrome. J Altern Complement Med. 2012;18:112-9.

19 Simren M, Barbara G, Flint HJ, Spiegel BM, Spiller RC, Vanner S, Verdu EF, Whorwell PJ, Zoetendal EG. Intestinal microbiota in functional bowel disorders: a Rome foundation report. Gut. 2013;62:159-76.

20 Spanhaak S, Havenaar R, Schaafsma G. The effect of consumption of milk fermented by Lactobacillus casei strain Shirota on the intestinal microflora and immune parameters in humans. Eur J Clin Nutr 1998;52:899-907.

21 Koebnick C, Wagner I, Leitzmann P, Stern U, Zunft HJ. Probiotic beverage containing Lactobacillus casei Shirota improves gastrointestinal symptoms in patients with chronic constipation. Can J Gastroenterol 2003;17:655-9. 
22 Barrett JS, Canale KE, Gearry RB, Irving PM, Gibson PR. Probiotic effects on intestinal fermentation patterns in patients with irritable bowel syndrome. World J Gastroenterol 2008;14:5020-4.

23 Matsuzaki T, Takagi A, Ikemura H, Matsuguchi T, Yokokura T. Intestinal microflora: probiotics and autoimmunity. J Nutr 2007;137(3 Suppl 2):798S-802S.

24 Yuki N, Watanabe K, Mike A, Tagami Y, Tanaka R, Ohwaki M, Morotomi M. Survival of a probiotic, Lactobacillus casei strain Shirota, in the gastrointestinal tract: selective isolation from faeces and identification using monoclonal antibodies. Int J Food Microbiol 1999;48:51-7.

25 van der Veek PP, van Rood YR, Masclee AA. Clinical trial: short- and long-term benefit of relaxation training for irritable bowel syndrome. Aliment Pharmacol Ther 2007;26:943-52.

26 van der Zee KI SR. Het meten van de algemene gezonsheidstoestand met de RAND-36, een handleiding. [Assessment of general health status with the RAND-36; guidebook]. Noordelijk Centrum voor Gezondheidsvraagstukken Rijksuniversiteit Groningen: Groningen, 1993.

27 Farivar SS, Cunningham WE, Hays RD. Correlated physical and mental health summary scores for the SF-36 and SF-12 Health Survey, V.I. Health Quality Life Outcomes 2007;5:54.

28 Gonsalkorale WM, Toner BB, Whorwell PJ. Cognitive change in patients undergoing hypnotherapy for irritable bowel syndrome. J Psychosom Res 2004;56:271-8.

29 Toner BB, Stuckless N, Ali A, Downie F, Emmott S, Akman D. The development of a cognitive scale for functional bowel disorders. Psychosom Med 1998;60:492-7.

30 Irvine EJ, Whitehead WE, Chey WD, Matsueda K, Shaw M, Talley NJ, Veldhuyzen van Zanten SJ. Design of treatment trials for functional gastrointestinal disorders. Gastroenterology 2006; 130:1538-51.

31 Goossens D, Jonkers D, Russel M, Stobberingh E, Van Den Bogaard A, StockbrUgger R. The effect of Lactobacillus plantarum 299v on the bacterial composition and metabolic activity in faeces of healthy volunteers: a placebo-controlled study on the onset and duration of effects. Aliment Pharmacol Ther 2003;18:495-505.

32 Camilleri M, Mangel AW, Fehnel SE, Drossman DA, Mayer EA, Talley NJ. Primary endpoints for irritable bowel syndrome trials: a review of performance of endpoints. Clin Gastroenterol Hepatol 2007;5: 534-40.

33 Charbonneau D, Gibb RD, Quigley EM. Fecal excretion of Bifidobacterium infantis 35624 and changes in fecal microbiota after eight weeks of oral supplementation with encapsulated probiotic. Gut Microbes 2013;4:201-11.

34 Williams E, Stimpson J, Wang D, Plummer S, Garaiova I, Barker M, Corfe B. Clinical trial: a multistrain probiotic preparation significantly reduces symptoms of irritable bowel syndrome in a double-blind placebo-controlled study. Aliment Pharmacol Ther 2009;29:97-103.

35 Kajander K, Myllyluoma E, Rajilic-Stojanovic M, Kyronpalo S, Rasmussen M, Jarvenpaa S, Zoetendal EG, de Vos WM, Vapaatalo H, Korpela R. Clinical trial: multispecies probiotic supplementation alleviates the symptoms of irritable bowel syndrome and stabilizes intestinal microbiota. Aliment Pharmacol Ther 2008;27:48-57.

36 Guglielmetti S, Mora D, Gschwender M, Popp K. Randomised clinical trial: Bifidobacterium bifidum MIMBb75 significantly alleviates irritable bowel syndrome and improves quality of life--a double-blind, placebo-controlled study. Aliment Pharmacol Ther 2011;33:1123-32.

37 Barbara G, Stanghellini V, De Giorgio R, Cremon C, Cottrell GS, Santini D, Pasquinelli G, Morselli-Labate AM, Grady EF, Bunnett NW, Collins SM, Corinaldesi R. Activated mast cells in proximity to colonic nerves correlate with abdominal pain in irritable bowel syndrome. Gastroenterology 2004;126:693-702.

38 O'Mahony L, McCarthy J, Kelly P, Hurley G, Luo F, Chen K, O'Sullivan GC, Kiely B, Collins JK, Shanahan F, Quigley EM. Lactobacillus and bifidobacterium in irritable bowel syndrome: symptom responses and relationship to cytokine profiles. Gastroenterology 2005;128:541-51.

39 Takeda K, Okumura K. Effects of a fermented milk drink containing Lactobacillus casei strain Shirota on the human NK-cell activity. J Nutr 2007;137(3 Suppl 2):791S-3S.

40 Koning CJ, Jonkers DMAE, Stobberingh EE, Out TA, Stockbrugger RW. Effect of a multispecies probiotic on components of the mucosal and systemic immune system in healthy volunteers treated with amoxycillin. Gut Pathogens 2005;54 (suppI VIII) A260.

41 Klosterhalfen S, Enck P. Psychobiology of the placebo response. Auton Neurosci 2006;125: 94-9. 
42 Chang L, Heitkemper MM. Gender differences in irritable bowel syndrome. Gastroenterology 2002;123:1686-701.

43 Camilleri M, Mayer EA, Drossman DA, Heath A, Dukes GE, McSorley D, Kong S, Mangel AW, Northcutt AR. Improvement in pain and bowel function in female irritable bowel patients with alosetron, a 5-HT3 receptor antagonist. Aliment Pharmacol Ther 1999;13:1149-59.

44 Kruis W, Chrubasik S, Boehm S, Stange C, Schulze J. A double-blind placebo-controlled trial to study therapeutic effects of probiotic Escherichia coli Nissle 1917 in subgroups of patients with irritable bowel syndrome. Int J Colorectal Dis 2012;27:467-74.

45 Patel SM, Stason WB, Legedza A, Ock SM, Kaptchuk TJ, Conboy L, Canenguez K, Park JK, Kelly E, Jacobson $E$, Kerr CE, Lembo AJ. The placebo effect in irritable bowel syndrome trials: a meta-analysis. Neurogastroenterol Motil 2005;17:332-40.

46 Kaptchuk TJ, Kelley JM, Conboy LA, Davis RB, Kerr CE, Jacobson EE, Kirsch I, Schyner RN, Nam BH, Nguyen LT, Park M, Rivers AL, McManus C, Kokkotou E, Drossman DA, Goldman P, Lembo AJ. Components of placebo effect: randomised controlled trial in patients with irritable bowel syndrome. BMJ (Clinical research ed 2008;336:999-1003.

47 Dorn SD, Kaptchuk TJ, Park JB, Nguyen LT, Canenguez K, Nam BH, Woods KB, Conboy LA, Stason WB, Lembo AJ. A meta-analysis of the placebo response in complementary and alternative medicine trials of irritable bowel syndrome. Neurogastroenterol Motil 2007;19: 630-7.

48 Pitz $M$, Cheang $M$, Bernstein $C N$. Defining the predictors of the placebo response in irritable bowel syndrome. Clin Gastroenterol Hepatol 2005;3:237-47.

49 Flaten MA, Aslaksen PM, Finset A, Simonsen T, Johansen O. Cognitive and emotional factors in placebo analgesia. J Psychosom Res 2006;61:81-9.

50 Kelley JM, Lembo AJ, Ablon JS, Villanueva JJ, Conboy LA, Levy R, Marci CD, Kerr CE, Kirsch I, Jacobson EE, Riess H, Kaptchuk TJ. Patient and practitioner influences on the placebo effect in irritable bowel syndrome. Psychosom Med 2009;71:789-97.

51 MacDonald AJ, Peden NR, Hayton R, Mallinson CN, Roberts D, Wormsley KG. Symptom relief and the placebo effect in the trial of an anti-peptic drug. Gut 1981;22:323-6.

52 Kaptchuk TJ, Friedlander E, Kelley JM, Sanchez MN, Kokkotou E, Singer JP, Kowalczykowski M, Miller FG, Kirsch I, Lembo AJ. Placebos without deception: a randomized controlled trial in irritable bowel syndrome. PloS One 2010;5:e15591.

53 Rome Foundation. Rome III: the functional Gastrointestinal Disorders. Third edition ed, 2006.

54 Spiller RC. Problems and challenges in the design of irritable bowel syndrome clinical trials: experience from published trials. Am J Med. 1999;107:91S-7S. 


\section{CHAPTER 4}

Explorative study on mechanisms contributing to beneficial effect of LcS probiotic treatment in Irritable Bowel Syndrome patients

A.Y. Thijssen, D.M.A.E. Jonkers, E. Elamin, A. Bast, I. Arts, A. Driessen, A. de Bruine, C.H.M. Clemens, A.A.M. Masclee 


\section{ABSTRACT}

\section{Background and aims}

Irritable bowel syndrome (IBS) has a multifactorial etiology, including for example disturbances in the intestinal microbiota, barrier function, immune function and visceral perception. In this study, we aimed to explore the effect of a probiotic intervention with Lactobacillus casei Shirota on underlying pathophysiological mechanisms in patients IBS.

\section{Methods}

The current explorative study is part of a randomised controlled probiotic intervention trial. Additional bio-samples and data were collected in subgroups of patients. Before start of (week 0 ) and at the end of the intervention period (week 8) blood was collected for (stimulated) cytokine analysis. Fecal samples were collected at week 0 , week 8 and week 16 (at the end of the 8 week follow-up period) for calprotectin measurements. Sigmoid biopsies were taken at week 0 and 8 for general histology, mast cell counts and tight junction analyses. A rectal barostat was performed to measure rectal compliance and visceroperception at week 0 and week 8 .

\section{Results}

No differences could be detected regarding (stimulated) plasma cytokine levels, fecal calprotectin, histological inflammation scores and mast cell counts in sigmoid biopsies. No differences were found in the mucosal expression of the tight junction proteins occludin and ZO-1 over time between the treatment groups, nor for rectal compliance and pain perception assessed by rectal barostat. Urge perception scores for the distensions at 32-40 $\mathrm{mmHg}$ were significantly lower in week 8 compared to week 0 in the probiotic group. No differences in urge were observed in the placebo group between week 8 and week 0 .

\section{Conclusion}

The additional experiments we performed in subgroups of IBS patients participating in a probiotic intervention trial, did not provide clear leads towards possible mechanisms of action of LCS, apart from possible changes in urge scores after probiotic treatment. 


\section{INTRODUCTION}

Irritable Bowel Syndrome (IBS) is a functional gastrointestinal (GI) disorder, ${ }^{1}$ with multifactorial pathophysiology, ${ }^{2}$ including e.g. altered motility, ${ }^{3}$ visceral hypersensitivity, ${ }^{4}$ altered gut permeability, ${ }^{5}$ low grade inflammation and immune activation, ${ }^{6}$ psychosocial factors, ${ }^{7}$ genetic factors ${ }^{8}$ and microbiota changes. ${ }^{9,10}$ A recent review concluded that microbial alterations are frequently observed in IBS patients and potentially drive or perpetuate GI symptoms. ${ }^{10}$ Apart from the microbial changes in the gut, several of the pathophysiological factors in IBS are potential targets of probiotic interventions. ${ }^{11,12}$ Many studies have investigated whether probiotic products have a beneficial role and may serve as treatment for IBS. A recent meta-analysis indicates that probiotics are effective as a therapy for IBS with respect to improvement of symptom scores. ${ }^{13}$ It should be noticed that overall the effects of probiotics on symptoms are modest and may differ between probiotic products. Most studies only focused on the effect of probiotic administration on subjective symptom scores and on quality of life, and did not take into account underlying mechanisms. Further insight into the mechanisms underlying the beneficial effect of probiotics in IBS may aid in optimizing probiotic interventions.

We performed a randomised double blind placebo controlled trial on the effect of Lactobacillus casei Shirota (LCS) administered daily for 8 weeks on symptoms in 80 patients with IBS. In this study we observed a significant improvement in symptoms after an additional 8 weeks follow-up, especially in males (Thijssen et al., accepted for publication EJGH). Before, during and after the LCS and placebo intervention study we performed additional side studies that allowed us to explore the effect of the intervention on underlying pathophysiological mechanisms of IBS.

These factors include visceral hypersensitivity, barrier function with tight junction proteins and inflammation (histology scores, mast cell count, fecal calprotectin, plasma cytokines).

Visceral hypersensitivity is a hallmark in IBS and is found in up to $50 \%$ of IBS patients. ${ }^{4,14,15}$ A significant correlation has been reported between visceral hypersensitivity and IBS symptoms. This also holds true for gut permeability ${ }^{16}$ that is controlled by tight junctions (TJs) and adherens junctions (AJs) sealing the intercellular space of the intestinal mucosa. ${ }^{17,18}$ Recent studies employing sugar absorption tests point to an increased intestinal permeability of the small bowel in IBS, especially in diarrhea-predominant IBS patients. ${ }^{19,20}$ With respect to TJ proteins, a reduced mRNA expression of the TJ protein ZO-1 has been observed in colonic biopsies of IBS patients. ${ }^{21} \mathrm{~A}$ reduced intestinal barrier function may give rise to antigen or microbial transfer with subsequent immune activation of the mucosa, resulting in inflammation and visceral hypersensitivity. ${ }^{5,22}$ Although endoscopy does not reveal mucosal 
abnormalities in IBS, histological evaluations point towards subtle inflammatory and immune activation in patients with IBS. ${ }^{23-25} \mathrm{~A}$ higher colonic mast cell count, combined with increased mast cell mediator release in close proximity to mucosal nerve endings ${ }^{23}$ and increased influx of lymphocytes and higher numbers of entero-endocrine cells ${ }^{26,27}$ has been observed. In the systemic compartment, a modest increase in baseline proinflammatory cytokines TNF- $\alpha, \mathrm{IL}-1 \beta, \mathrm{IL}-6 \mathrm{IL}-8$ and an increased IL-10/IL-12 ratio has been described. ${ }^{28-30}$ These pathophysiological factors associated with IBS (i.e. visceral perception, intestinal barrier function and activation of the immune system) may become modified or altered by specific micro-organisms and/or alterations in gut microbiota composition such as in probiotic interventions. ${ }^{9}$ Aim of the present additional study was to explore in potential pathophysiological mechanisms involved in the beneficial effect of LCS in the intervention trial we performed in IBS patients .

\section{MATERIALS AND METHODS}

\section{Subjects}

The current explorative study is part of a larger trial conducted between 2007 and 2009, including 80 IBS patients between 18 and 65 years of age who fulfilled the Rome II criteria. The Rome II criteria were used in the trial protocol, which originated from 2005. Subjects were asked to participate via the outpatient clinics of four hospitals (three secondary hospitals and one tertiary care centre) and via local advertisements. IBS subtypes (i.e. diarrhea, constipation, alternating, undefined) were defined by the Rome II criteria and based on symptom diaries kept during the run-in period.

Exclusion criteria included a history of major abdominal surgery (excluding appendectomy, cholecystectomy, ovariectomy and hysterectomy), intake of more than $500 \mathrm{ml}$ of yoghurt per day, lactose intolerance, pregnancy, lactation, unstable organic disease and a history of drug or alcohol abuse. Subjects were not allowed to use laxatives, bulking agents, anti-diarrheals, pain medication, antibiotics, prebiotics or probiotics for four weeks before and during the study period. Only occasional use of paracetamol or non-steroidal anti-inflammatory drugs for pain relief (related to IBS or other causes) was permitted. Subjects were instructed to maintain their usual dietary habits throughout the entire study protocol. All concurrent medication use was recorded at inclusion and its' use had to remain stable during the study.

This human intervention study was approved by the Leiden University Medical Center Ethics Committee (Leiden, The Netherlands), and conducted in full accordance with the principles of the Declaration of Helsinki (52nd WMA General Assembly, Edinburgh, Scotland, Oct 2000). All patients gave their written informed consent prior to 
participation. This trial was registered in the Dutch Trial Registration (www.trialregister.nl), TC number 1235.

\section{Study design and probiotic product}

The multicentre study was performed according to a randomised, double-blind, placebo-controlled, parallel-grouped design. The total study lasted 22 weeks and consisted of three periods: four to six weeks run-in, eight weeks intervention and an additional eight weeks follow-up period. Both the probiotic and placebo product were provided by Yakult Europe, Almere, The Netherlands. During the eight week intervention period, patients had to take one bottle of probiotic dairy product $\left(6.5 \times 10^{9} \mathrm{CFU}\right.$ LCS $)$ or placebo twice daily.

Subgroups of patients were willing to undergo additional bio-sample collection, sigmoidoscopy and/or rectal barostat measurement to study markers for inflammation, intestinal barrier function and visceral perception as outlined in further detail below.

\section{Plasma cytokine analysis}

Before (week 0 ) and at the end of the intervention period (week 8), blood was collected in a $6 \mathrm{ml}$ sodium-heparine tubes.

The blood sample was kept at room temperature for 70 minutes (min) and then incubated with lipopolysaccharide (LPS) E.col (25 $\mu \mathrm{g} / \mathrm{dl})$ and PHA $(5 \mu \mathrm{g} / \mathrm{ml})$ for 48 hours at $37^{\circ} \mathrm{C}$.

Thereafter, the supernatant was collected and stored at $-80^{\circ} \mathrm{C}$ until further use.

Cytokines (i.e. IL-1 $\beta$, IL-2, IL-4, IL-5, IL-6, IL-8, IL-10, IL-12, IL-13, IL-17, G-CSF, GM-CSF, IFN- $\gamma$, MCP-1, MIP-1 $\beta$ and TNF- $\alpha$ ) in the stimulated and unstimulated supernatants were determined using a multiplex immunoassay $\mathrm{kit}^{31}$ according to manufacturer's instructions (Bio-Rad, Veenendaal, The Netherlands). In brief, $50 \mu$ of the undiluted supernatant or standard was incubated with the antibody-coated beads in a 96 well $1.2 \mu \mathrm{m}$ filter plate. After $30 \mathrm{~min}$ of incubation, a cocktail of biotinylated secondary antibodies was added to each well and incubated for another $30 \mathrm{~min}$. After subsequent incubation with streptavidin-PE for $10 \mathrm{~min}$ the fluorescence intensity of the beads was measured using the Bio-Plex system in combination with the Bio-Plex manager software version 3.0 (Bio-Rad).

\section{Fecal calprotectin}

Fecal samples were collected at week 0 , week 8 and week 16 (at the end of the 8 week follow-up period) and directly frozen at $-20^{\circ} \mathrm{C}$ upon defecation until further analysis.

Approximately $100 \mathrm{mg}$ of wet feces was diluted 50 times in extraction buffer $(0.1 \mathrm{~mol} / \mathrm{l}$ tris, $0.15 \mathrm{NaCl}, 1 \mathrm{~mol} / \mathrm{I}$ Urea, $10 \mathrm{mmol} / / \mathrm{CaCl}_{2}, 0.1 \mathrm{~mol} / \mathrm{l}$ Citric acid, $\left.5 \mathrm{~g} / \mathrm{l} \mathrm{BSA}, \mathrm{pH} 8.0\right) .{ }^{32}$ 
Samples were shaken for $30 \mathrm{~min}$ and subsequently centrifuged for 20 minutes (10000 g, $4{ }^{\circ} \mathrm{C}$ ). The supernatant was used for analysis of calprotectin using a standard ELISA kit (HBT, Uden, The Netherlands) according to the manufacturer's instructions.

\section{Intestinal inflammation, mast cell counts}

A sigmoidoscopy was performed at week 0 and week 8 . Four biopsies were taken at $20 \mathrm{~cm}$ above the anal verge. Two biopsies were frozen directly in liquid nitrogen and stored at $-80^{\circ} \mathrm{C}$ for further analysis of tight junction proteins. The other two biopsies were fixed in buffered formalin (of $4 \%$ formaldehyde), embedded in paraffin and processed for immunohistochemistry using the haematoxylin eosin stain. Microscopic inflammation was assessed by an experienced pathologist ( $\mathrm{AdB}$ ) according to clinical standards for assessment of inflammation in intestinal mucosa (i.e. $0=$ no inflammation, $1=$ mild inflammation, $2=$ moderate inflammation, $3=$ severe inflammation). ${ }^{33}$

Additional biopsy sections were incubated with mouse-monoclonal antibodies against tryptase (Dako, Glostrup, Denmark), diluted 1:400 in a PBS solution with 1\% BSA for 60 minutes. Following thorough washing in PBS, slides were incubated for 30 minutes at room temperature with the Envision + System- HRP labelled polymer Anti-mouse (Dako, Glostrup, Denmark). After a second washing in PBS, slides were stained using Vector Novared Substrate (Vector Laboratories, Burlingame CA, USA).

An experienced pathologist (AD) who was blinded with respect to clinical and histological data scored the mast cell numbers. From each slide, 6-10 high power fields were randomly scored from well stained and cut areas using light microscopy (40xmagnification) and expressed as number of mast cells per 100 crypts.

\section{Tight junction protein analysis}

Immunofluorescent staining was performed as described previously with minor modifications. ${ }^{34-36}$ Confocal images were obtained and processed by Leica TCS SPE confocal laser scanning microscope (Leica Micro systems GmbH, Mannheim, Germany), and Image J software, ${ }^{37}$ respectively. For quantification, images were acquired at $512 \times 512$ pixel resolutions and z-stacks were obtained using Leica Application Suite Advanced Fluorescence software (Leica Microsystems $\mathrm{GmbH}$ ). Images were processed and quantified by calculating the area under the curve (AUC). Briefly, fluorescent staining of ZO-1 and occludin in the TJ region, perpendicular to the apical cell surface of the epithelium in three different areas, was subjected to projection and passed through a Gaussian smoothing filter. These areas were selected randomly within three different $Z$ sections. Staining was analyzed in the mid region of the villi. Plot profiles of the staining intensity along the perpendicular lines were generated using Image J software $^{37}$ and AUC was calculated using Matlab R2013a software (Natick, MA, USA). 


\section{Barostat measurements}

An barostat (Synectics Visceral Stimulator, Synectics Medical, Stockholm, Sweden) was used to measure rectal compliance and visceroperception via a protocol described before, ${ }^{38}$ at week 0 and week 8 . Patients were studied in a left lateral position. The distension protocol consisted of phasic isobaric, ascending distensions in steps of $4 \mathrm{mmHg}$, starting at $4 \mathrm{mmHg}$. Each pressure step lasted one minute, followed by a 30 second period at $0 \mathrm{mmHg}$. The maximum pressure was set at $40 \mathrm{mmHg}$ or the pressure at which the patient felt too uncomfortable to continue the procedure. At each pressure step, patients were asked to rate urge and pain on a $100 \mathrm{~mm}$ Visual Analogue Scale (VAS) $(0=$ none, $100=$ intolerable). Dynamic compliance was calculated by dividing the highest change in volume during a pressure step by the change in pressure ( $4 \mathrm{mmHg}$ ), and compliance curves were calculated by plotting pressure and volume per treatment group.

\section{Statistical analysis}

Data of all patients that had been randomised to the probiotic or placebo treatment and participated in one or more pathophysiological side studies were included in the analysis, i.e. per protocol analysis. All statistical analyses were performed with SPSS for Windows, version 15 (SPSS inc, Chicago II.). Differences between treatment groups were assessed with the independent-samples t-test for parametric data and the MannWhitney-U test for non-parametric continuous data. Differences within a treatment group (paired data) were assessed by the Wilcoxon signed rank test. A Friedman test was used to assess differences over time for non-parametric data. The level of significance was set at $p \leq 0.05$ using two-sided tests.

\section{RESULTS}

No significant difference in improvement of symptom scores between probiotic and placebo treated IBS patients were found after an 8 week intervention. However, we did find a significant difference in several individual symptom scores and the total day score in favour of the probiotic treatment after subjects finished the intervention and the follow-up period, 16 weeks in total. The beneficial effect of the intake of LcS was most pronounced in the male population. The female population showed a marked placebo effect (Thijssen et al., accepted for publication EJGH). 


\section{Plasma cytokines}

Samples both before and at the end of treatment were available from 12 patients in the probiotic and 15 patients in the placebo group. Demographic data, use of medication or medical history were comparable between the probiotic and placebo group (data not shown). Stimulated cytokine levels (median [range]) are given in Table 4.1. Comparing the delta values (end-start of treatment) of the probiotic group with the placebo group revealed no significant differences for any of the cytokines (Mann-Whitney $U$ test, all $p>0.10)$. No significant changes in cytokine levels within the placebo or probiotic group were detected.

\section{Fecal calprotectin}

Fecal samples were available from 45 subjects at week 0, 8 and 16 (probiotic group $n=22$; placebo group $n=23$ ). Demographic data, use of medication or medical history did not differ between both treatment groups (data not shown).

No significant differences were detected in calprotectin concentration (mean \pm SEM) between probiotic and placebo group at any time point (week $0: 6.9 \pm 1.9 \mathrm{ug} / \mathrm{g}$ vs. $4.0 \pm 0.9 \mathrm{ug} / \mathrm{g}, \mathrm{p}=0.18$; week 8: $6.9 \pm 1.5 \mathrm{ug} / \mathrm{g}$ vs. $4.7 \pm 1.3 \mathrm{ug} / \mathrm{g}, \mathrm{p}=0.28$; week 16 : $5.4 \pm 1.3 \mathrm{ug} / \mathrm{g}$ vs. $5.4 \pm 2.3 \mathrm{ug} / \mathrm{g}, \mathrm{p}=0.99$ ). No significant changes were detected over time within the placebo or probiotic group (probiotic: $p=0.30$, placebo: $p=0.80$ ).

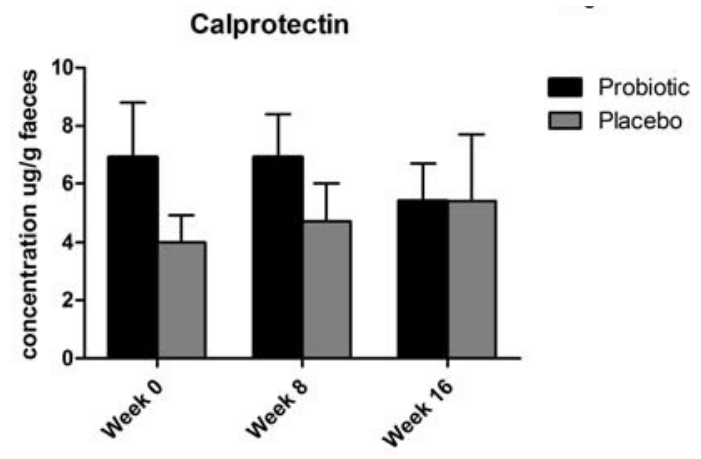

Figure 4.1 Calprotectin concentrations (ug/g feces, mean \pm SEM) for probiotic and placebo treated subjects at week 0,8 and 16 . No significant differences could be detected between or within treatment groups 


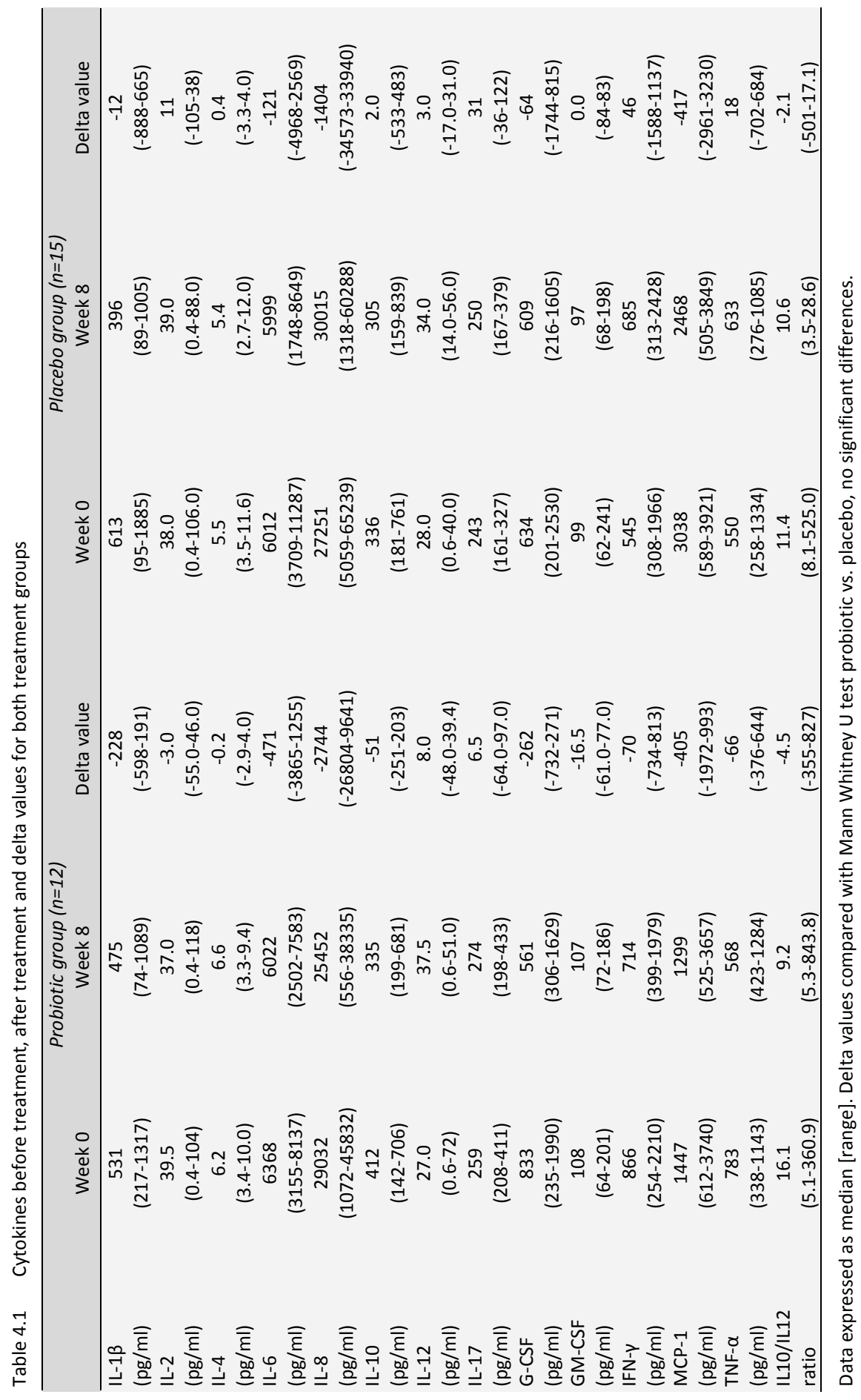




\section{Intestinal inflammation, mast cell counts}

Baseline and end of treatment biopsies for evaluation of intestinal inflammation and mast cell counts were available for 9 patients in the probiotic group and for 11 patients in the placebo group. The baseline characteristics between the two groups with respect to demographic data, use of medication or medical history were comparable (data not shown). In none of the biopsies the histological scores showed signs of intestinal inflammation. No significant differences in mast cell counts per 100 crypts (mean \pm SEM) were found between probiotic and placebo treated patients at week 0 or week 8; neither were significant differences detected in response to treatment in the probiotic or placebo groups (probiotic: $141 \pm 20$ vs. $151 \pm 26$; placebo $209 \pm 28$ vs. $195 \pm 29$; Figure 4.2).

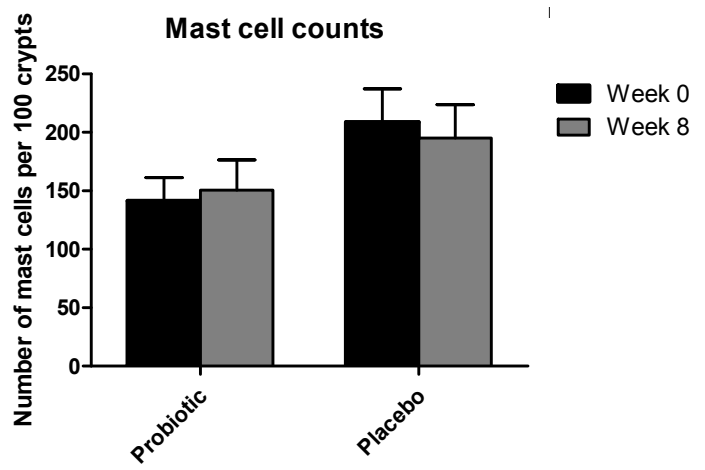

Figure 4.2 Mast cell counts (number per 100 crypts, mean \pm SEM) for probiotic and placebo treated subjects at week 0 and 8 . No significant differences could be detected between or within treatment groups

\section{Tight junction proteins}

Results of tight junction protein (TJP) analysis are shown in Figure 4.3. TJP analyses on week 0 and 8 were available for 10 patients in the probiotic and 10 patients in the placebo treated group. Demographic data, use of medication or medical history did not differ between both treatment groups (data not shown).

With respect to ZO-1, no differences were observed between or within groups. Occludin expression in the probiotic group was significantly higher at baseline and week 8 compared to placebo, but no differences over time were found in the expression of Occludin within the treatment groups. 

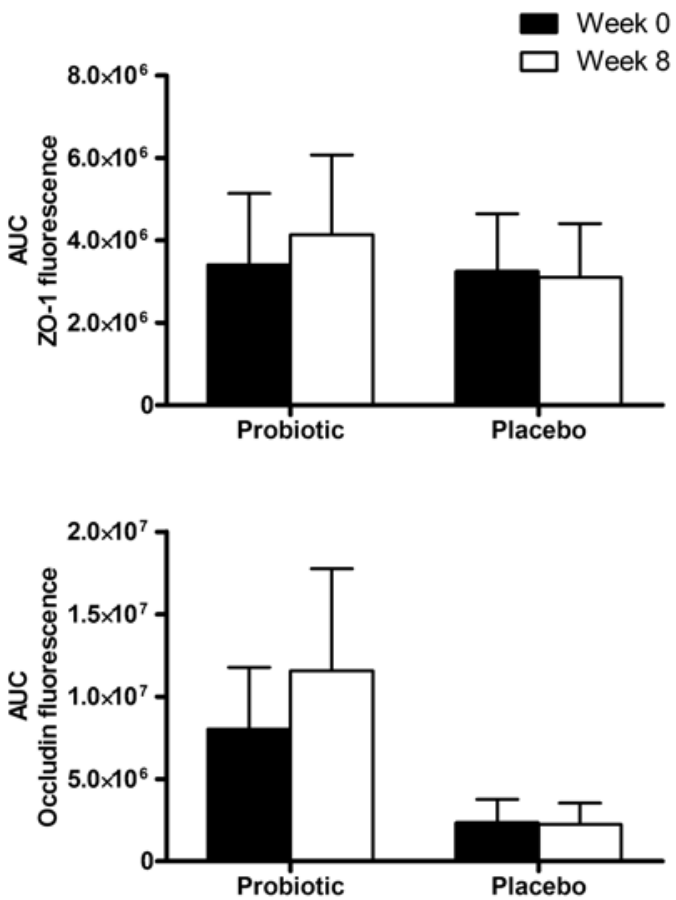

Figure 4.3 Tight junction proteins ZO-1 and Occludin (area under the curve mean $\pm S D$ ) for probiotic and placebo treated subjects at week 0 and 8 . No significant differences could be detected for ZO-1 between or within treatment groups. Occludin expression in the probiotic group was significantly higher at baseline $(p=0.001)$ and week $8(p=0.003)$ compared to placebo, but no differences over time were found in the expression of Occludin within the treatment groups

\section{Visceral sensitivity}

Rectal barostat data before and after treatment were available for 8 patients in the probiotic group and 13 patients in the placebo group. Demographic data, use of medication or medical history did not differ between both treatment groups (data not shown).

Pressure-volume curves during isobaric distensions (ranging from 4 to $40 \mathrm{mmHg}$ ) for both treatment groups before and after treatment are shown in Figure 4.4.

Rectal compliance did not differ significantly either between or within treatment groups (probiotic week 0: $32.5 \pm 28.5 \mathrm{ml} / \mathrm{mmHg}$; placebo week 0: $24.6 \pm 18.1 \mathrm{ml} / \mathrm{mmHg}$; probiotic week 8: $32.8 \pm 22.3 \mathrm{ml} / \mathrm{mmHg}$; placebo week 8: $26.7 \pm 21.4 \mathrm{ml} / \mathrm{mmHg}$.

Urge perception scores (VAS) for the distensions at $32-40 \mathrm{mmHg}$ were significantly lower in week 8 compared to week 0 in the probiotic group (Figure 4.5A). 


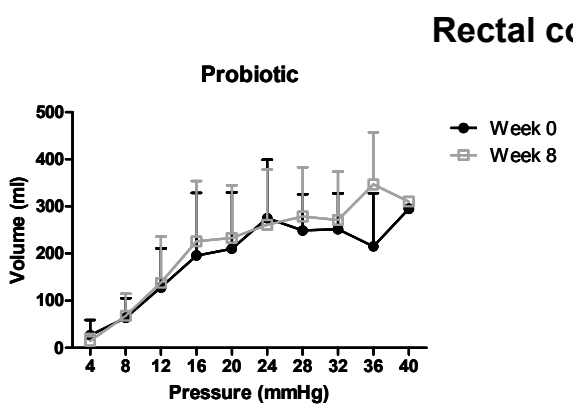

Placebo

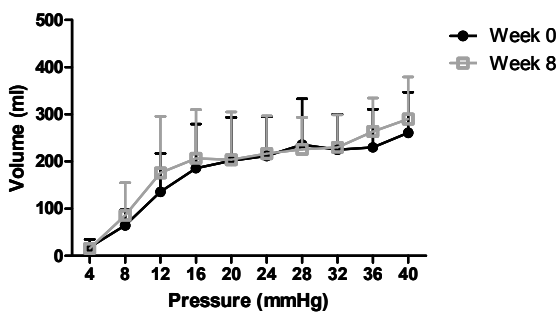

Figure 4.4 Rectal compliance (pressure/volume curves mean $\pm \mathrm{SD}$ ) for probiotic and placebo treated subjects at week 0 and 8 . No significant differences could be detected between or within treatment groups.

A

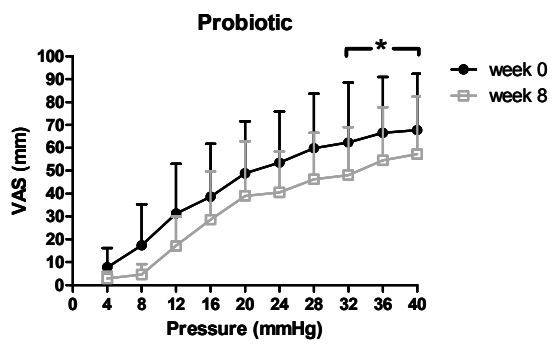

\section{Urge score}

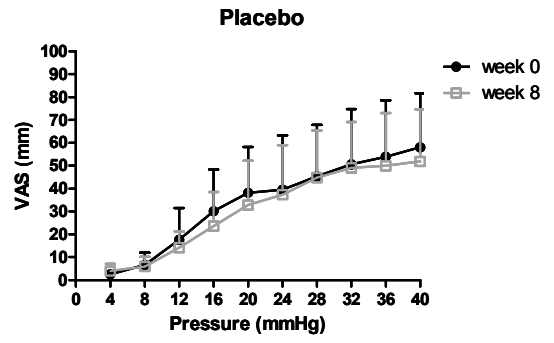

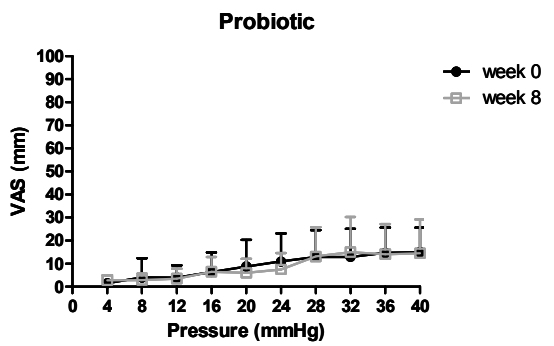

Placebo

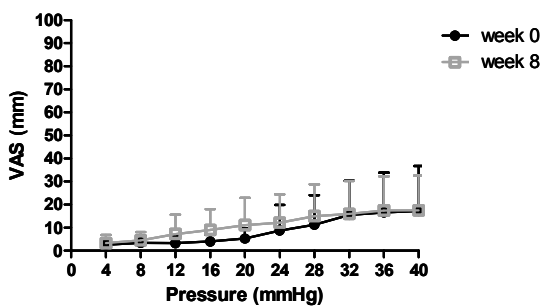

Figure 4.5 A. Urge perception (VAS scores mean \pm SD) for probiotic and placebo treated subjects at week 0 and 8 . Urge perception for the distensions at $32-40 \mathrm{mmHg}$ were significantly lower in week 8 compared to week 0 in the probiotic group $(p<0.05)$. No differences in urge were observed in the placebo group between week 8 and week 0 . No differences could be detected between the treatment groups at week 0 or 8 . B. Pain perception (VAS scores mean \pm SD) for probiotic and placebo treated subjects at week 0 and 8 . No significant differences could be detected between or within treatment groups. 
No differences in urge were observed in the placebo group between week 8 and week 0 . No differences could be detected between the treatment groups at week 0 or 8 . No difference could be detected in pain perception scores (VAS) within and between both treatment groups (Figure 4.5B).

\section{DISCUSSION}

This explorative study on the effect of an 8 week intervention with the probiotic LcS in patients with IBS assessed potential pathophysiological mechanisms underlying the beneficial effect on symptom improvement after probiotic treatment. No differences were found with regard to plasma cytokine levels, fecal calprotectin, mast cell numbers or tight junction protein expression. With respect to visceral sensitivity, only a significant decrease in urge perception at 8 weeks was found at higher barostat pressures within the probiotc group, but not between the two treatment groups.

Consumption of a probiotic drink containing LCS has been reported to improve natural killer (NK) cell activity with a more anti-inflammatory cytokine profile in an older healthy population ${ }^{39}$ and normalization of IL-10 levels in patients with compensated alcoholic liver cirrhosis. ${ }^{40}$ Additionally, intake of LCS was effective in restoring the NK-cell activity of habitual smokers ${ }^{[41]}$ and appeared to be beneficial in reducing the frequency of upper respiratory tract infections. ${ }^{42}$ Although data on the effect of LCS on cytokine production are limited, these above observations indicate that LcS may have a beneficial effect on the immune system.

In our study, plasma cytokine levels did not differ between probiotic and placebo treatment, nor within the groups over time. Matricon et al. recently evaluated immune activation in IBS and concluded that mononuclear cells from IBS patients have an abnormal cytokine secretory response to an immune challenge. ${ }^{43}$ Specific probiotic strains or species have the ability to stimulate and modulate the host defense, including the innate and the acquired immune system. ${ }^{11,44,45}$ Lower pro-inflammatory cytokine levels and increased anti-inflammatory cytokine levels have been reported during probiotic treatment. ${ }^{46}$ O'Mahony et al. found an 8 week treatment with Bifidobacterium infantis 35624 to result in an increased IL-10/IL-12 ratio in parallel with a decrease in symptom scores. ${ }^{30}$ A more recent trial compared the probiotic Saccharomyces boulardii with placebo treatment and found a significant decrease in blood and tissue levels of IL- 8 and TNF- $\alpha$, an increase of IL-10 levels and the IL-10/IL-12 ratio. ${ }^{47}$ The different findings compare to our study may be due to differences between probiotic strains. Furthermore, it has to be noted that the effects of changes in individual cytokine responses for the host benefit are difficult to interpret. ${ }^{48}$ Therefore, we performed additional analyses on marker for intestinal inflammation. 
Calprotectin is a marker of intestinal inflammation. ${ }^{49}$ In larger groups of IBS patients significantly higher fecal calprotectin levels have been reported compared to healthy subjects $^{50}$ but differences are very modest. In the current study, fecal calprotectin concentrations did not differ over time nor between treatment groups.

With respect to colonic histology, no signs of inflammation were found in the biopsy specimens. In line with these findings, we did not observe significant differences in mast cell counts between probiotic and placebo treated patients, nor between week 8 and week 0 . Mast cells frequently persist in post inflammatory conditions and are able to release a variety of inflammatory mediators. In IBS patients an increased number of mast cells in the rectocolonic mucosa has been reported previously and mast cells are more often found in a degranulating state, ${ }^{23,51}$ especially in patients with diarrheapredominant or post-infectious IBS. The patients participating in the LCS probiotic trial underwent sigmoidoscopy for additional biopsy collection on a voluntary basis. Therefore, only small numbers were available for histological analyses and the study was not powered for subgroup analysis on IBS subtype or gender difference. Future studies evaluating effects of therapeutic interventions in IBS with respect to underlying pathophysiological mechanisms, should include not only a larger number of patients but should also perform more in depth analyses of mucosal biopsies, including specific staining of immune cells, mucosal release of cytokines and mast cell mediator release.

Increased intestinal permeability has been reported in patients with IBS, especially in those with diarrhea-predominant IBS. Intestinal barrier function can be measured by dual or multiple sugar absorption tests but also by evaluating the expression of key tight junction proteins sealing the intercellular space. A protective effect of probiotic species on intestinal barrier function has been suggested previously. ${ }^{52}$ So far, data on the expression of tight junction proteins in intestinal biopsies of IBS are limited. We observed that occludin expression in the probiotic group was higher both at baseline and at week 8 compared to placebo, but no differences over time (week 8 to week 0 ) in expression of either ZO-1 or occludin were found within the treatment groups.

Visceral hypersensitivity is a hall mark of IBS and present in up to $50-60 \%$ of IBS patients despite the fact that IBS is a heterogeneous disorder. It has been postulated that the efficacy of therapeutic interventions in IBS may be improved by selecting patients for trials based on a shared underlying mechanism. In the present study we did not select on visceral sensitivity. Mean scores of pain showed no significant differences over time, neither did rectal compliance. However, perception for urge was significantly lower at the high pressure range after 8 weeks of probiotic treatment compared to week 0 . No such difference could be found in placebo treated patients. Although not supported by differences between groups, the above finding warrants further investigation in larger groups of patients, as recently also animal studies have shown that specific probiotic 
strains (i.e. bifidobacteria and lactobacillus species) are able to reduce visceral hypersensitivity. ${ }^{53,54}$ Furthermore, in a human trial, a significant beneficial effect of a multispecies probiotic on visceral hypersensitivity has been observed. ${ }^{55}$

The additional experiments we report on in this chapter were explorative with respect to design and methods and suffer from low patient numbers. The original trial was powered for the evaluation of symptom scores as primary outcome measure. On a voluntary basis, IBS patients participating in the trial underwent extra sample collection. Furthermore, not all additional analyses were performed in the same subgroup, hindering correlation analysis between various experiments. Despite all these shortcomings and drawbacks some conclusions can be drawn. First, future therapeutic IBS studies should enable subgroup analyses. Second, baseline characteristics were found to vary markedly between patients. Fortunately, subjects served as their own controls when assessing the effect of a therapeutic intervention. Third, disturbances in inflammatory and immune and barrier markers in IBS are very subtle and not pronounced enough to show alterations in response to therapeutic interventions in small groups of patients.

\section{CONCLUSION}

Probiotic treatment with LCS was found to decrease symptoms in IBS patients. The additional experiments we performed did not provide clear leads towards possible mechanisms of action of LCS, apart from changes in urge scores after probiotic treatment. 


\section{REFERENCES}

1 Longstreth GF, Thompson WG, Chey WD, Houghton LA, Mearin F, Spiller RC. Functional bowel disorders. Gastroenterology 2006;130:1480-91.

2 Mertz HR. Irritable bowel syndrome. N Engl J Med 2003;349:2136-46.

3 McKee DP, Quigley EM. Intestinal motility in irritable bowel syndrome: is IBS a motility disorder? Part 1. Definition of IBS and colonic motility. Dig Dis Sci 1993;38:1761-72.

4 Bouin $M$, Plourde V, Boivin M, Riberdy M, Lupien F, Laganiere M, Verrier P, Poitras P. Rectal distention testing in patients with irritable bowel syndrome: sensitivity, specificity, and predictive values of pain sensory thresholds. Gastroenterology 2002;122:1771-7.

5 Barbara G. Mucosal barrier defects in irritable bowel syndrome. Who left the door open? Am J Gastroenterol 2006;101:1295-8.

6 Azpiroz F, Bouin M, Camilleri M, Mayer EA, Poitras P, Serra J, Spiller RC. Mechanisms of hypersensitivity in IBS and functional disorders. Neurogastroenterol Motil 2007;19(1 Suppl): 62-88.

7 Budavari Al, Olden KW. Psychosocial aspects of functional gastrointestinal disorders. Gastroenterol Clin North Am 2003;32:477-506.

8 Park MI, Camilleri M. Genetics and genotypes in irritable bowel syndrome: implications for diagnosis and treatment. Gastroenterol Clin North Am 2005;34:305-17.

9 Parkes GC, Brostoff J, Whelan K, Sanderson JD. Gastrointestinal microbiota in irritable bowel syndrome: their role in its pathogenesis and treatment. Am J Gastroenterol 2008;103:1557-67.

10 Rajilic-Stojanovic M, Jonkers DM, Salonen A, Hanevik K, Raes J, Jalanka J, de Vos WM, Manichanh C, Golic N, Enck P, Philippou E, Iraqi FA, Clarke G, Spiller RC, Penders J. Intestinal Microbiota And Diet in IBS: Causes, Consequences, or Epiphenomena? Am J Gastroenterol 2015;110:278-87.

11 Shida K, Nanno M. Probiotics and immunology: separating the wheat from the chaff. Trends Immunol 2008;29:565-73.

12 Camilleri M. Probiotics and irritable bowel syndrome: rationale, putative mechanisms, and evidence of clinical efficacy. J Clin Gastroenterol 2006;40:264-9.

13 Ford AC, Quigley EM, Lacy BE, Lembo AJ, Saito YA, Schiller LR, Soffer EE, Spiegel BM, Moayyedi P. Efficacy of prebiotics, probiotics, and synbiotics in irritable bowel syndrome and chronic idiopathic constipation: systematic review and meta-analysis. Am J Gastroenterol 2014; 109:1547-61.

14 Mertz H, Naliboff B, Munakata J, Niazi N, Mayer EA. Altered rectal perception is a biological marker of patients with irritable bowel syndrome. Gastroenterology 1995;109:40-52.

15 van der Veek PP, Van Rood YR, Masclee AA. Symptom severity but not psychopathology predicts visceral hypersensitivity in irritable bowel syndrome. Clin Gastroenterol Hepatol 2008; 6:321-8.

16 Zhou Q, Zhang B, Nicholas Verne G. Intestinal membrane permeability and hypersensitivity in the irritable bowel syndrome. Pain 2009;146:41-6.

17 Van Itallie CM, Anderson JM. The molecular physiology of tight junction pores. Physiology (Bethesda) 2004;19:331-8.

18 Rao RK, Seth A, Sheth P. Recent Advances in Alcoholic Liver Disease I. Role of intestinal permeability and endotoxemia in alcoholic liver disease. Am J Physiol 2004;286:G881-4.

19 Dunlop SP, Hebden J, Campbell E, Naesdal J, Olbe L, Perkins AC, Spiller RC. Abnormal intestinal permeability in subgroups of diarrhea-predominant irritable bowel syndromes. Am J Gastroenterol 2006;101:1288-94.

20 Mujagic Z, Ludidi S, Keszthelyi D, Hesselink MA, Kruimel JW, Lenaerts K, Hanssen NM, Conchillo JM, Jonkers DM, Masclee AA. Small intestinal permeability is increased in diarrhoea predominant IBS, while alterations in gastroduodenal permeability in all IBS subtypes are largely attributable to confounders. Aliment Pharmacol Ther 2014;40:288-97.

21 Piche T, Barbara G, Aubert P, Bruley des Varannes S, Dainese R, Nano JL, Cremon C, Stanghellini V, De Giorgio R, Galmiche JP, Neunlist M. Impaired intestinal barrier integrity in the colon of irritable bowel syndrome patients: involvement of soluble mediators. Gut 2009;58:196-201.

22 Travis S, Menzies I. Intestinal permeability: functional assessment and significance. Clin Sci (Lond) 1992;82:471-88. 
23 Barbara G, Stanghellini V, De Giorgio R, Cremon C, Cottrell GS, Santini D, Pasquinelli G, Morselli-Labate AM, Grady EF, Bunnett NW, Collins SM, Corinaldesi R. Activated mast cells in proximity to colonic nerves correlate with abdominal pain in irritable bowel syndrome. Gastroenterology 2004;126:693-702.

24 Barbara G, Wang B, Stanghellini V, de Giorgio R, Cremon C, Di Nardo G, Trevisani M, Campi B, Geppetti P, Tonini M, Bunnett NW, Grundy D, Corinaldesi R. Mast cell-dependent excitation of visceralnociceptive sensory neurons in irritable bowel syndrome. Gastroenterology 2007; 132:26-37.

25 Dunlop SP, Jenkins D, Spiller RC. Distinctive clinical, psychological, and histological features of postinfective irritable bowel syndrome. Am J Gastroenterol 2003;98:1578-83.

26 Spiller RC, Jenkins D, Thornley JP, Hebden JM, Wright T, Skinner M, Neal KR. Increased rectal mucosal enteroendocrine cells, $T$ lymphocytes, and increased gut permeability following acute Campylobacter enteritis and in post-dysenteric irritable bowel syndrome. Gut 2000;47: 804-11.

27 Sundin J, Rangel I, Kumawat AK, Hultgren-Hornquist E, Brummer RJ. Aberrant mucosal lymphocyte number and subsets in the colon of post-infectious irritable bowel syndrome patients. Scand J Gastroenterol 2014;49:1068-75.

28 Liebregts T, Adam B, Bredack C, Roth A, Heinzel S, Lester S, Downie-Doyle S, Smith E, Drew P, Talley NJ, Holtmann G. Immune activation in patients with irritable bowel syndrome. Gastroenterology 2007;132:913-20.

29 Dinan TG, Quigley EM, Ahmed SM, Scully P, O'Brien S, O'Mahony L, O'Mahony S, Shanahan F, Keeling PW. Hypothalamic-pituitary-gut axis dysregulation in irritable bowel syndrome: plasma cytokines as a potential biomarker? Gastroenterology 2006;130:304-11.

30 O'Mahony L, McCarthy J, Kelly P, Hurley G, Luo F, Chen K, O'Sullivan GC, Kiely B, Collins JK, Shanahan F, Quigley EM. Lactobacillus and bifidobacterium in irritable bowel syndrome: symptom responses and relationship to cytokine profiles. Gastroenterology 2005;128:541-51.

31 de Jager W, te Velthuis H, Prakken BJ, Kuis W, Rijkers GT. Simultaneous detection of 15 human cytokines in a single sample of stimulated peripheral blood mononuclear cells. Clin Diagn Lab Immunol 2003;10:133-9.

32 van der Sluijs Veer G, van den Hoven B, Russel MG, van den Bergh FA. Time-resolved fluorimetric immunoassay of calprotectin: technical and clinical aspects in diagnosis of inflammatory bowel diseases. Clin Chem Lab Med 2006;44:292-8.

33 Saverymuttu SH, Camilleri M, Rees H, Lavender JP, Hodgson HJ, Chadwick VS. Indium 111-granulocyte scanning in the assessment of disease extent and disease activity in inflammatory bowel disease. A comparison with colonoscopy, histology, and fecal indium 111-granulocyte excretion. Gastroenterology 1986;90:1121-8.

34 Elamin E, Masclee A, Dekker J, Jonkers D. Ethanol disrupts intestinal epithelial tight junction integrity through intracellular calcium-mediated Rho/ROCK activation. Am J Physiol 2014;306: G677-85.

35 Keszthelyi D, Troost FJ, Jonkers DM, van Eijk HM, Lindsey PJ, Dekker J, Buurman WA, Masclee AA. Serotonergic reinforcement of intestinal barrier function is impaired in irritable bowel syndrome. Aliment Pharmacol Ther 2014;40:392-402.

36 Karczewski J, Troost FJ, Konings I, Dekker J, Kleerebezem M, Brummer RJM, Wells JM. Regulation of human epithelial tight junction proteins by Lactobacillus plantarum in vivo and protective effects on the epithelial barrier. Am J Physiol-Gastr L 2010;298:G851-9.

37 Abramoff MD, Magelhaes PJ, Ram SJ. Image Processing with ImageJ. Biophotonics Int 2004;11:36-42.

38 van der Veek PP, Swenne CA, Vooren H, Schoneveld AL, Maestri R, Masclee AA. Viscerosensorycardiovascular reflexes: altered baroreflex sensitivity in irritable bowel syndrome. Am J Physiol Regul Integr Comp Physiol 2005;289:R970-6.

39 Dong H, Rowland I, Thomas LV, Yaqoob P. Immunomodulatory effects of a probiotic drink containing Lactobacillus casei Shirota in healthy older volunteers. Eur J Nutr 2013;52: 1853-63.

40 Stadlbauer V, Mookerjee RP, Hodges S, Wright GA, Davies NA, Jalan R. Effect of probiotic treatment on deranged neutrophil function and cytokine responses in patients with compensated alcoholic cirrhosis. J Hepatol 2008;48:945-51.

41 Morimoto K, Takeshita T, Nanno M, Tokudome S, Nakayama K. Modulation of natural killer cell activity by supplementation of fermented milk containing Lactobacillus casei in habitual smokers. Prev Med 2005;40:589-94. 
42 Gleeson M, Bishop NC, Oliveira M, Tauler P. Daily probiotic's (Lactobacillus casei Shirota) reduction of infection incidence in athletes. Int J Sport Nutr Exerc Metab 2011;21:55-64.

43 Matricon J. Commentary: associations between immune activation, intestinal permeability and irritable bowel syndrome - author's reply. Aliment Pharmacol Ther 2013;37:278-9.

44 Oelschlaeger TA. Mechanisms of probiotic actions - A review. Int J Med Microbiol 2009.

45 Delcenserie V, Martel D, Lamoureux M, Amiot J, Boutin Y, Roy D. Immunomodulatory effects of probiotics in the intestinal tract. Curr Issues Mol Biol 2008;10:37-54.

46 Gionchetti P, Rizzello F, Campieri M. Probiotics in gastroenterology. Curr Opin Gastroenterol 2002;18:235-9.

47 Abbas Z, Yakoob J, Jafri W, Ahmad Z, Azam Z, Usman MW, Shamim S, Islam M. Cytokine and clinical response to Saccharomyces boulardii therapy in diarrhea-dominant irritable bowel syndrome: a randomized trial. Eur J Gastroenterol Hepatol 2014;26:630-9.

48 Chung KF. Cytokines in chronic obstructive pulmonary disease. Eur Respir J 2001;34:50s-9s.

49 Langhorst J, Elsenbruch S, Koelzer J, Rueffer A, Michalsen A, Dobos GJ. Noninvasive markers in the assessment of intestinal inflammation in inflammatory bowel diseases: performance of fecal lactoferrin, calprotectin, and PMN-elastase, CRP, and clinical indices. Am J Gastroenterol 2008;103: 162-9.

50 Dolwani S, Metzner M, Wassell JJ, Yong A, Hawthorne AB. Diagnostic accuracy of faecal calprotectin estimation in prediction of abnormal small bowel radiology. Aliment Pharmacol Ther 2004;20:615-21.

51 Cremon C, Gargano L, Morselli-Labate AM, Santini D, Cogliandro RF, De Giorgio R, Stanghellini V, Corinaldesi R, Barbara G. Mucosal immune activation in irritable bowel syndrome: gender-dependence and association with digestive symptoms. Am J Gastroenterol 2009;104:392-400.

52 Karczewski J, Troost FJ, Konings I, Dekker J, Kleerebezem M, Brummer RJ, Wells JM. Regulation of human epithelial tight junction proteins by Lactobacillus plantarum in vivo and protective effects on the epithelial barrier. Am J Physiol Gastrointest Liver Physiol 2010;298: G851-9.

53 Agostini S, Goubern M, Tondereau V, Salvador-Cartier C, Bezirard V, Leveque M, Keranen H, Theodorou V, Bourdu-Naturel S, Goupil-Feuillerat N, Legrain-Raspaud S, Eutamene H. A marketed fermented dairy product containing Bifidobacterium lactis CNCM I-2494 suppresses gut hypersensitivity and colonic barrier disruption induced by acute stress in rats. Neurogastroenterol Motil 2012;24:376-e172.

54 Rousseaux C, Thuru X, Gelot A, Barnich N, Neut C, Dubuquoy L, Dubuquoy C, Merour E, Geboes K, Chamaillard M, Ouwehand A, Leyer G, Carcano D, Colombel JF, Ardid D, Desreumaux P. Lactobacillus acidophilus modulates intestinal pain and induces opioid and cannabinoid receptors. Nat Med 2007;13:35-7.

55 Bazzocchi G, Gionchetti P, Almerigi PF, Amadini C, Campieri M. Intestinal microflora and oral bacteriotherapy in irritable bowel syndrome. Dig Liver Dis 2002;34 Suppl 2:S48-53. 


\section{CHAPTER 5}

Plasma 5-hydroxytryptamine and 5-hydroxyindole acetic acid levels: indicators for altered serotonin metabolism in Irritable Bowel Syndrome?

A.Y. Thijssen*, Z. Mujagic*, D.M.A.E. Jonkers, S. Ludidi, D. Keszthelyi, M.A. Hesselink, C.M. Clemens, J.M. Conchillo, J.W. Kruimel, A.A.M. Masclee

* Both authors contributed equally to this manuscript

Submitted 


\section{ABSTRACT}

\section{Background and aims}

Alterations in serotonin (5-HT) metabolism have been postulated to play a role in the pathogenesis of Irritable Bowel Syndrome (IBS). However, previous reports regarding 5-HT metabolism in IBS are contradicting. The aim of this study was to compare platelet poor plasma (PPP) 5-HT and 5-hydroxyindole acetic acid (5-HIAA) levels and their ratio in a large cohort of IBS patients and healthy controls (HC), including IBS subgroup analysis.

\section{Methods}

IBS patients and HCs were evaluated for fasting PPP 5-HT and 5-HIAA levels. Furthermore, gastrointestinal (GI-)symptom diary, quality of life (QoL), anxiety and depression scores were assessed in the two weeks before blood sampling.

\section{Results}

154 IBS patients and $137 \mathrm{HC}$ were included. No differences were detected in plasma 5-HT between groups. 5-HIAA concentrations and 5-HIAA/5-HT ratio were significantly lower in IBS compared to HC: $24.6 \pm 21.9$ vs. $39.0 \pm 29.5 \mathrm{ug} / \mathrm{I}(\mathrm{p}<0.001)$ and $(8.4 \pm 12.2$ vs. $13.5 \pm 16.6 ; p<0.01)$. Subtype analysis for 5 -HIAA showed all subtypes to be significantly different from HC. The 5-HIAA/5-HT ratio was significantly lower in the IBS-mixed (IBS$\mathrm{M})$ subtype versus $\mathrm{HC}$. Linear regression analysis points to an influence of gender but not of Gl-symptoms, psychological scores or medication use.

\section{Conclusion}

Fasting plasma 5-HT levels did not differ between IBS and HC. A significant decrease in fasting 5-HIAA concentrations and 5-HIAA/5-HT ratio was found in IBS, in which all subtypes separately showed lower 5-HIAA levels compared to HC. The 5-HIAA/5-HT ratio was significantly lower in IBS-M versus HC. An IBS-specific significantly lower 5-HIAA concentration was found in female compared to male patients. 


\section{INTRODUCTION}

Irritable Bowel Syndrome (IBS) is a highly prevalent disorder with up to $15 \%$ of the Western population affected and a female predominance. ${ }^{1,2}$ The Rome III criteria offer support in diagnosing $\mathrm{IBS}^{3,4}$ with further subtyping based on predominant bowel habits. ${ }^{5}$ The pathophysiology of IBS is still incompletely understood. ${ }^{6}$ An important role has been claimed for dysregulations along the brain-gut axis. ${ }^{7}$ Serotonin (5-hydroxytryptamine, 5-HT) as (neuro)transmitter ${ }^{7-9}$ not only modulates physiological and behavioral processes in the brain ${ }^{10}$ but is also a key factor in the regulation of secretion, motility and perception in the gut. ${ }^{11}$

The enterochromaffin (EC) cells in the intestinal epithelium produce $90-95 \%$ of total

5-HT in the human body. ${ }^{11-13} 5-\mathrm{HT}$ is synthesized from tryptophan by tryptophan hydroxylase and aromatic amino acid decarboxylase. Upon release, 5-HT is inactivated via uptake by the serotonin reuptake transporter (SERT) located in the epithelial cells lining the gut lumen $n^{7,11,14}$ and broken down by monoamine oxidase (MAO) into 5-hydroxy indoleacetic acid (5-HIAA), which is excreted in urine. ${ }^{13,15,16}$ Decreased SERT activity results in decreased 5-HT uptake and therefore decreased 5-HIAA production. ${ }^{17}$ Systemic $5-\mathrm{HT}$ is believed to be primarily derived from the EC cells ${ }^{16}$ and is rapidly taken up by platelets, which consequently contain the majority of serotonin in peripheral blood. ${ }^{10,18}$ Platelet poor plasma (PPP) levels of 5-HT are considered to reflect 5-HT metabolism in the GI tract ${ }^{13,18}$ and plasma levels of 5-HIAA reflect the turnover of $5-\mathrm{HT} .^{8}$

Previous studies have explored 5-HT metabolism in IBS, but results are difficult to interpret and contradicting. Increased plasma 5-HT levels have been found in IBS, $8,19-21$ both in fasting and postprandial conditions, while others did not find a difference in fasting 5-HT levels compared to controls or levels were below detection threshold. ${ }^{20,22}$ With respect to plasma 5-HIAA, the principal metabolite of 5-HT, Atkinson et al. noted that 5-HIAA levels were slightly decreased in IBS-C. ${ }^{8}$ The 5-HIAA/5-HT ratio, representing turnover of $5-\mathrm{HT}$, was found to be decreased in diarrhea predominant IBS patients. ${ }^{19,20}$ It should be acknowledged that data on 5-HT metabolism are influenced by a number of variables: e.g. fasting or (meal) stimulated condition, expression and activity of SERT, reuptake of serotonin within the gut and transport of serotonin in liver, lungs and platelets ${ }^{13}$ and presence of concurrent psychopathology in IBS patients ${ }^{23-25}$ such as anxiety and depression. ${ }^{26-28}$ Interpretation of published data on human serotonin metabolism in IBS is further hampered by factors such as sample processing, the analytical technique used, small sample size studies, the heterogeneous nature of IBS, imbalance in distribution among IBS subtypes, sampling in fasting versus postprandial state, presence of psychopathology and use of drugs prescribed for IBS that modify gastrointestinal function or the $5-\mathrm{HT}$ system. ${ }^{29}$ Large studies are needed, 
preferably from well characterized IBS patient groups that assess parameters of 5-HT metabolism taking into account IBS subtypes and potential confounding factors.

We hypothesized that (1) plasma 5-HT levels and 5-HIAA concentrations are altered in IBS patients compared to healthy controls, and that this (2) depends on the IBS subtype and (3) is related to more severe abdominal symptoms and to altered anxiety and depression scores. The primary aim of this study was therefore to compare platelet poor plasma 5-HT and 5-HIAA levels and their ratio in a large cohort of wellcharacterized IBS patients and healthy controls. The secondary aim was to compare differences in these parameters between subgroups of IBS patients based on IBS subtypes and severity of abdominal and psychological symptoms.

\section{MATERIALS AND METHODS}

The present study is part of a larger cohort study on the phenotypical and genotypical characterization of patients with IBS and age and gender matched healthy controls, the Maastricht-IBS cohort, wherein multiple parameters were assessed according to standardized procedures. Patients and controls that handed in a blood sample for assessment of 5-HT metabolism were included in the current study. All subjects have given written informed consent prior to their inclusion. The study was approved by the Medical Ethics Committee of the Maastricht University Medical Centre+ (MUMC+) and executed according to the revised Declaration of Helsinki $\left(59^{\text {th }}\right.$ general assembly of the WMA, Seoul, South Korea, Oct. 2008). The study has been registered at the US National Library of Medicine (http://www.clinicaltrials.gov NCT00775060).

\section{Study participants}

From February 2009 until present time, patients with IBS between 18-75 years of age, fulfilling Rome III criteria, are recruited via the outpatient clinic of the department of Gastroenterology-Hepatology of MUMC+ and via general practitioner (GP) offices in Maastricht and the surrounding area. IBS patients were subtyped based on predominant bowel habits according to the Rome III criteria. IBS diagnosis was confirmed by a gastroenterologist or GP and when indicated endoscopy with biopsies, abdominal imaging by ultrasonography or CT scan, and/or blood, breath and fecal analysis were performed to exclude organic disease. Patients with a history of abdominal surgery, apart from appendectomy, laparoscopic cholecystectomy and hysterectomy were excluded.

Healthy controls ( $\mathrm{HC}$ ) between 18-75 years of age were recruited by advertisements in newspapers, on bulletin boards at Maastricht University and on a website for subject 
recruitment. A brief medical history was taken to rule out history of gastrointestinal disorders or presence of gastrointestinal complaints.

Use of medication was recorded for all subjects.

\section{Assessment of serotonergic metabolism}

Participants arrived at the MUMC+ after an overnight fast. Blood samples were drawn from the antecubital vein using precooled K2EDTA tubes. To avoid oxidative breakdown of platelets, $0,1 \mathrm{ml} 1.4 \%$ ascorbic acid (Sigma Aldrich, St. Louis, MO) was added to the tubes. PPP samples were obtained by centrifuging tubes at $2300 \mathrm{~g}$ at $4^{\circ} \mathrm{C}$ for 10 minutes. Supernatants were aliquoted and frozen immediately at $-80^{\circ} \mathrm{C}$ until further analysis. Concentration of 5-HT and 5-HIAA were determined blind (i.e. on coded samples) using high-performance liquid chromatography (HPLC) as described previously by Hirowatari et al. $^{30}$ The lower detection limit of $5-\mathrm{HT}$ and 5 -HIAA was $3.3 \mu \mathrm{g} / \mathrm{l}$ and $0.4 \mu \mathrm{g} / \mathrm{l}$, respectively. Data for subjects below the detection limit were based on the average number between 0 and the detection limit for further analyses. For 5-HT and 5-HIAA the intra-assay coefficient of variability (CV) was $<5 \%$ for both parameters, the interassay CV was $5 \%$ and $7 \%$, respectively.

\section{Questionnaires}

Within a period of 2 weeks prior to collection of blood samples, questionnaires on demographical characteristics, lifestyle factors and the use of medication were completed by all subjects. Symptoms of abdominal discomfort, abdominal pain, bloating, flatulence, nausea and overall Gl symptom burden were scored daily using a 14 day symptom diary. ${ }^{31}$

The validated Dutch version (RAND-36) of the Medical Outcomes Study (MOS) 36-item Short Form Health Survey (SF-36) (New England Medical Centre Hospitals, 1991), was used to measure generic health-related QoL. ${ }^{32}$ The SF-36 consists of eight domains with an outcome between 0 and 100, with questions on functional health, well-being and physical and mental health. High scores indicate a high quality of life. From the 8 domains, a physical (PCS) and mental (MCS) composite score can be derived (and used as a general indicator for QoL). ${ }^{33,34}$

Depressive and anxiety symptoms were assessed using the validated Hospital Anxiety and Depression Scale (HADS) and the State-Trait Anxiety Inventory (STAI) version DY. The HADS questionnaire consists of two 7-item scales, for anxiety and for depression, each with a score ranging from $0-21$. A mean score $\geq 8$ on the anxiety or depression subscale shows the presence of anxiety or depressive symptoms with the most optimal balance between sensitivity and specificity, ${ }^{35}$ thereby indicating presence of a possible mood disturbance. ${ }^{36}$ The STAI contains 40 questions on a 4-point scale (1-4), clustered into two subscales: i.e. State-anxiety, assessing momentary anxiety symptoms, and 
Trait-anxiety, measuring how anxious participants 'generally' feel. The questionnaires were completed at home and therefore the State-score was not used in the current analysis, as it represents momentary anxiety which did not match with the time of blood sampling. A score of 20-39 indicates low, 40-59 moderate and 60-80 high anxiety in general. ${ }^{37}$

\section{Statistical analysis}

Statistical analysis was performed using IBM SPSS Statistics version 21.0 (IBM Statistics for Windows, Chicago, IL, USA).

Differences in baseline characteristics between IBS patients and HC were tested with the Chi-square test (categorical data) and the independent-samples t-test (for parametric continuous data). Differences between subtypes of IBS and HC were tested using one-way-analysis of variance (ANOVA). To correct for multiple comparisons, the Bonferroni correction was applied.

Linear regression analysis was used to assess the association between the presence of IBS or IBS subtypes and the plasma parameters of 5-HT metabolism and to adjust for possible confounding factors. Therefore, we first conducted a crude analysis. Secondly, the statistically significant results were adjusted for possible confounding factors using the backward elimination methods. The following parameters were included in the analyses: age, sex, BMI, psychological (anxiety or depressive) symptoms, current smoking and use of selective serotonin reuptake inhibitors (SSRI), proton pump inhibitors (PPI), and medication that affects motility (i.e. laxatives, prokinetics, opioids, spasmolytics and anti-diarrheal drugs). All analyses were performed for IBS patients as a whole group as well as for the subtypes in separate analyses as dummy variables. Missing values were excluded list wise. Data are expressed as mean $\pm S D$. A two-sided p-value $<0.05$ was considered to be statistically significant.

\section{RESULTS}

\section{Baseline characteristics}

From the IBS cohort, we included 154 IBS patients (IBS-Total) and 137 healthy controls (HC) with PPP samples available. With respect to predominant bowel habits, 52 (34\%) were classified as IBS-diarrhea (IBS-D), 33 (22\%) as IBS-constipation (IBS-C), 60 (38\%) as IBS-mixed (IBS-M) and 9 (6\%) patients as IBS-undefined (IBS-U).

Patient characteristics, current medication use, scores for QoL and anxiety and depression are shown in Table 5.1. No significant differences in age, gender, BMI or alcohol use were observed between IBS and HC. A significant higher percentage of IBS 
patients was smoking at time of inclusion in the cohort $(p<0.01)$. Use of medication also differed significantly: PPIs, SSRIs and both motility decreasing and increasing drugs were significantly more frequently used by IBS patients versus HC (all $p<0.01$ ). QoL for both physical and mental scale (SF-PCS and SF-MCS) was significantly impaired in IBS compared to $\mathrm{HC}(\mathrm{p}<0.01)$. Not only were the levels of anxiety and depression symptoms significantly higher in IBS versus HC, but the percentages of IBS patients affected with anxiety and/or depression based on HADS (scores $\geq 8$ ) were also increased in IBS versus HC $(p<0.01)$. Furthermore, Trait-anxiety scores were significantly higher in IBS compared to $\mathrm{HC}(\mathrm{p}<0.01)$. All diary symptom scores were significantly higher in IBS compared to HC (supplementary data in table S5.1, all $\mathrm{p}<0.01$ ). All $p$-values represent significance after correction for multiple testing.

Table 5.1 Baseline characteristics in IBS patients (IBS-Total) and healthy controls (HC).

\begin{tabular}{|c|c|c|c|}
\hline Parameter & $\begin{array}{c}\text { IBS-Total } \\
n=154\end{array}$ & $\begin{array}{c}H C \\
n=137\end{array}$ & \\
\hline \multicolumn{4}{|l|}{ Demographics } \\
\hline $\operatorname{Sex}(M / F)$ & $30 \% / 70 \%$ & $39 \% / 61 \%$ & \\
\hline Age (years) & $44.5 \pm 16.3$ & $44.2 \pm 19.3$ & \\
\hline BMI $\left(\mathrm{kg} / \mathrm{m}^{2}\right)$ & $24.9 \pm 4.4$ & $24.0 \pm 3.9$ & \\
\hline Current smokers & $25 \%$ & $8.5 \%$ & $* *$ \\
\hline Alcohol use (\%yes) & $52 \%$ & $51 \%$ & \\
\hline \multicolumn{4}{|l|}{ Actual medication use } \\
\hline PPI & $26 \%$ & $2 \%$ & $* *$ \\
\hline NSAID & $11 \%$ & $9 \%$ & \\
\hline SSRI & $17 \%$ & $2 \%$ & $* *$ \\
\hline Motility - & $30 \%$ & $0 \%$ & $* *$ \\
\hline Motility + & $20 \%$ & $0 \%$ & $* *$ \\
\hline \multicolumn{4}{|l|}{ Quality of life } \\
\hline SF-PCS & $40.9 \pm 10.0$ & $54.6 \pm 5.5$ & $* *$ \\
\hline SF-MCS & $46.3 \pm 11.3$ & $54.1 \pm 7.6$ & $* *$ \\
\hline \multicolumn{4}{|l|}{ Anxiety and depression } \\
\hline HADS-A score & $6.9 \pm 3.8$ & $3.7 \pm 2.8$ & $* *$ \\
\hline HADS-D score & $4.5 \pm 4.0$ & $1.9 \pm 2.6$ & $* *$ \\
\hline HADS-A $\geq 8$ & $34 \%$ & $12 \%$ & $* *$ \\
\hline HADS-D $\geq 8$ & $22 \%$ & $5 \%$ & $* *$ \\
\hline HADS-A and/or $-\mathrm{D} \geq 8$ & $38 \%$ & $15 \%$ & $* *$ \\
\hline TRAIT score & $40.4 \pm 12.4$ & $30.8 \pm 8.7$ & $* *$ \\
\hline
\end{tabular}

Continuous data expressed as mean \pm SD. Motility $+:$ medication that positively affect motility, i.e. laxatives and prokinetic drugs; Motility - : medication that negatively affect motility, i.e. opioids, spasmolytics and antidiarrheal drugs. PCS: physical composite score; MCS: mental composite score.

$* * * p<0.01$ IBS vs. HC after correction for multiple testing

\section{IBS subtype analysis}

Because the number of patients with IBS-U was small, this subgroup was not included in the subtype analyses. No differences were found with respect to age, gender, BMI 
and use of medication between subtypes (data not shown). All diary symptom scores were significantly higher for all subtypes compared to HC (all $p<0.001$ ), but no significant differences could be detected between the IBS subtypes apart from diarrhea symptoms in IBS-D and constipation symptoms in IBS-C (data not shown). In Table 5.2, the scores for anxiety, depression and quality of life are presented per IBS subtype. The QoL scores were significantly decreased in all IBS subtypes compared to HC, both for the physical and mental domain (all $p<0.001$ ). Between IBS subgroups no significant differences in QoL were found. The HADS anxiety, depression and Trait-anxiety scores were significantly increased in all subtypes compared to HC. However, a significant higher percentage of affected patients (HADS scores $\geq 8$ ) were only found among IBS-D and IBS-M patients but not among IBS-C patients compared to $\mathrm{HC}(\mathrm{p}<0.01)$.

Table 5.2 QoL, anxiety and depression according to IBS subtype

\begin{tabular}{lccccc}
\hline Parameter & $\mathrm{HC}$ & $\mathrm{IBS}-\mathrm{D}$ & IBS-C & IBS-M & IBS-U \\
& $\mathrm{n}=137$ & $\mathrm{n}=52$ & $\mathrm{n}=33$ & $\mathrm{n}=60$ & $\mathrm{n}=9$ \\
\hline SF-PCS & $54.6 \pm 5.5$ & $39.9 \pm 9.7^{* * *}$ & $38.0 \pm 10.7^{* * *}$ & $42.7 \pm 9.9 * * *$ & $44.6 \pm 7.8$ \\
SF-MCS & $54.1 \pm 7.6$ & $47.2 \pm 10.8^{* * *}$ & $45.9 \pm 10.4^{* * *}$ & $45.6 \pm 11.9^{* * *}$ & $46.8 \pm 14.1$ \\
HADS-A score & $3.7 \pm 2.8$ & $7.0 \pm 3.9^{* * *}$ & $7.0 \pm 3.9^{* * *}$ & $7.0 \pm 3.8^{* * *}$ & $5.7 \pm 3.5$ \\
HADS-D score & $1.9 \pm 2.6$ & $4.6 \pm 3.6^{* * *}$ & $4.9 \pm 3.8^{* * *}$ & $4.4 \pm 4.2^{* * *}$ & $2.1 \pm 5.3$ \\
HADS-A $\geq 8$ & $12 \%$ & $40 \% * *$ & $27 \%$ & $35 \% * *$ & $11 \%$ \\
HADS-D $\geq 8$ & $5 \%$ & $23 \% * *$ & $17 \%$ & $22 \% * *$ & $22 \%$ \\
HADS-A and/or -D $\geq 8$ & $15 \%$ & $44 \% * *$ & $30 \%$ & $38 \% * *$ & $22 \%$ \\
TRAIT score & $30.8 \pm 8.7$ & $40.8 \pm 13.4^{* * *}$ & $40.4 \pm 10.0^{* * *}$ & $40.5 \pm 12.1^{* * *}$ & $38.0 \pm 16.1$ \\
\hline
\end{tabular}

Continuous data are expressed as mean $\pm S D ; * * p<0.01 ; * * p<0.001$ Subtype vs. HC.

One-way ANOVA with Bonferroni correction was used for continuous data and $\mathrm{Chi}^{2}$, corrected for multiple testing by multiplying $p$-value $\times 4$, for dichotomous data. No significant differences could be detected between IBS subtypes for all variables.

\section{Plasma 5-HT, 5-HIAA and 5-HIAA/5HT ratio}

In total, $42 \%$ of IBS patients and $42 \%$ of controls had 5 -HT concentrations below the detection limit of $3.3 \mu \mathrm{g} / \mathrm{l}$. Data for 5 -HIAA were in the detectable range for all subjects. The data of the crude linear regression analyses of the IBS-Total, IBS subgroups and HC are presented in Table 5.3.

Table 5.3 Crude linear regression analysis of for plasma 5-HT and 5-HIAA concentrations and 5-HIAA/5-HT ratio for IBS-Total and IBS subtypes versus HC.

\begin{tabular}{llllllllllllll}
\hline Parameter & \multicolumn{1}{l}{ IBS-Total } & \multicolumn{3}{c}{ IBS-D } & \multicolumn{3}{c}{ IBS-C } & \multicolumn{3}{c}{ IBS-M } \\
& B & $95 \% \mathrm{Cl}$ & $p$-value & $\beta$ & $95 \% \mathrm{Cl}$ & $p$-value & $\beta$ & $95 \% \mathrm{Cl}$ & $p$-value & $\beta$ & $95 \% \mathrm{Cl}$ & $p$-value \\
\hline 5-HT $(\mu \mathrm{g} / \mathrm{l})$ & 0.1 & $-2.7 ; 3.0$ & 0.928 & -2.3 & $-6.3 ; 1.6$ & 0.242 & 0.1 & $-4.6 ; 4.7$ & 0.984 & 2.9 & $-0.9 ; 6.6$ & 0.139 \\
5-HIAA $(\mu \mathrm{g} / \mathrm{l})$ & -14.4 & $-20.4 ;-8.4$ & $<0.001$ & -10.0 & $-18.2 ;-1.7$ & 0.018 & -14.2 & $-20.1 ;-4.4$ & 0.005 & -17.6 & $-25.5 ;-9.8$ & $<0.001$ \\
5-HIAA/5-HT ratio & -5.1 & $-8.4 ;-1.8$ & 0.003 & -2.8 & $-7.4 ; 1.8$ & 0.233 & -3.3 & $-8.8 ; 2.2$ & 0.244 & -7.9 & $-12.4 ;-3.5$ & $<0.001$ \\
\hline
\end{tabular}

$B=$ regression coefficient, representing the difference in 5-HT, 5-HIAA and 5-HIAA/5-HT, respectively, of IBS-Total and IBS subtypes compared to HC. $95 \%$ confidence intervals $(\mathrm{CI})$ and $p$-values are shown. IBS-U is not shown due to small sample size. 
The baseline 5-HT levels (Figure 5.1) did not differ significantly between IBS and HC $(7.2 \pm 14.9$ versus $7.1 \pm 8.8 \mathrm{ug} / \mathrm{l})$. However, 5-HIAA concentrations (Figure 5.2) were significantly lower in IBS compared to controls: $24.6 \pm 21.9$ versus $39.0 \pm 29.5 \mathrm{ug} / \mathrm{l}$, respectively $(p<0.001)$.

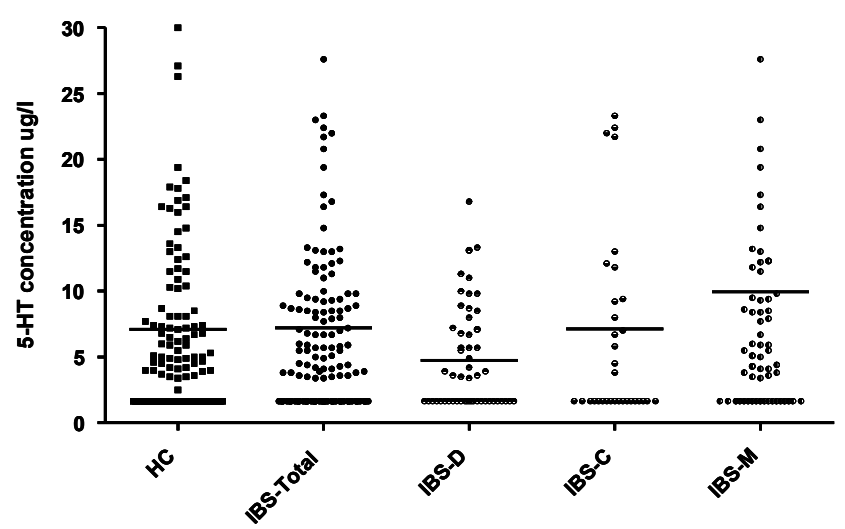

Figure 5.1 Scatterplot for 5-HT concentrations, presented for healthy controls (HC), the total IBS group (IBS-Total) and three subtypes: IBS-D, IBS-C, and IBS-M. IBS-U was not presented due a to small sample size. There were no statistically significant differences between groups. The following dots with a value $>30 \mu \mathrm{g} / \mathrm{l}$ were left out of the graph to improve the visibility of the data, but were included in the analyses: HC 36.6; 43.5; 46.1; 53.9, IBS-C 32.5, IBS-M $175.8 \mathrm{ug} / \mathrm{l}$.

After expanding the model with confounding variables, 5-HIAA levels remained significantly lower in IBS-Total compared to $\mathrm{HC}(\beta-13.8,95 \% \mathrm{Cl}:-19.7 ;-7.8, \mathrm{p}<0.001)$. Backward elimination did not reveal a significant influencing parameter in this model but did show a trend for gender $(p=0.06)$. Subtype analysis for 5 -HIAA showed all subtypes to be significantly different compared to HC (Table 5.3, Figure 5.2).

The 5-HIAA/5-HT ratio (Table 5.3, Figure 5.3) was significantly lower in IBS compared to controls: $(8.4 \pm 12.2$ versus $13.5 \pm 16.6$, respectively $\mathrm{p}<0.01)$ and in IBS-M compared to controls $(5.5 \pm 5.6$ versus $13.5 \pm 16.6$, respectively, $p<0.001$ ). Furthermore, the $5-\mathrm{HIAA} / 5$ $\mathrm{HT}$ ratio was significantly lower in IBS-M versus IBS-D $(\beta-5.1,95 \% \mathrm{Cl}$ : $-9.1 ;-1.2$ $p=0.012$ ). No significant effects were observed for the potential confounding factors tested and no significant differences were found between other IBS-subtypes apart from IBS-M and controls. 
Since the linear regression model showed a possible influence of gender on 5-HIAA concentrations, we performed a separate analysis only within the IBS patients group to assess the effect of gender on 5-HIAA concentrations in IBS patients.

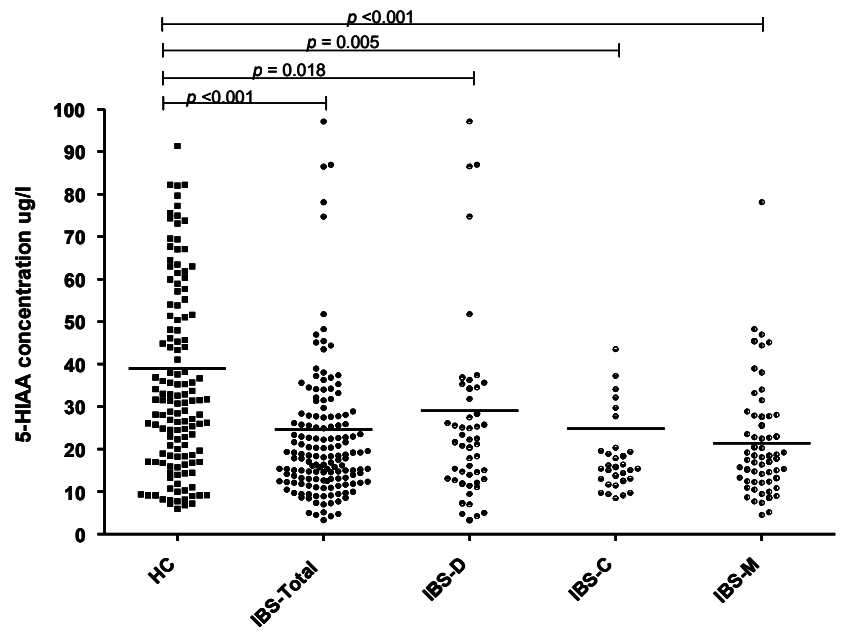

Figure 5.2 Scatterplot for 5-HIAA concentrations, presented for HC, IBS-Total, and three subtypes: IBS-D, IBS-C, and IBS-M. IBS-U was not presented due a to small sample size. Significant differences presented in the graph. The following dots with a value $>100 \mu \mathrm{g} / \mathrm{l}$ were left out of the graph to improve the visibility of the data, but were included in the analyses: HC 104.9; 125.1; 125.5; 127.6; 211.9, IBS-D 103.3; 117.3, IBS-C 115.3; $140.0 \mathrm{ug} / \mathrm{l}$.

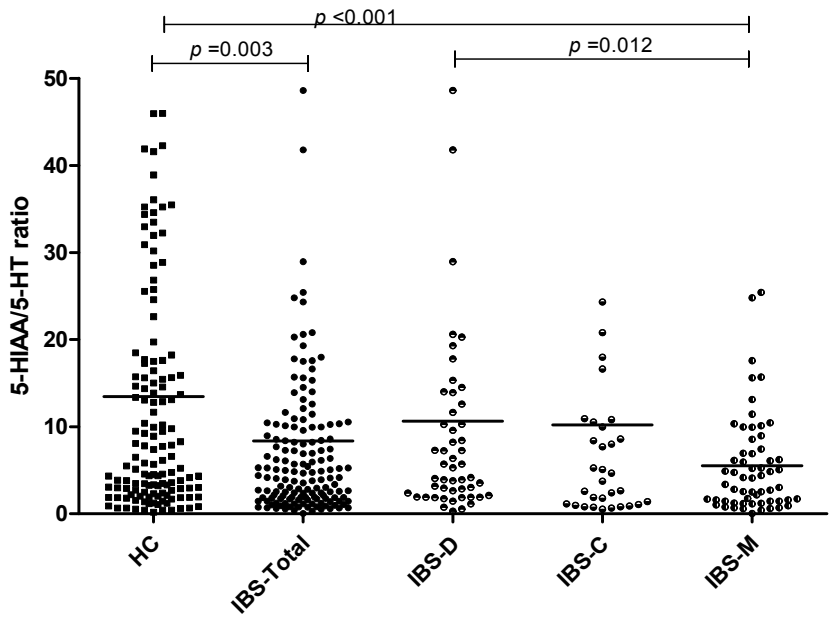

Figure 5.3 Scatterplot for 5-HIAA / 5-HT ratio presented for: HC, IBS-Total, and three subtypes: IBS-D, IBS-C, and IBS-M. Significant differences presented in the graph. 
Linear regression analysis showed a $\beta$ of 8.1 (95\% Cl: 0.6 ; $15.7, p=0.04)$, pointing to a significantly lower 5-HIAA concentration in female IBS patients compared to male IBS patients. No influence was found for other patient characteristics tested. To delineate whether the finding was IBS-specific, we repeated this analysis in HC (NS), pointing to an IBS-specific difference in systemic 5 HIAA between females and males.

\section{DISCUSSION}

In a large group of well-characterized IBS patients, no alterations were observed in plasma fasting 5-HT concentrations compared to controls. However, a significant decrease in 5-HIAA concentrations and in the 5-HIAA/5-HT ratio was found in patients with IBS. All IBS subtypes showed lower 5-HIAA levels compared to controls, but the difference was most pronounced in the IBS-M group. The 5-HIAA/5-HT ratio also was significantly lower in the total IBS group and IBS-M compared to controls. Apart from a possible gender effect on 5-HIAA levels, no influence was found for abdominal symptoms, anxiety and/or depression nor for medication use on plasma 5-HT, 5-HIAA or their ratio in IBS patients or subgroups.

The fasting 5-HT levels did not significantly differ between IBS or subgroups and HC. Our data confirm previous studies by among others Kilkens et al. ${ }^{22}$ and Houghton et al., ${ }^{19}$ showing that fasting platelet-poor-plasma 5-HT levels in IBS were not different from controls. ${ }^{20}$ In contrast, higher fasting 5-HT levels have been observed by others in IBS-D patients, ${ }^{8,38}$ but also in IBS irrespective of subtype. ${ }^{27}$ Numerous stimuli lead to 5-HT release; i.e. ingestion of food, vagal or sympathetic adrenergic stimulation, lowering of luminal $\mathrm{pH}$, mucosal distortion and obstruction of gut motility. ${ }^{39}$ Several trials that assessed 5-HT levels after meal stimulation found an increase in 5-HT levels in IBS compared to controls. ${ }^{19,20,27,38}$ Unfortunately, most of these studies did not take into account existing differences in baseline values. ${ }^{19,20,27}$ Hougthon et al. did correct for baseline levels, after which differences in postprandial 5-HT levels were no longer significant. ${ }^{38}$ Atkinson et al. ${ }^{8}$ have shown an increase in 5 -HT after meal stimulation in controls and IBS-D but not in IBS-C. In our study, $42 \%$ of the fasting samples had $5-\mathrm{HT}$ concentrations below the detection limit. These data indicate that measurement of systemic 5-HT levels has little relevance for discrimination of IBS from controls and in the future attention should focus (more) on mucosal levels of 5-HT and its metabolites.

We also assessed 5-HIAA as a marker of 5-HT metabolism and our data point to a pronounced decrease in 5-HIAA concentrations in IBS patients and in the IBS-D, IBS-C and IBS-M subtypes compared to controls. Previously, a decrease in 5-HIAA has been observed in IBS-C patients ${ }^{[8]}$ but most studies focused on 5-HT and/or ratio data. ${ }^{19-21}$ 
The lower 5-HIAA concentrations found in our IBS patients may result from a decrease in serotonergic metabolism by a reduced MAO activity (intestinal or extra-intestinal) or decreased uptake of 5-HT by SERT. Previously, mucosal SERT expression was found to be decreased in IBS-C and IBS-D patients, but studies did not report on IBS-M subtype. $^{40-42}$ Decreased mucosal SERT activity in IBS may result in an increase in mucosal availability of 5-HT leading to luminal hypersensitivity, hypermotility and diarrhea. It has been speculated by Coates et al. and Shekhar et al. that continued exposure of the mucosa to 5-HT may eventually result in the desensitization of 5-HT receptors with decreased reflex activity and give rise to luminal hyposecretion and constipation. ${ }^{43,44}$ Taken together, these factors stress the relevance to evaluate 5-HT metabolism at intestinal level. We have not assessed SERT activity, which is a limitation of the present study.

In general, little is known on the influence of SSRI use on systemic 5-HT and 5-HIAA levels. The mechanism of action of SSRIs is almost entirely based on SERT inhibition. ${ }^{13}$ Previous studies exploring the influence of SSRI use on 5-HT metabolism have resulted in contradicting results with respect to $5-\mathrm{HT}$ cerebrospinal fluid concentrations before and after acute SSRI administration. ${ }^{45,46}$ Acute administration of citalopram in IBS patients resulted in increased PPP 5-HT levels in combination with enhanced memory performance, leading to the assumption that SSRI administration increases $5-\mathrm{HT}$ at synapses, but it is still uncertain how this may affect $5-\mathrm{HT}$ activity at central nervus system (CNS) or intestinal level. ${ }^{22}$ Furthermore, little is known about chronic use of SSRIs on 5-HT synthesis. ${ }^{47}$ Our data do not provide evidence for an influence of SSRI use on systemic 5-HT and 5 HIAA concentrations. However, future focus should be directed more towards local, i.e. intestinal, instead of systemic level.

Anxiety and depression are more prevalent among IBS patients compared to the general population. ${ }^{31,48}$ In our own tertiary center for referral of patients with complex functional gastrointestinal disorders (FGIDs), in as much as $50 \%$ of the patients an anxiety disorder is diagnosed and in $20 \%$ a mood disorder. ${ }^{49} \mathrm{~A}$ high prevalence of anxiety and depression was confirmed in our IBS cohort, including patients from general practitioners, secondary and tertiary referral. Changes in 5-HT metabolism have been reported to be more pronounced in patients with psychiatric comorbidity. ${ }^{10,50}$ We did not observe a significant influence of anxiety and/or depression symptoms on plasma markers of 5-HT metabolism. A few other studies have assessed the correlation between plasma 5-HT metabolism and anxiety/depression symptoms in IBS patients but results were not in line with each other and do not point to a specific direction of influence by anxiety or depression disorders on 5-HT metabolism. ${ }^{26,27}$ 
Our study is the first to observe distinctly different results for IBS-M patients with respect to serotonin metabolism with a decreased 5-HIAA/5-HT ratio. The differences in the IBS-M group are not explained by symptom scores, psychological comorbidity, gender or use of medication. In previous studies on serotonin metabolism, this subgroup of IBS patients has not been analyzed separately. ${ }^{8,19,20,27}$ This is remarkable since the IBS-M subtype is the most common IBS subtype. ${ }^{51-53}$ With regard to 5-HT metabolism in our study, IBS-M seemed not simply a mix of IBS-D and IBS-C data. IBS-M patients had the lowest 5-HIAA levels and 5-HIAA/5-HT ratio compared to all the other subtypes. A recently published large scale study showed significantly higher scores for IBS-M patients regarding somatization and somatic symptom scores compared to either IBS-C or IBS-D. ${ }^{54}$ However, in another study no significant differences between IBS-D, IBS-C and IBS-M with respect to IBS severity, abdominal pain, level of somatization, QoL and anxiety or depression scores were found. ${ }^{55}$ We postulate, based on the differences in particularly 5-HIAA/5-HT ratio, that IBS-M may be a truly separate entity in IBS, possibly with a different pathophysiological background in comparison to IBS-D and IBS-C.

Linear regression analysis revealed an influence of gender on 5-HIAA concentrations in IBS but not in controls. Female IBS patients had significantly lower 5-HIAA concentrations compared to IBS males. Previously, female patients were found to have lower SERT expression, which could explain lower 5-HIAA concentrations. ${ }^{56}$ Differences in systemic 5-HT between males and females have also been observed previously in one study, in which fasting PPP 5-HT levels were significantly higher compared to HC, which was explained after stratifying the groups by IBS-D men only. A relation with menstrual cycle could not be proven in that study. No gender differences were found in 5-HIAA concentrations. ${ }^{38}$ The lower 5-HIAA levels we observed in IBS females cannot be explained by differences in subtype distribution, psychological comorbidity or use of medication. Menstrual cycle phase was not taken into account in our study, neither were stress factors, which have been shown to be potential confounders. ${ }^{12,26}$

The method we employed for assessment of 5-HT and 5-HIAA in PPP has previously been described by Hirowatari et al, and is considered to be a reliable method with adequate specificity, sensitivity and reproducibility. ${ }^{57}$ It should be acknowledged that in our study $42 \%$ of IBS patients and comparable numbers of controls had $5-\mathrm{HT}$ concentrations below the detection limit, a finding in line with data by Bearcroft et al.. ${ }^{20}$ Brand et al systematically reviewed 101 trials that have measured 5-HT in PPP and found that methods to measure $5-\mathrm{HT}$ vary widely. ${ }^{58}$ The concentration of $5-\mathrm{HT}$ in platelets may exceed free plasma concentration, leaving the possibility open that what is measured in PPP reflects leakage of 5-HT from platelets during preparation instead of the actual concentration in plasma. ${ }^{13}$ Therefore, the assessment of 5-HIAA levels seems 
more useful for the assessment of systemic serotonin metabolism than the quantification of 5-HT itself. However, due to the wide distribution of 5-HIAA levels in both IBS patients and $\mathrm{HC}$ and the indication that the systemic measurements not fully represents or reflects intestinal metabolism, both 5-HT and 5-HIAA plasma levels do not seem to be very useful as a potential biomarker in IBS patients. Assessment of serotonin metabolism at intestinal level, combined with systemic measurements, of 5-HT and 5-HIAA may help to provide a better insight into the 5-HT metabolism in $\mathrm{IBS}^{8,28}$ however, a wide spread in mucosal assessment of 5 -HT has also been seen in previously performed studies. $^{59}$

\section{CONCLUSION}

Fasting plasma 5-HT levels were not significantly different between IBS patients and healthy controls. However, our data showed a significant decrease in fasting 5-HIAA concentrations and 5-HIAA/5-HT ratio in IBS, in which all IBS subtypes separately have lower 5-HIAA levels compared to controls and the 5-HIAA/5-HT ratio was significantly lower in IBS-M versus controls. Linear regression analysis points to an influence of gender but not of symptoms, anxiety and/or depression or medication use.

Our study demonstrated that although fasting 5-HT plasma levels are not changed in IBS compared to controls, the differences in 5-HIAA levels may reflect altered 5-HT metabolism in IBS patients. 


\section{REFERENCES}

1 Longstreth GF, Thompson WG, Chey WD, Houghton LA, Mearin F, Spiller RC. Functional bowel disorders. Gastroenterology 2006;130:1480-91.

2 Hungin AP, Whorwell PJ, Tack J, Mearin F. The prevalence, patterns and impact of irritable bowel syndrome: an international survey of 40,000 subjects. Aliment Pharmacol Ther 2003;17: 643-50.

3 Olden KW. Diagnosis of irritable bowel syndrome. Gastroenterology 2002;122:1701-14.

4 Camilleri M, Heading RC, Thompson WG. Clinical perspectives, mechanisms, diagnosis and management of irritable bowel syndrome. Aliment Pharmacol Ther 2002;16:1407-30.

5 El-Salhy M. Irritable bowel syndrome: diagnosis and pathogenesis. World J Gastroenterol WJG 2012;18:5151-63.

6 Drossman DA, Camilleri M, Mayer EA, Whitehead WE. AGA technical review on irritable bowel syndrome. Gastroenterology 2002;123:2108-31.

7 Kim DY, Camilleri M. Serotonin: a mediator of the brain-gut connection. Am J Gastroenterol 2000;95:2698-709.

8 Atkinson W, Lockhart S, Whorwell PJ, Keevil B, Houghton LA. Altered 5-hydroxytryptamine signaling in patients with constipation- and diarrhea-predominant irritable bowel syndrome. Gastroenterology 2006;130:34-43.

9 Berger M, Gray JA, Roth BL. The expanded biology of serotonin. Ann Rev Med 2009;60: 355-66.

10 Cremon C, Carini G, Wang B, Vasina V, Cogliandro RF, De Giorgio R, Stanghellini V, Grundy D, Tonini M, De Ponti F, Corinaldesi R, Barbara G. Intestinal serotonin release, sensory neuron activation, and abdominal pain in irritable bowel syndrome. Am J Gastroenterol 2011;106: 1290-8.

11 Gershon MD. Review article: serotonin receptors and transporters -- roles in normal and abnormal gastrointestinal motility. Aliment Pharmacol Ther 2004;20 Suppl 7:3-14.

12 Matricon J, Meleine M, Gelot A, Piche T, Dapoigny M, Muller E, Ardid D. Review article: Associations between immune activation, intestinal permeability and the irritable bowel syndrome. Aliment Pharmacol Ther 2012;36:1009-31.

13 Gershon MD, Tack J. The serotonin signaling system: from basic understanding to drug development for functional GI disorders. Gastroenterology 2007;132:397-414.

14 Mawe GM, Coates MD, Moses PL. Review article: intestinal serotonin signalling in irritable bowel syndrome. Aliment Pharmacol Ther 2006;23:1067-76.

15 Tack J, Janssen P, Wouters M, Boeckxstaens G. Targeting serotonin synthesis to treat irritable bowel syndrome. Gastroenterology 2011;141:420-2.

16 Erspamer V, Testini A. Observations on the release and turnover rate of 5-hydroxytryptamine in the gastrointestinal tract. J Pharm Pharmacol 1959;11:618-23.

17 Nikisch G, Mathe AA, Czernik A, Eap CB, Jimenez-Vasquez P, Brawand-Amey M, Baumann P. Stereoselective metabolism of citalopram in plasma and cerebrospinal fluid of depressive patients: relationship with 5-HIAA in CSF and clinical response. J Clin Psychopharmacol 2004; 24:283-90.

18 Park SY, Park MH, Yoon KW, Cho SB, Lee WS, Park CH, Kim HS, Choi SK, Rew JS. Plasma 5-hydroxytryptamine concentration and its correlation with psychopathology in patients with irritable bowel syndrome. Gut and liver 2009;3:26-30.

19 Houghton LA, Atkinson W, Whitaker RP, Whorwell PJ, Rimmer MJ. Increased platelet depleted plasma 5-hydroxytryptamine concentration following meal ingestion in symptomatic female subjects with diarrhoea predominant irritable bowel syndrome. Gut 2003;52:663-70.

20 Bearcroft CP, Perrett D, Farthing MJ. Postprandial plasma 5-hydroxytryptamine in diarrhoea predominant irritable bowel syndrome: a pilot study. Gut 1998;42:42-6.

21 Dunlop SP, Coleman NS, Blackshaw E, Perkins AC, Singh G, Marsden CA, Spiller RC. Abnormalities of 5hydroxytryptamine metabolism in irritable bowel syndrome. Clin Gastroenterol Hepatol 2005;3:349-57.

22 Kilkens TO, Honig A, Fekkes D, Brummer RJ. The effects of an acute serotonergic challenge on brain-gut responses in irritable bowel syndrome patients and controls. Aliment Pharmacol Ther 2005;22:865-74.

23 Bradford K, Shih W, Videlock EJ, Presson AP, Naliboff BD, Mayer EA, Chang L. Association between early adverse life events and irritable bowel syndrome. Clin Gastroenterol Hepatol 2012;10:385-390 e381-3 
24 Sykes MA, Blanchard EB, Lackner J, Keefer L, Krasner S. Psychopathology in irritable bowel syndrome: support for a psychophysiological model. J Behav Med 2003;26:361-72.

25 Kim JJ. Serotonin, stress, and conditioning. Biol Psychiatry 2008;63:819-20.

26 Stasi C, Bellini M, Costa F, Mumolo MG, Ricchiuti A, Grosso M, Duranti E, Metelli MR, Gambaccini D, Bianchi L, Di Tanna GL, Laffi G, Taddei S, Marchi S. Neuroendocrine markers and psychological features in patients with irritable bowel syndrome. Int J Colorectal Dis 2013; 28:1203-8.

27 Park SY, Park MH, Yoon KW, Cho SB, Lee WS, Park CH, Kim HS, Choi SK, Rew JS. Plasma 5-hydroxytryptamine concentration and its correlation with psychopathology in patients with irritable bowel syndrome. Gut Liver 2009;3:26-30.

28 Keszthelyi D, Troost FJ, Jonkers DM, Kruimel JW, Leue C, Masclee AA. Decreased levels of kynurenic acid in the intestinal mucosa of IBS patients: relation to serotonin and psychological state. J Psychosom Res 2013;74:501-4.

29 Faresjo A, Grodzinsky E, Johansson S, Wallander MA, Faresjo T, Timpka T. Self-reported use of pharmaceuticals among patients with irritable bowel syndrome in primary care. J Manag Care Pharm 2008;14:870-7.

30 Hirowatari Y, Hara K, Kamihata H, Iwasaka T, Takahashi H. High-performance liquid chromatographic method with column-switching and post-column reaction for determination of serotonin levels in platelet-poor plasma. Clin Biochem 2004;37:191-7.

31 Thijssen AY, Jonkers DM, Leue C, van der Veek PP, Vidakovic-Vukic M, van Rood YR, Clemens $\mathrm{CH}$, Masclee AA. Dysfunctional cognitions, anxiety and depression in irritable bowel syndrome. J Clin Gastroenterol 2010;44:e236-41.

32 van der Zee KI SR. Het meten van de algemene gezonsheidstoestand met de RAND-36, een handleiding. [Assessment of general health status with the RAND-36; guidebook]. Noordelijk Centrum voor Gezondheidsvraagstukken Rijksuniversiteit Groningen: Groningen, 1993.

33 Creed F, Ratcliffe J, Fernandez L, Tomenson B, Palmer S, Rigby C, Guthrie E, Read N, Thompson D. Health-related quality of life and health care costs in severe, refractory irritable bowel syndrome. Ann Intern Med 2001;134:860-8.

34 Farivar SS, Cunningham WE, Hays RD. Correlated physical and mental health summary scores for the SF-36 and SF-12 Health Survey, V.I. Health Qual Life Outcomes 2007;5:54.

35 Bjelland I, Dahl AA, Haug TT, Neckelmann D. The validity of the Hospital Anxiety and Depression Scale. An updated literature review. J Psychosom Res 2002;52:69-77.

36 Zigmond AS, Snaith RP. The hospital anxiety and depression scale. Acta Psychiatr Scand 1983;67: 361-70.

37 Spielberger GaL. State-trait Anxiety Inventory. Consulting Psychologists Press 1970.

38 Houghton LA, Brown H, Atkinson W, Morris J, Fell C, Whorwell PJ, Lockhart S, Keevil B. 5hydroxytryptamine signalling in irritable bowel syndrome with diarrhoea: effects of gender and menstrual status. Aliment Pharmacol Ther 2009;30:919-29.

39 McLean PG, Borman RA, Lee K. 5-HT in the enteric nervous system: gut function and neuropharmacology. Trends Neurosci 2007;30:9-13.

40 Foley S, Garsed K, Singh G, Duroudier NP, Swan C, Hall IP, Zaitoun A, Bennett A, Marsden C, Holmes G, Walls A, Spiller RC. Impaired uptake of serotonin by platelets from patients with irritable bowel syndrome correlates with duodenal immune activation. Gastroenterology 2011; 140:1434-1443 e1431.

41 Kerckhoffs AP, ter Linde JJ, Akkermans LM, Samsom M. SERT and TPH-1 mRNA expression are reduced in irritable bowel syndrome patients regardless of visceral sensitivity state in large intestine. Am J Physiol Gastrointest Liver Physiol 2012;302:G1053-60.

42 El-Salhy M, Wendelbo I, Gundersen D. Serotonin and serotonin transporter in the rectum of patients with irritable bowel disease. Mol Med Rep 2013;8:451-5.

43 Coates MD, Mahoney CR, Linden DR, Sampson JE, Chen J, Blaszyk H, Crowell MD, Sharkey KA, Gershon MD, Mawe GM, Moses PL. Molecular defects in mucosal serotonin content and decreased serotonin reuptake transporter in ulcerative colitis and irritable bowel syndrome. Gastroenterology 2004;126:1657-64. 
44 Shekhar C, Monaghan PJ, Morris J, Issa B, Whorwell PJ, Keevil B, Houghton LA. Rome III functional constipation and irritable bowel syndrome with constipation are similar disorders within a spectrum of sensitization, regulated by serotonin. Gastroenterology 2013;145:749-57.

45 Carpenter LL, Anderson GM, Siniscalchi JM, Chappell PB, Price LH. Acute changes in cerebrospinal fluid 5-HIAA following oral paroxetine challenge in healthy humans. Neuropsychopharmacology 2003;28:339-47.

46 Barton DA, Esler MD, Dawood T, Lambert EA, Haikerwal D, Brenchley C, Socratous F, Hastings J, Guo L, Wiesner G, Kaye DM, Bayles R, Schlaich MP, Lambert GW. Elevated brain serotonin turnover in patients with depression: effect of genotype and therapy. Arch Gen Psychiatry 2008;65:38-46.

47 Honig G, Jongsma ME, van der Hart MC, Tecott LH. Chronic citalopram administration causes a sustained suppression of serotonin synthesis in the mouse forebrain. PloS One 2009;4: e6797.

48 Levy RL, Olden KW, Naliboff BD, Bradley LA, Francisconi C, Drossman DA, Creed F. Psychosocial aspects of the functional gastrointestinal disorders. Gastroenterology 2006; 130: 1447-58.

49 Kruimel J, Leue C, Winkens B, Marcus D, Schoon S, Dellink R, van Os J, Masclee A. Integrated medicalpsychiatric outpatient care in functional gastrointestinal disorders improves outcome: a pilot study. Eur J Gastroenterol Hepatol 2015;27:721-7.

50 Kim JJ. Serotonin, stress, and conditioning. Biol Psychiatry 2008;63:819-20.

51 Wilson S, Roberts L, Roalfe A, Bridge P, Singh S. Prevalence of irritable bowel syndrome: a community survey. Br J Gen Pract 2004;54:495-502.

52 Lin S, Mooney PD, Kurien M, Aziz I, Leeds JS, Sanders DS. Prevalence, investigational pathways and diagnostic outcomes in differing irritable bowel syndrome subtypes. Eur J Gastroenterol Hepatol 2014;26:1176-80.

53 Ford AC, Bercik P, Morgan DG, Bolino C, Pintos-Sanchez MI, Moayyedi P. Characteristics of functional bowel disorder patients: a cross-sectional survey using the Rome III criteria. Aliment Pharmacol Ther 2014;39:312-21.

54 Patel P, Bercik P, Morgan DG, Bolino C, Pintos-Sanchez MI, Moayyedi P, Ford AC. Irritable bowel syndrome is significantly associated with somatisation in 840 patients, which may drive bloating. Aliment Pharmacol Ther 2015;41:449-58.

55 Rey de Castro NG, Miller V, Carruthers HR, Whorwell PJ. Irritable bowel syndrome: a comparison of subtypes. J Gastroenterol Hepatol 2015;30:279-85.

56 Franke L, Schmidtmann M, Riedl A, van der Voort I, Uebelhack R, Monnikes H. Serotonin transporter activity and serotonin concentration in platelets of patients with irritable bowel syndrome: effect of gender. J Gastroenterol 2010;45:389-98.

57 Hirowatari Y, Hara K, Kamihata H, Iwasaka T, Takahashi H. High-performance liquid chromatographic method with column-switching and post-column reaction for determination of serotonin levels in platelet-poor plasma. Clin Biochem 2004;37:191-7.

58 Brand T, Anderson GM. The measurement of platelet-poor plasma serotonin: a systematic review of prior reports and recommendations for improved analysis. Clin Chem 2011;57: 1376-86.

59 Keszthelyi D, Troost FJ, Jonkers DM, van Donkelaar EL, Dekker J, Buurman WA, Masclee AA. Does acute tryptophan depletion affect peripheral serotonin metabolism in the intestine? Am J Clin Nutr 2012;95:603-8. 
SUPPLEMENTARY DATA

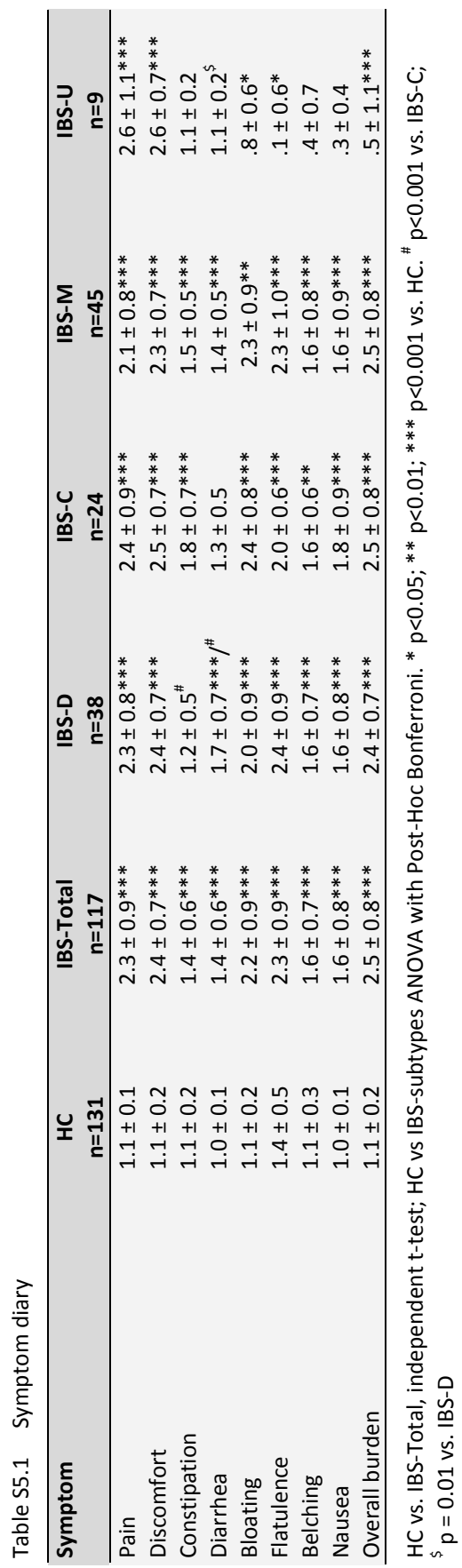




\section{CHAPTER 6}

Gender differences in Irritable Bowel Syndrome, separate pathophysiological background?

A.Y. Thijssen, D.M.A.E. Jonkers, S. Ludidi, D. Keszthelyi, M.A. Hesselink, Z. Mujagic, A.A.M. Masclee

In preparation for submission 


\section{ABSTRACT}

\section{Background and aims}

The prevalence of Irritable Bowel Syndrome (IBS) as well as the clinical presentation differs between males and females. However, studies on gender differences with regard to potential pathophysiological factors in IBS are lacking. We aimed to explore whether differences exist in pathophysiological mechanisms between female and male IBS patients.

\section{Methods}

Clinical, demographic data, feces and plasma samples were available for a subgroup of IBS and healthy controls (HC) participating in the Maastricht-IBS cohort. A set of fecal and serological markers associated with various underlying mechanisms were analyzed with respect to gender differences: i.e. fecal chromogranin A, human beta defensin 2, calprotectin, short chain fatty acids (SCFAs), plasma citrulline and cytokines. Furthermore, demographic variables, a 14-day symptom diary, the Gastrointestinal symptom rating scale (GSRS), quality of life (QoL), anxiety and depression scores were assessed in the two weeks before biosample collection.

\section{Results}

Female IBS patients showed higher discomfort scores and more impaired physical QoL compared to male IBS patients $(p<0.05)$. Furthermore, significantly lower total SCFA and citrulline concentrations were found in female compared to male IBS patients (all $\mathrm{p}<0.05$ ), but not in $\mathrm{HC}$. In a linear regression analysis, only BMI showed a significant association with the total SFCA concentrations without changing the gender difference. No gender differences were observed for the other biomarkers tested.

\section{Conclusion}

This study showed that discomfort scores are higher and fecal SCFA concentrations are decreased in female versus male IBS patients. Analyses of microbiota and/or colonic metabolism as explanation for gender difference in IBS deserves further evaluation. 


\section{INTRODUCTION}

Irritable Bowel Syndrome (IBS) is a highly prevalent functional disorder with a clear female predominance (i.e. 70\%). ${ }^{1,2}$ Female IBS patients are found to differ from male IBS patients with respect to clinical presentation on several aspects. First, the constipation subtype IBS (IBS-C) $)^{3,4}$ is more frequent among females. Second, more severe scores for constipation related symptoms ${ }^{5,6}$ and abdominal pain ${ }^{7}$ have been reported in women compared to men with IBS. Third, a recent cohort study showed that female IBS patients report more severe symptoms and have more impaired quality of life. ${ }^{8}$ Fourth, female IBS patients are also more likely to report additional (functional) gastrointestinal (GI) symptoms and conditions (i.e. globus, dysphagia, bloating and fecal incontinence $)^{5,9}$ and comorbid diseases, such as migraine headache, fibromyalgia and chronic pelvic pain. ${ }^{10-12}$ Fifth, women with IBS also more easily seek healthcare. ${ }^{7}$ Although the phenotype of IBS differs by gender, it is unclear whether underlying patho-physiological mechanisms are different between female and male IBS patients.

IBS is a multifactorial disease involving a complex interplay between the brain and the gut. A disturbed barrier function, ${ }^{13}$ intestinal microbiota composition and activity, ${ }^{14}$ low grade immune activation, ${ }^{15}$ altered motility and visceroperception, ${ }^{16}$ altered central nervous system processing as well as psychosocial factors are associated with IBS. ${ }^{17,18}$ Different exposure to life stressors and more frequent co-diagnosis of psychiatric disorders (depression and anxiety) have been observed in female versus male IBS patients, ${ }^{19-21}$ pointing to a dysregulation along the brain-gut axis. Serotonin (5-hydroxytryptamine, 5-HT) has a key role in the brain-gut axis homeostasis, modulating behavioral and intestinal processes. ${ }^{22,23}$ Recently, we observed gender related differences in serotonin (5-HT) metabolism in IBS with lower systemic levels of the serotonin metabolite 5-HIAA (chapter 5 , submitted for publication). In a placebo controlled probiotic trial, a beneficial response was observed in male IBS patents but not in females due to a more pronounced placebo effect in the female group, pointing to gender differences in therapeutic responsiveness (Thijssen et al., accepted for publication). Further data on possible pathophysiological differences by gender in IBS are lacking.

In our Maastricht-IBS cohort, ${ }^{24,25}$ a set of 15 biomarkers has been assessed to explore whether a specific biomarker profile representing various underlying pathophysiological mechanisms, was able to differentiate IBS patients from healthy controls. Fecal samples have been examined with regard to a) calprotectin, an indicator of intestinal inflammation, ${ }^{26}$ b) human 6 -defensin 2 (HBD2), as intestinal antimicrobial peptide $^{27}$ c) short chain fatty acids (SCFAs, i.e. acetate, propionate, butyrate, valerate, and calproate) as metabolic products and indicators of the interaction between diet, 
microbiota and the host ${ }^{28,29}$ and d) chromogranin $\mathrm{A}(\mathrm{CgA})$, as indicator of the intestinal neuroendocrine cell activity. ${ }^{30}$ Blood markers assessed in that study were a) plasma citrulline as marker for intestinal absorptive and barrier capacity ${ }^{31}$ and b) nonstimulated plasma cytokine levels (i.e. interleukin (IL)-1 $\beta$, IL-6, IL-8, IL-10, IL-12p70 and tumour necrosis factor (TNF)- $\alpha$ ) as markers of systemic immune activation. ${ }^{32}$ A novel, multi-domain biomarker panel with high positive predictive value for IBS has been identified in this study (submitted for publication).

We hypothesize that the phenotype differences in female versus male IBS patients relate to a different pathophysiological background. The previously tested detailed biomarkers set associated with various pathophysiological mechanisms in IBS was used to screen for gender differences within the IBS population and to explore differences in pathophysiological background between IBS males and females.

\section{MATERIALS AND METHODS}

The present study is part of a larger cohort study (i.e. the Maastricht-IBS cohort) on the phenotypical and genotypical characterization of patients with IBS, ${ }^{24}$ wherein extensive demographic, clinical and lifestyle factors were collected and multiple fecal and plasma markers were assessed according to standardized procedures. The subgroup of IBS patients and healthy controls that handed in a blood sample and/or stool sample for biomarker analyses was included in the current study. All subjects gave written informed consent prior to their inclusion. The cohort study was approved by the Medical Ethics Committee of the Maastricht University Medical Centre+ (MUMC+) and executed according to the revised Declaration of Helsinki $\left(59^{\text {th }}\right.$ general assembly of the WMA, Seoul, South Korea, Oct. 2008). The study has been registered at the US National Library of Medicine (http://www.clinicaltrials.gov NCT00775060).

\section{Study participants}

Between February 2009 and August 2013, patients with IBS between 18-75 years of age, fulfilling Rome III criteria, were recruited via the outpatient clinic of the department of Gastroenterology-Hepatology of the MUMC+ and via general practitioners (GP) offices in Maastricht and the surrounding area. IBS patients were subtyped based on predominant bowel habits according to the Rome III criteria. IBS diagnosis was confirmed by a gastroenterologist or GP and if indicated endoscopy with biopsies, abdominal imaging by ultrasonography or CT scan, and/or blood, breath and fecal analysis were performed to exclude organic disease. Patients with a history of abdominal surgery, except appendectomy, laparoscopic cholecystectomy and hysterectomy were excluded. 
To assess if possible differences are IBS specific, a group of healthy controls (HC) between 18-75 years of age was recruited by advertisements in newspapers, on bulletin boards at Maastricht University and on a website for subject recruitment to serve as a control group. A brief medical history was taken to rule out history of gastrointestinal disorders or presence of gastrointestinal complaints.

\section{Questionnaires}

Within a period of 2 weeks prior to collection of blood and/or stool samples, questionnaires on demographic characteristics, lifestyle factors, clinical history and use of medication were completed by all subjects. Symptoms of abdominal discomfort, abdominal pain, diarrhea, constipation, bloating, flatulence, belching, nausea and overall $\mathrm{Gl}$ symptom burden were scored daily in a 14-day symptom diary. ${ }^{6}$ Furthermore, the presence of $\mathrm{Gl}$ symptoms was assessed using the validated gastrointestinal symptom rating scale (GSRS), consisting of 16 items clustered into five major GI syndromes: abdominal pain, reflux, diarrhea, indigestion and constipation syndrome. $^{33}$

The validated Dutch version (RAND-36) of the Medical Outcomes Study (MOS) 36-item Short Form Health Survey (SF-36) (New England Medical Centre Hospitals, 1991) was used to measure generic health-related QoL, ${ }^{34}$ as described previously. ${ }^{6,35,36}$ Depressive and anxiety symptoms were assessed using the validated Hospital Anxiety and Depression Scale (HADS). 6,37,38

\section{Measurement of biomarkers}

Fecal and blood samples were collected of participating subjects using standardized collection procedures. Venous blood was collected in $\mathrm{K}_{2}$ EDTA (BD Vacutainer) tubes and centrifuged to obtain plasma supernatants, which were aliquoted and frozen at $-80^{\circ} \mathrm{C}$ until further analyses. In the same time period subjects collected stool samples, which were aliquoted and stored at $-80^{\circ} \mathrm{C}$ within 24 hours after defecation.

All markers were measured simultaneously by a commercial partner (Medical Laboratory Dr. Stein \& Colleague, The Netherlands) to avoid additional freeze-thaw cycles. Fecal Calprotectin and HBD2 were measured using commercial enzyme-linked immunosorbent assays (ELISA, by Bühlmann Laboratories, Switserland, and Immunodiagnostik $A G$, Germany, respectively) ${ }^{27,39}$ and $\operatorname{CgA}$ using a commercial radioimmunoassay (RIA, Euro-diagnostika, Sweden). ${ }^{27}$ All test kits were used according to the manufacturers' instructions. Fecal SCFAs, i.e. acetate, propionate, butyrate, valerate and caproate, were measured by gas chromatography-mass spectrometry (GC-MS) according to the method described by Garciá-Villalba et al. ${ }^{40}$ Concentrations of plasma citrulline were determined by high pressure liquid chromatography (HPLC) fluorescence detection as described previously. ${ }^{31}$ Plasma cytokines, i.e. IL-1B, IL-6, IL-8, 
IL-10, IL-12p70 and TNF- $\alpha$, were measured by ProcartaPlex ${ }^{\mathrm{TM}}$ multiplex immunoassay (eBioscience, USA). ${ }^{41,42}$

\section{Statistical analysis}

Statistical analysis was performed using IBM SPSS Statistics version 21.0 (IBM Statistics for Windows, Chicago, IL, USA). We tested differences between females and males within the IBS group and within the healthy control group to assess if differences were IBS-specific.

Differences in baseline characteristics between female and male IBS patients were tested with the Chi-square test for categorical data, the independent-samples t-test for parametric data and the Mann-Whitney-U test for non-parametric continuous data. Correction for multiple testing was performed by multiplying $p$-values times the number of variables tested in that part of the analysis. Linear regression analysis was used to assess the association between gender and biomarkers being significantly altered in IBS and to adjust for possible confounding effects of disease-related factors. Therefore, we first conducted a crude analysis. Secondly the statistically significant results were adjusted for possible confounding factors, using the backward elimination method. The following parameters were included in the analyses: age, BMI, IBS subtype, current smoking status, alcohol use, use of medication, symptom, QoL and HADS scores. All analyses were performed for IBS patients as a whole group. Missing values were excluded list wise. A two-sided $p$-value $<0.05$ was considered to be statistically significant.

\section{RESULTS}

\section{Clinical characteristics}

Samples for biomarker analyses were available from 326 IBS patients ( 233 females and 93 males) and 167 HC (104 females and 63 males). Demographic, lifestyle and clinical data from these subjects are shown in Table 6.1.

For IBS patients, no gender differences were found with regard to age, BMI, subtype of IBS or medication use. In HC males were significantly older $(p<0.05)$ and had a significantly higher BMI $(p<0.001)$ than females. In the IBS group, but not in controls, alcohol use was significantly less frequent among female patients $(p<0.001)$.

With regard to symptom scores, IBS females had higher end of day diary scores for discomfort, pain, bloating, flatulence, overall burden and for abdominal pain syndrome by the GSRS compared to males. After correcting for multiple testing, only discomfort 
remained significantly increased $(p<0.01)$. In the HC group, females scored higher on discomfort, overall burden in the end of day dairy score and on abdominal pain syndrome by GSRS when compared to males, but no significant differences remained after correction for multiple testing. Female IBS patients scored significantly worse compared to IBS males for physical QoL ( $p<0.01)$.

Table 6.1 Baseline characteristics of IBS patients and healthy controls (HC) according to gender.

\begin{tabular}{|c|c|c|c|c|}
\hline Parameter & $\begin{array}{c}\text { Female IBS } \\
n=233\end{array}$ & $\begin{array}{c}\text { Male IBS } \\
n=93\end{array}$ & $\begin{array}{c}\text { Female HC } \\
n=104\end{array}$ & $\begin{array}{c}\text { Male HC } \\
n=63\end{array}$ \\
\hline Age (years) & $41.8 \pm 16.5$ & $45.4 \pm 17.5$ & $40.5 \pm 19.3$ & $47.9 \pm 18.1$ \\
\hline $\mathrm{BMI}\left(\mathrm{kg} / \mathrm{m}^{2}\right)$ & $24.8 \pm 4.7$ & $25.5 \pm 4.3$ & $23.0 \pm 3.8^{\#}$ & $25.5 \pm 3.6$ \\
\hline Current smokers \% & 23.0 & 27.4 & 8.8 & 6.6 \\
\hline Alcohol use \% & $49.8^{\$}$ & 78.3 & 79.0 & 83.9 \\
\hline \multicolumn{5}{|l|}{ Subtypes (\%) } \\
\hline IBS-D & 31.3 & 38.7 & NA & NA \\
\hline IBS-C & 18.9 & 17.2 & NA & NA \\
\hline IBS-M & 41.6 & 38.7 & NA & NA \\
\hline IBS-U & 8.2 & 5.4 & NA & NA \\
\hline \multicolumn{5}{|l|}{ Medication (\%YES): } \\
\hline PPI & 23.0 & 27.3 & 1.9 & 1.6 \\
\hline NSAID & 14.6 & 10.2 & 13.5 & 4.8 \\
\hline SSRI & 14.6 & 14.8 & 3.8 & 0.0 \\
\hline Motility decreasing & 16.4 & 12.5 & 0.0 & 0.0 \\
\hline Motility increasing & 22.1 & 15.9 & 1.0 & 0.0 \\
\hline \multicolumn{5}{|l|}{ Symptom scores } \\
\hline Diary- discomfort & $2.5 \pm 0.7^{\$}$ & $2.2 \pm 0.8$ & $1.2 \pm 0.2$ & $1.1 \pm 0.1$ \\
\hline Diary-pain & $2.3 \pm 0.8$ & $2.1 \pm 0.9$ & $1.1 \pm 0.2$ & $1.0 \pm 0.05$ \\
\hline Diary-constipation & $1.5 \pm 0.7$ & $1.4 \pm 0.6$ & $1.1 \pm 0.2$ & $1.0 \pm 0.2$ \\
\hline Diary-diarrhea & $1.5 \pm 0.6$ & $1.4 \pm 0.6$ & $1.0 \pm 0.1$ & $1.0 \pm 0.1$ \\
\hline Diary-bloating & $2.3 \pm 0.9$ & $2.0 \pm 0.9$ & $1.1 \pm 0.2$ & $1.1 \pm 0.2$ \\
\hline Diary-flatulence & $2.4 \pm 0.8$ & $2.1 \pm 1.0$ & $1.3 \pm 0.5$ & $1.4 \pm 0.4$ \\
\hline Diary-belching & $1.7 \pm 0.8$ & $1.6 \pm 0.8$ & $1.1 \pm 0.3$ & $1.1 \pm 0.3$ \\
\hline Diary-nausea & $1.7 \pm 0.8$ & $1.5 \pm 0.9$ & $1.0 \pm 0.1$ & $1.0 \pm 0.1$ \\
\hline Diary overall burden & $2.6 \pm 0.7$ & $2.3 \pm 0.9$ & $1.1 \pm 0.3$ & $1.0 \pm 0.1$ \\
\hline Abdominal pain syndrome-GSRS & $3.4 \pm 1.2$ & $3.0 \pm 1.2$ & $1.8 \pm 0.8$ & $1.5 \pm 0.5$ \\
\hline Reflux syndrome-GSRS & $2.1 \pm 1.4$ & $2.0 \pm 1.3$ & $1.3 \pm 0.6$ & $1.1 \pm 0.3$ \\
\hline Diarrhea syndrome-GSRS & $3.4 \pm 1.6$ & $3.4 \pm 1.5$ & $1.5 \pm 0.7$ & $1.3 \pm 0.5$ \\
\hline Indigestion syndrome-GSRS & $4.1 \pm 1.4$ & $3.7 \pm 1.3$ & $2.0 \pm 0.9$ & $1.9 \pm 0.8$ \\
\hline Constipation syndrome-GSRS & $3.3 \pm 1.5$ & $3.0 \pm 1.3$ & $1.7 \pm 0.9$ & $1.4 \pm 0.7$ \\
\hline \multicolumn{5}{|l|}{ Questionnaires: } \\
\hline QoL-Physical composite score & $40.0 \pm 10.3^{\$}$ & $44.1 \pm 10.2$ & $54.7 \pm 6.1$ & $54.3 \pm 5.0$ \\
\hline QoL-Mental composite score & $46.5 \pm 11.0$ & $45.8 \pm 11.7$ & $53.2 \pm 8.5$ & $55.4 \pm 6.2$ \\
\hline HADS-A score & $7.0 \pm 3.9$ & $6.9 \pm 3.9$ & $3.9 \pm 2.9$ & $3.2 \pm 2.6$ \\
\hline HADS-D score & $4.5 \pm 3.8$ & $5.0 \pm 4.1$ & $2.0 \pm 2.7$ & $1.7 \pm 2.2$ \\
\hline HADS-A $\geq 8 \%$ & 38.3 & 37.8 & 12.9 & 8.1 \\
\hline HADS-D $\geq 8 \%$ & 21.7 & 23.5 & 6.9 & 3.2 \\
\hline HADS-A and/or $-\mathrm{D} \geq 8 \%$ & 42.7 & 44.4 & 16.8 & 9.7 \\
\hline
\end{tabular}

Continuous data expressed as mean $\pm S D$.

\$Significant difference between female and male IBS patients after correction for multiple testing $(p<0.05)$;

\# Significant difference between female and male healthy controls after correction for multiple testing $(p<0.05)$. NA not applicable. 


\section{Biomarker data}

Fecal markers were available for 264 IBS patients (193 females, 71 males) and 165 HC (102 females and 63 males) (Table 6.2).

Table 6.2 Fecal biomarkers for IBS and HC by gender

\begin{tabular}{lcccc}
\hline Parameter & $\begin{array}{c}\text { Female IBS } \\
\mathbf{n = 1 9 3}\end{array}$ & $\begin{array}{c}\text { Male IBS } \\
\mathbf{n = 7 1}\end{array}$ & $\begin{array}{c}\text { Female HC } \\
\mathbf{n = 1 0 2}\end{array}$ & $\begin{array}{c}\text { Male HC } \\
\mathbf{n}=\mathbf{6 3}\end{array}$ \\
\hline CgA nmol/g & $16.3[8.3 ; 48.5]$ & $14.4[7.2 ; 40.9]$ & $9.4[1.5 ; 124.1]$ & $10.0[2.2 ; 100.7]$ \\
HBD-2 ng/g & $29.3[17.1 ; 43.7]$ & $34.7[20.0 ; 61.7]$ & $35.6[5.0 ; 677.4]$ & $45.5[5.0 ; 427.9]$ \\
Calprotectin ug/g & $42.4[19.3 ; 77.9]$ & $32.4[13.7 ; 81.4]$ & $20.2[5.0 ; 534.0]$ & $25.0[5.0 ; 316.8]$ \\
Acetate umol/g & $30.1[21.0 ; 45.0]^{\$}$ & $40.3[27.4 ; 55.6]$ & $34.1[5.9 ; 76.9]$ & $38.4[10.4 ; 73.4]$ \\
Proprionate umol/g & $8.7[5.4 ; 13.3]^{\$}$ & $11.5[7.0 ; 17.1]$ & $9.3[1.7 ; 27.4]$ & $11.2[2.9 ; 25.6]$ \\
Butyrate umol/g & $7.5[4.6 ; 12.6]$ & $9.5[5.6 ; 15.3]$ & $8.6[1.2 ; 29.8]$ & $10.3[1.3 ; 35.1]$ \\
Valerate umol/g & $1.2[0.8 ; 1.7]$ & $1.5[0.9 ; 2.2]$ & $1.3[0.1 ; 4.5]^{\#}$ & $1.7[0.1 ; 4.3]$ \\
Calproate umol/g & $0.07[0.02 ; 0.50]$ & $0.11[0.02 ; 0.67]$ & $0.3[0.01 ; 3.3]$ & $0.4[0.01 ; 4.3]$ \\
Total SCFA umol/g & $49.3[33.4 ; 72.0]^{\$}$ & $62.6[43.5 ; 97.7]$ & $54.9[9.5 ; 120.0]$ & $64.2[16.3 ; 133.2]$ \\
\hline
\end{tabular}

Data expressed as median [IQR], non-parametric test Mann-Whitney-U.

\$Significant difference between female and male IBS patients after correction for multiple testing $(p<0.05)$;

\# Significant difference between female and male healthy controls after correction for multiple testing $(p<0.05)$

No gender differences were observed for CgA, HBD-2 and calprotectin. However, total SCFA concentrations were significantly lower in female IBS patients compared to male IBS patients. This was also found for acetate and propionate (all $p<0.05$ after correction for multiple testing).

In the healthy controls no significant differences were observed in fecal total SCFA between males and females. However, with respect to valerate, levels were significantly lower in females versus males $(p<0.05$ after correction for multiple testing).

Plasma markers were available for 268 IBS patients ( 188 females, 80 males) and 164 HC (101 females and 63 males) (Table 6.3).

In IBS patients but also in healthy controls, significant lower values of plasma citrulline were found in females compared to males $(p<0.01)$. After correction for multiple testing, the difference only remained significant in the IBS group $(p<0.05)$. IL-10 concentrations were lower in female IBS patients compared to male IBS patients, but this did not remain significant after correction for multiple testing. 
Table 6.3 Plasma biomarkers for IBS patients and healthy controls (HC) according to gender

\begin{tabular}{|c|c|c|c|c|}
\hline Parameter & $\begin{array}{c}\text { Female IBS } \\
n=188\end{array}$ & $\begin{array}{c}\text { Male IBS } \\
n=80\end{array}$ & $\begin{array}{c}\text { Female HC } \\
n=101\end{array}$ & $\begin{array}{c}\text { Male HC } \\
n=63\end{array}$ \\
\hline Citrulline umol/I & $39.1[31.0 ; 47.7]^{\$}$ & $45.6[38.7 ; 55.6]$ & $37.8[20.4 ; 87.6]$ & $41.7[25.8 ; 70.1]$ \\
\hline IL-1 $\beta$ ug/I & $0.1[0.1 ; 1.1]$ & $0.1[0.1 ; 1.1]$ & 0.1 [0.1;19.9] & $0.1[0.1 ; 16.9]$ \\
\hline IL-6 ug/I & $0.2[0.2 ; 0.2]$ & $0.2[0.2 ; 0.2]$ & $0.5[0.2 ; 58.1]$ & $0.5[0.2 ; 71.3]$ \\
\hline IL-8 ug/I & $1.5[0.9 ; 2.4]$ & $1.9[0.9 ; 2.7]$ & $1.6[0.01 ; 23.9]$ & $1.6[0.5 ; 11.4]$ \\
\hline IL-10 ug/I & $0.8[0.6 ; 1.0]$ & $0.9[0.7 ; 1.2]$ & $0.8[0.2 ; 7.2]$ & $0.8[0.2 ; 6.7]$ \\
\hline IL-12 ug/I & $2.1[1.1 ; 3.0]$ & $2.1[1.2 ; 2.8]$ & $1.2[0.1 ; 38.4]$ & $0.7[0.1 ; 15.8]$ \\
\hline IL-10/IL-12 ratio & $0.4[0.2 ; 0.7]$ & $0.5[0.3 ; 0.9]$ & $0.6[0.04 ; 30.6]$ & $0.7[0.1 ; 35.4]$ \\
\hline TNF $\alpha$ ug/l & $0.1[0.1 ; 3.5]$ & $0.1[0.1 ; 3.4]$ & $0.1[0.1 ; 42.6]$ & $0.1[0.1 ; 87.8]$ \\
\hline
\end{tabular}

Data expressed as median [IQR], non-parametric test Mann-Whitney-U.

${ }^{\$}$ Significant difference between female and male IBS patients after correction for multiple testing $(p<0.05)$

\section{Linear regression analysis}

Linear regression analysis was performed for fecal SCFA levels and plasma citrullin to correct for possible confounding factors on the gender differences in IBS patients.

Linear regression analysis for total SFCAs showed a $\beta$ of 19.1 (95\% Cl: 10.0;28.3, $\mathrm{p}<0.001)$ reflecting lower total fecal SFCA concentrations in females compared to males. After expanding the model with possibly confounding factors, the total SFCA levels remained significantly lower in female compared to male IBS patients ( $\beta$ 15.8, $95 \% \mathrm{Cl}: 4.1 ; 27.5 \mathrm{p}=0.008)$. Backward elimination of least statistically significant cofactors, revealed that only BMI showed a significant association with the total SFCA concentrations with a $\beta$ of $1.9(95 \% \mathrm{Cl}: 1.0 ; 2.8, p<0.001)$, pointing to a higher $\mathrm{BMI}$ generating higher SFCA concentrations without influencing the difference between female and male IBS patients. No influence could be detected of medication use, IBS subtype, symptom scores, anxiety and/or depression scores nor for QoL scores.

Linear regression analysis with citrulline as dependent factor showed a $\beta 7.6(95 \% \mathrm{Cl}$ : $4.5 ; 10.8, p<0.001$ ) reflecting a lower citrulline concentration in female compared to male IBS patients. After expanding the model with confounding factors, this remained significant with a $\beta$ of 6.8 (95\% Cl: $2.7 ; 10.9, p=0.001)$. Backward elimination of least statistically significant co-factors revealed that age and NSAID use had a significant association with higher citrulline concentrations, but both did not influence the difference between female and male IBS patients. No influence could be detected of other medication use, IBS subtype, symptom scores, anxiety and/or depression scores nor for QoL scores. After explorative linear regression analysis in the HC group for citrulline, the difference in citrulline concentration in $\mathrm{HC}$ was also significantly influenced by age and NSAID use, without influencing the gender difference in the HC group (data not shown). 


\section{DISCUSSION}

It was found that female IBS patients had significantly higher discomfort diary scores and more impaired physical QoL compared to male IBS patients. We also observed a significant decrease in fecal SCFA concentration in female compared to male IBS patients, but not in healthy controls, pointing to gender related differences in colonic metabolism and microbiota in female IBS patients. After correction for potential confounders, BMI was found to significantly affect the SCFA concentrations without influencing the gender difference.

For the present analysis, we evaluated consecutive IBS patients from the Maastricht-IBS cohort. In line with previous studies, ${ }^{5-7}$ we confirmed that symptom scores for discomfort were significantly higher in female compared to male IBS patients. In addition, physical QoL was significantly more impaired in female versus male IBS patients. We did not observe differences in IBS subtype distribution between females and males, although previous studies have pointed towards higher frequency of the IBS-C subtype among the female IBS population. ${ }^{3,4}$

This is the first study focusing on gender differences in potential pathophysiological factors involved in IBS. We screened for differences in biomarkers associated with various pathophysiological mechanisms. No gender specific differences were found in biomarkers pointing to low grade inflammation (calprotectin, cytokines). Only IL-10 was significantly lower in IBS females, but did not remain significant after correction for multiple testing. Furthermore, both fecal $\mathrm{CgA}$ as a marker for intestinal neuroendocrine cell activity, and HBD-2, as antimicrobial peptide, released upon inflammation or pathogen exposure and reflecting host-microbe interaction, showed no IBS specific gender differences.

Citrulline was found to be significantly different between females and males both in IBS and controls. Plasma citrulline concentration is a quantitative marker of enterocyte mass and functional absorptive capacity of the small intestine and the difference was not found to be disease specific. ${ }^{31}$

After correction for multiple testing the citrulline difference remained significant only in the IBS group. Linear regression analysis showed a correlation of citrulline with age and NSAID use in both IBS and HC without significantly affecting the gender difference. Older subjects have higher citrulline concentrations. This has been reported previously and is not an IBS-specific feature. ${ }^{31}$ A significant gender difference was found for the total SCFA concentration, being significantly lower in female versus male IBS patients but not in $\mathrm{HC}$. The findings remained significant after correction for possible confounding factors in a multivariate analysis. Data on SCFAs in IBS are limited. In one study, lower concentrations of total SCFA were found in IBS-D patients compared to 
controls. ${ }^{43}$ Within a heterogeneous IBS population, no differences in fecal SCFAs were found between a subgroup undergoing dietary restriction of fermentable short chain carbohydrates compared to a subgroup maintaining their normal dietary habits, neither at baseline nor after dietary intervention. ${ }^{44}$ In none of the studies gender difference has been assessed. However, gender differences in fecal SCFA concentrations in line with our data have been reported previously. In healthy subjects and in patients with microscopic colitis, but also in animal studies, higher serum and fecal SCFA concentration have been found in males compared to females, ${ }^{45-47}$ being independent of dietary intake. ${ }^{46}$

SCFA are produced in the human colon by bacterial fermentation of complex carbohydrates not digested in the small intestine. ${ }^{29}$ A decrease in fecal SCFAs, as observed in female IBS patients, should be considered as potentially unfavorable. SCFAs, especially butyrate, have been found to influence colonic motility, prevent overgrowth of pathogens, inhibit inflammation and carcinogenesis, reinforce various components of the colonic defence barrier and decrease oxidative stress. ${ }^{29,46}$ The production of SCFA is dependent on the microbiota composition and its functional capacity. ${ }^{48}$ It is generally accepted that the intestinal microbial composition in IBS is different from controls. However, a specific microbial signature in IBS has not been identified up to now. ${ }^{49}$ This may partly be due to differences in molecular methods that have been employed and on the heterogeneity of IBS patients included. Variations in microbial composition related to gender, IBS subtype, host genetics and presence of comorbidities have not been taken into account. ${ }^{50,51}$

Data on bacterial profiles in females and males are limited. One study clearly found differences in microbiota composition between females and males irrespective of dietary pattern, both in humans and in animals. ${ }^{52}$ The microbiota composition and is metabolic activity may be affected by gender, due to for example by the influence of sex hormones, ${ }^{53}$ but further studies are needed.

Although a few studies have pointed to a gender difference in both SCFAs and microbiota in healthy subjects irrespective of diet, ${ }^{46,52}$ dietary intake does influence SCFA production ${ }^{29}$ and possibly also microbiota composition. Unfortunately, data on microbiota and diet were not available in our study. IBS patients are known to modulate their dietary intake based on perceived food intolerances. ${ }^{54}$ Especially intake of fermentable carbohydrates is reported to provoke symptoms. ${ }^{55}$ Furthermore, it should be noted that most SCFAs that have been produced are rapidly absorbed in the proximal colon, and therefore we cannot exclude the lower SCFA concentrations to result from increased absorption in females.

Linear regression analysis did not show an influence of symptom, QoL and anxiety/depression scores on the SCFA concentrations and the gender difference 
detected. However, our data showed that a higher BMI did result in higher fecal SCFA concentrations, although the gender difference remained significant.

This finding is in line with studies reporting colonic fermentation and the microbiota composition to be altered in obese humans and animals, i.e. being more effective in converting carbohydrates into SCFA. ${ }^{46,56}$ The increased SCFA production in obese subjects remained significant after correction for age and gender. ${ }^{57}$ Although in the present study, BMI did not differ between male and female IBS patients, a slightly higher BMI was found in female IBS compared to female HC subjects. The influence of $\mathrm{BMI}$ on IBS symptomatology however, is not clear. In our study, we could not find a higher BMI to be associated with higher symptom scores (data not shown).

Bjorkman et al. have suggested that gender differences in IBS patients are related to general gender structures and cultural norms, rather than to differences in the disorder per se or in the underlying pathophysiological mechanisms. ${ }^{8}$

Our data confirm gender differences in IBS phenotype with a potential role of microbial activity as SCFA concentrations were decreased in female IBS patients compared to male IBS patients. More detailed analyses of microbiota and/or colonic metabolism with focus on gender differences in IBS should be undertaken. 


\section{REFERENCES}

1. Heitkemper MM, Jarrett ME. Update on irritable bowel syndrome and gender differences. Nutr Clin Pract. 2008;23:275-83.

2. Schmulson $M$, Adeyemo $M$, Gutiérrez-Reyes $G$, Charúa-Guindic L, Farfán-Labonne B, Ostrosky-Solis $F$, Díaz-Anzaldúa A, Medina L, Chang L. Differences in gastrointestinal symptoms according to gender in Rome II positive IBS and dyspepsia in a Latin American population. Am J Gastroenterol. 2010;105: 925-32.

3. Anbardan SJ, Daryani NE, Fereshtehnejad SM, Taba Taba Vakili S, Keramati MR, Ajdarkosh H. Gender Role in Irritable Bowel Syndrome: A Comparison of Irritable Bowel Syndrome Module (ROME III) Between Male and Female Patients. J Neurogastroenterol Motil. 2012;18:70-7.

4. Herman J, Pokkunuri V, Braham L, Pimentel M. Gender distribution in irritable bowel syndrome is proportional to the severity of constipation relative to diarrhea. Gend Med. 2010;7:240-6.

5. Lee OY, Mayer EA, Schmulson M, Chang L, Naliboff B. Gender-related differences in IBS symptoms. Am J Gastroenterol. 2001;96:2184-93.

6. Thijssen AY, Jonkers DM, Leue $C$, van der Veek PP, Vidakovic-Vukic M, van Rood YR, et al. Dysfunctional cognitions, anxiety and depression in irritable bowel syndrome. J Clin Gastroenterol. 2010;44:e236-41.

7. Adeyemo MA, Spiegel BM, Chang L. Meta-analysis: do irritable bowel syndrome symptoms vary between men and women? Aliment Pharmacol Ther. 2010;32:738-55.

8. Bjorkman I, Jakobsson Ung E, Ringstrom G, Tornblom H, Simren M. More similarities than differences between men and women with irritable bowel syndrome. Neurogastroenterol Motil. 2015;27:796-804.

9. Chang L, Toner BB, Fukudo S, Guthrie E, Locke GR, Norton NJ, Sperber AD. Gender, age, society, culture, and the patient's perspective in the functional gastrointestinal disorders. Gastroenterology. 2006;130:1435-46.

10. Chang L, Heitkemper MM. Gender differences in irritable bowel syndrome. Gastroenterology. 2002;123:1686-701.

11. Whitehead WE, Palsson OS, Levy RR, Feld AD, Turner M, Von Korff M. Comorbidity in irritable bowel syndrome. Am J Gastroenterol. 2007;102:2767-76.

12. Meleine M, Matricon J. Gender-related differences in irritable bowel syndrome: potential mechanisms of sex hormones. World J Gastroenterol WJG. 2014;20:6725-43.

13. Barbara G. Mucosal barrier defects in irritable bowel syndrome. Who left the door open? Am J Gastroenterol. 2006;101:1295-8.

14. Parkes GC, Brostoff J, Whelan K, Sanderson JD. Gastrointestinal microbiota in irritable bowel syndrome: their role in its pathogenesis and treatment. Am J Gastroenterol. 2008;103:1557-67.

15. Azpiroz F, Bouin M, Camilleri M, Mayer EA, Poitras P, Serra J, Spiller RC. Mechanisms of hypersensitivity in IBS and functional disorders. Neurogastroenterol Motil. 2007;19(1 Suppl):62-88.

16. Camilleri M, Di Lorenzo C. Brain-gut axis: from basic understanding to treatment of IBS and related disorders. J Pediatr Gastroenterol Nutr 2012;54:446-53.

17. Qin HY, Cheng CW, Tang XD, Bian ZX. Impact of psychological stress on irritable bowel syndrome. World J Gastroenterol WJG. 2014;20:14126-31.

18. Camilleri M, Heading RC, Thompson WG. Clinical perspectives, mechanisms, diagnosis and management of irritable bowel syndrome. Aliment Pharmacol Ther. 2002;16:1407-30.

19. Spiller RC. Irritable bowel syndrome: gender, infection, lifestyle or what else? Dig Dis. 2011;29:215-21.

20. Faresjo A, Grodzinsky E, Hallert C, Timpka T. Patients with irritable bowel syndrome are more burdened by co-morbidity and worry about serious diseases than healthy controls--eight years follow-up of IBS patients in primary care. BMC Public Health. 2013;13:832.

21. Tang YR, Yang WW, Wang YL, Lin L. Sex differences in the symptoms and psychological factors that influence quality of life in patients with irritable bowel syndrome. Eur J Gastroenterol Hepatol. 2012;24:702-7.

22. Kim DY, Camilleri M. Serotonin: a mediator of the brain-gut connection. Am J Gastroenterol. 2000;95:2698-709.

23. Berger M, Gray JA, Roth BL. The expanded biology of serotonin. Ann Rev Med. 2009;60: 355-66. 
24. Mujagic Z, Ludidi S, Keszthelyi D, Hesselink MA, Kruimel JW, Lenaerts K, Hanssen NM, Conchillo JM, Jonkers DM, Masclee AA. Small intestinal permeability is increased in diarrhoea predominant IBS, while alterations in gastroduodenal permeability in all IBS subtypes are largely attributable to confounders. Aliment Pharmacol Ther. 2014;40:288-97.

25. Ludidi S, Mujagic Z, Jonkers D, Keszthelyi D, Hesselink M, Kruimel J, Conchillo J, Masclee A. Markers for visceral hypersensitivity in patients with irritable bowel syndrome. Neurogastroenterol Motil. 2014;26:1104-11.

26. Langhorst J, Elsenbruch S, Koelzer J, Rueffer A, Michalsen A, Dobos GJ. Noninvasive markers in the assessment of intestinal inflammation in inflammatory bowel diseases: performance of fecal lactoferrin, calprotectin, and PMN-elastase, CRP, and clinical indices. Am J Gastroenterol. 2008;103:162-9.

27. Ohman L, Stridsberg M, Isaksson S, Jerlstad P, Simren M. Altered levels of fecal chromogranins and secretogranins in IBS: relevance for pathophysiology and symptoms? Am J Gastroenterol. 2012;107:440-7.

28. Tana C, Umesaki Y, Imaoka A, Handa T, Kanazawa M, Fukudo S. Altered profiles of intestinal microbiota and organic acids may be the origin of symptoms in irritable bowel syndrome. Neurogastroenterol Motil. 2010;22:512-9.

29. Hamer HM, Jonkers D, Venema K, Vanhoutvin S, Troost FJ, Brummer RJ. Review article: the role of butyrate on colonic function. Aliment Pharmacol Ther. 2008;27:104-19.

30. Facer P, Bishop AE, Lloyd RV, Wilson BS, Hennessy RJ, Polak JM. Chromogranin: a newly recognized marker for endocrine cells of the human gastrointestinal tract. Gastroenterology. 1985;89:1366-73.

31. Crenn P, Messing B, Cynober L. Citrulline as a biomarker of intestinal failure due to enterocyte mass reduction. Clin Nutr. 2008;27:328-39.

32. Bashashati M, Rezaei N, Shafieyoun A, McKernan DP, Chang L, Öhman L, Quigley EM, Schmulson M, Sharkey KA, Simrén M. Cytokine imbalance in irritable bowel syndrome: a systematic review and metaanalysis. Neurogastroenterol Motil. 2014;26:1036-48.

33. Svedlund J, Sjodin I, Dotevall G. GSRS--a clinical rating scale for gastrointestinal symptoms in patients with irritable bowel syndrome and peptic ulcer disease. Dig Dis Sci. 1988;33:129-34.

34. van der Zee KI SR. Het meten van de algemene gezonsheidstoestand met de RAND-36, een handleiding. [Assessment of general health status with the RAND-36; guidebook]1993.

35. Creed F, Ratcliffe J, Fernandez L, Tomenson B, Palmer S, Rigby C, et al. Health-related quality of life and health care costs in severe, refractory irritable bowel syndrome. Ann Intern Med. 2001;134:860-8.

36. Farivar SS, Cunningham WE, Hays RD. Correlated physical and mental health summary scores for the SF-36 and SF-12 Health Survey, V.I. Health Qual Life Outcomes. 2007;5:54.

37. Bjelland I, Dahl AA, Haug TT, Neckelmann D. The validity of the Hospital Anxiety and Depression Scale. An updated literature review. J Psychosom Res. 2002;52:69-77.

38. Zigmond AS, Snaith RP. The hospital anxiety and depression scale. Acta Psychiatr Scand. 1983;67: 361-70.

39. Langhorst J, Junge A, Rueffer A, Wehkamp J, Foell D, Michalsen A, et al. Elevated human beta-defensin2 levels indicate an activation of the innate immune system in patients with irritable bowel syndrome. Am J Gastroenterol. 2009;104:404-10.

40. Garcia-Villalba R, Gimenez-Bastida JA, Garcia-Conesa MT, Tomas-Barberan FA, Espin JC, Larrosa M. Alternative method for gas chromatography-mass spectrometry analysis of short-chain fatty acids in faecal samples. J Sep Sci. 2012;35:1906-13.

41. Farzi A, Reichmann F, Meinitzer A, Mayerhofer R, Jain P, Hassan AM, et al. Synergistic effects of NOD1 or NOD2 and TLR4 activation on mouse sickness behavior in relation to immune and brain activity markers. Brain Behav Immun. 2015;44:106-20.

42. Whelan RA, Rausch S, Ebner F, Gunzel D, Richter JF, Hering NA, et al. A transgenic probiotic secreting a parasite immunomodulator for site-directed treatment of gut inflammation. Mol Ther. 2014;22: 1730-40.

43. Treem WR, Ahsan N, Kastoff G, Hyams JS. Fecal short-chain fatty acids in patients with diarrheapredominant irritable bowel syndrome: in vitro studies of carbohydrate fermentation. J Pediatr Gastroenterol Nutr. 1996;23:280-6. 
44. Staudacher HM, Lomer MC, Anderson JL, Barrett JS, Muir JG, Irving PM, et al. Fermentable carbohydrate restriction reduces luminal bifidobacteria and gastrointestinal symptoms in patients with irritable bowel syndrome. J Nutr. 2012;142:1510-8.

45. Jakobsdottir G, Bjerregaard JH, Skovbjerg H, Nyman M. Fasting serum concentration of short-chain fatty acids in subjects with microscopic colitis and celiac disease: no difference compared with controls, but between genders. Scand J Gastroenterol 2013;48:696-701.

46. McOrist AL, Miller RB, Bird AR, Keogh JB, Noakes M, Topping DL, Vonion MA. Fecal butyrate levels vary widely among individuals but are usually increased by a diet high in resistant starch. J Nutr. 2011;141:883-9.

47. Karunasena E, McMahon KW, Chang D, Brashears MM. Host responses to the pathogen Mycobacterium avium subsp. paratuberculosis and beneficial microbes exhibit host sex specificity. Appl Environ Microbiol. 2014;80:4481-90.

48. Macfarlane S, Macfarlane GT. Regulation of short-chain fatty acid production. Proc Nutr Soc. 2003;62:67-72.

49. Rajilic-Stojanovic M, Jonkers DM, Salonen A, Hanevik K, Raes J, Jalanka J, de Vos WM, Manichanh C, Golic N, Enck P, Philippou E, Iraqi FA, Clarke G, Spiller RC, Penders J. Intestinal Microbiota And Diet in IBS: Causes, Consequences, or Epiphenomena? Am J Gastroenterol. 2015;110:278-87.

50. Pimentel M, Talley NJ, Quigley EM, Hani A, Sharara A, Mahachai V. Report from the multinational irritable bowel syndrome initiative 2012. Gastroenterology. 2013;144:e1-5.

51. Kennedy PJ, Cryan JF, Dinan TG, Clarke G. Irritable bowel syndrome: a microbiome-gut-brain axis disorder? World J Gastroenterol WJG. 2014;20:14105-25.

52. Bolnick DI, Snowberg LK, Hirsch PE, Lauber CL, Org E, Parks B, Lusis AJ, Knight R, Caporaso JG, Svanbäck R. Individual diet has sex-dependent effects on vertebrate gut microbiota. Nat Commun. 2014;5:4500.

53. Yurkovetskiy L, Burrows M, Khan AA, Graham L, Volchkov P, Becker L, Antonopoulos D, Umesaki Y, Chervonsky AV. Gender bias in autoimmunity is influenced by microbiota. Immunity. 2013;39:400-12.

54. Monsbakken KW, Vandvik PO, Farup PG. Perceived food intolerance in subjects with irritable bowel syndrome-- etiology, prevalence and consequences. Eur J Clin Nutr. 2006;60:667-72.

55. Mansueto P, Seidita A, D'Alcamo A, Carroccio A. Role of FODMAPs in Patients With Irritable Bowel Syndrome: A Review. Nutr Clin Pract. 2015..

56. Fernandes J, Su W, Rahat-Rozenbloom S, Wolever TM, Comelli EM. Adiposity, gut microbiota and faecal short chain fatty acids are linked in adult humans. Nutr Diabetes. 2014;4:e121.

57. Schwiertz A, Taras D, Schäfer K, Beijer S, Bos NA, Donus C, Hardt PD. Microbiota and SCFA in lean and overweight healthy subjects. Obesity (Silver Spring). 2010;18:190-5. 


\section{CHAPTER 7}

Symptoms in patients with Ulcerative Colitis in remission are associated with visceral hypersensitivity and mast cell activity

E.A. van Hoboken, A.Y. Thijssen, R. Verhaaren, P.P.J. van der Veek, F.A. Prins, H.W. Verspaget, A.A.M. Masclee 


\section{ABSTRACT}

\section{Background \& Aims}

Patients with Ulcerative Colitis in remission (UCR) frequently report Irritable Bowel Syndrome (IBS-)like symptoms. Recent studies have pointed to the role of mast cells in mediating visceral hypersensitivity in IBS. We hypothesized that visceral hypersensitivity is frequently present in patients with UCR and is related to the quantity and activity of mast cells in the sigmoid mucosa.

\section{Material and methods}

A group of 17 controls and 19 patients with UCR were studied. Rectal compliance and perception were measured by electronic barostat. Sigmoid biopsies were taken to quantify the amount of mast cells, degranulating mast cells and mast cells in close proximity to mucosal nerve endings.

\section{Results}

Visceroperception was significantly increased in UCR $(p<0.05)$ versus controls. Rectal perception correlated positively with IBS-like symptoms in UCR $(r=0.69 ; p<0.05)$. The amount of mucosal mast cells (per 100 crypts) was significantly increased in UCR vs. controls: $228 \pm 20$ vs. $163 \pm 18(p<0.05)$. In the UCR patients a higher percentage of mucosal mast cells was in close proximity to nerve endings ( $58 \pm 4$ vs. $38 \pm 3 \%$ in controls; $\mathrm{p}<0.05)$ or was degranulating $(40 \pm 7$ vs. $16 \pm 4 \%$ in controls; $p<0.05)$. There was a significant but weak correlation between quantity of mucosal mast cells and pain perception $(r=0.32 ; p<0.05)$.

\section{Conclusion}

Rectal hypersensitivity is associated with mucosal presence and activation of mast cells and with IBS-like symptoms in patients with UCR. 


\section{INTRODUCTION}

Irritable bowel syndrome (IBS) is a functional bowel disorder characterized by abdominal discomfort or pain associated with disordered defecation. ${ }^{1}$ Visceral hypersensitivity is a hallmark of IBS $^{2}$ and is present in up to $60 \%$ of patients. ${ }^{3}$ The mechanisms underlying visceral hypersensitivity are not completely understood. Several authors have pointed to persistent low grade intestinal inflammation with release of mediators and triggering of receptors on nerve endings in IBS patients. While routine histology does not reveal significant mucosal abnormalities, quantitative histology and immunohistochemistry point to subtle morphologic changes in IBS. ${ }^{4-8}$ The observation that a subset of IBS patients develop symptoms after an episode of acute gastroenteritis $^{9-11}$ underlines the role of inflammation and inflammation related changes in the pathophysiology of IBS. Mast cells frequently persist in post inflammatory conditions and are able to release a variety of inflammatory mediators. Barbara et al were the first to demonstrate that in IBS patients: 1) the number of mast cells in the rectocolonic mucosa is significantly increased 2) mast cells are more often found in a degranulating state 3 ) mast cells are more often located in close proximity to mucosal nerve endings and 4) the amount of mast cells in close proximity to nerves significantly correlates with abdominal symptoms. These observations indicate that colonic mast cell infiltration and mediator release in proximity to mucosal nerves may contribute to abdominal symptoms and to hypersensitivity in IBS patients. ${ }^{5,8}$

Inflammatory Bowel Disease (IBD) results from a genetic predisposition with an inappropriate and ongoing activation of the innate and adaptive mucosal immune system with changes in barrier function driven by luminal microbiota and various antigens. ${ }^{12}$ In patients with active Ulcerative Colitis (UC) the number of inflammatory cells, including mast cells in the colorectal mucosa is significantly increased. ${ }^{13}$ Patients with active UC experience symptoms such as pain, diarrhea and blood loss that correlate with endoscopic and histological severity of the disease. ${ }^{14}$ Remarkably, in a previous study it was shown that active UC was not associated with visceral hypersensitivity, possibly due to induction of anti-nociceptive pathways. ${ }^{15}$ However, a substantial subset of at least on third of UC patients that are in remission report symptoms in absence of any endoscopic sign of disease activity. ${ }^{16}$ The situation observed in these patients resembles that of patients with IBS. We speculate that the previous inflammatory process of UC has resulted in visceral hypersensitivity, which persists even though the inflammatory infiltrate has regressed and gut architecture has been restored. ${ }^{13,17}$ While inflammatory cells disappear mast cells remain present in peripheral tissue when the inflammatory process has gone into remission. We hypothesize that hypersensitivity to rectal distension is present in a substantial percentage of patients with UC in remission (UCR), with at mucosal level a persistently higher number of mast cells in proximity to nerve endings, as is found in IBS. 
Therefore we evaluated a) visceroperception (b) mast cell density and mast cell activation c) relation between visceroperception and mast cells and d) proximity of mast cells to nerve endings in patients with ulcerative colitis in remission in comparison with a group of non-UC controls.

\section{METHODS}

\section{Subjects}

Participants were recruited among 1) UC patients scheduled for colonoscopy for surveillance of ulcerative colitis and 2) healthy subjects scheduled for colonoscopy for follow up of polyps or with a family history of colon cancer. Age was between 18 and $65 \mathrm{yrs}$ and BMI was below $30 \mathrm{~kg} / \mathrm{m}^{2}$. Subjects were excluded if they had undergone major abdominal surgery or had significant comorbidity.

In the patients with UC, disease activity, based on the Mayo Score ${ }^{18}$ had to be zero, when otherwise patients were excluded. In the controls and UCR patients the presence of any inflammatory condition was excluded based on histology and no findings other than polyps were observed.

\section{Study design}

After informed consent was given, patients were asked to complete a 14-day symptom diary card at home. Symptoms of discomfort, pain, constipation, diarrhea and bloating were scored daily on a 5-point Likert Scale. By adding the scores of the five items, a mean symptom score was calculated and used as an indicator for the impact of IBS-like symptoms. This method has previously been described by our group (2).

\section{Barostat measurements}

An electronic barostat (Synectics Visceral Stimulator, Synectics Medical, Skovlunde, Denmark) was used to measure rectal compliance and visceroperception, as described previously. ${ }^{19}$ Pressure $(\mathrm{mmHg})$, volume $(\mathrm{ml})$ and compliance $(\mathrm{ml} / \mathrm{mmHg})$ were continuously monitored. Each subject underwent a staircase ramp distension

procedure in supine position. Pressure distensions started at $0 \mathrm{mmHg}$ and were increased by $1 \mathrm{mmHg}$ every 30 seconds until a maximum of $40 \mathrm{mmHg}$ was reached. At all even pressures patients were asked to rate sensations of urge/discomfort and rectal pain on a $100 \mathrm{~mm}$ Visual Analog Scale (VAS) ( $0=$ none, 100=intolerable). Patients and volunteers were not aware of the design of the barostat protocol to exclude anticipation with occurrence of specific sensations. 


\section{Endoscopy}

Endoscopy and barostat procedure were performed on the same day. The barostat procedure was performed first, the endoscopy was performed at least two hours after the barostat procedure. Bowel preparation started the day before the barostat and the endoscopy and consisted of 4 liter of a macrogol-solution. Colonoscopy was performed up to the cecum. The endoscopist assessed macroscopic disease activity. Biopsies were taken for routine surveillance/ disease activity assessment and extra biopsies from the sigmoid were taken for later analysis with electron-microscopy.

\section{Immunohistochemistry}

Embedded biopsies were cut on a microtome at $5 \mu \mathrm{m}$ and placed on APES coated slides and incubated with Mouse-Monoclonal Antibodies against tryptase (DakoCytomation), diluted at $1: 1600$ in a PBS/BSA $1 \%$ solution.

Following thorough washing in PBS, slides were reincubated for $30 \mathrm{~min}$ at room temperature with the Envision + System-HRP labeled polymer Anti-mouse (DakoCytomation), undiluted. After a second washing in PBS, slides were stained using Vector Novared Substrate (Vector Labatories).

\section{Mast cell counts}

The investigators who scored mast cell numbers, were blinded with respect to clinical data. From each slide, various pictures were taken from well stained and cut areas (light microscope, $40 \mathrm{x}$ magnification) in areas of lamina propria and in the presence of crypts. From these, five pictures were randomly taken for analysis. The ratio of mast cells per 100 crypts was calculated by counting the amount of mast cell divided by the amount of crypts (and multiplied by 100).

\section{Electron microscopy}

Tissue blocks were fixed with $1 \%$ paraformaldehyde $1.5 \%$ glutaraldehyde in 0.1 cacodylate buffer $(\mathrm{pH} 7.4)$ and post fixed with $1 \%$ osmium tetroxide, embedded in Epon, and ultrathin sectioned $(90 \mathrm{~nm})$ with a Leica Ultracut UCT ultramicrotome. Ultrathin sections were collected on copper grids. The sections were post-stained with uranyl acetate and Reynold's lead citrate (both Sigma) and were examined using a JEOL JEM-1011 electron microscope operating at $60 \mathrm{kV}$. Images were digitalized using a MegaView III camera.

The entire copper grids were screened for the presence of mast cells using a magnification of 1500 . Whenever mast cells were identified, magnification was increased to 5000 and pictures of the mast cell and its direct environment were taken (Figure 7.1). Afterwards mast cell pictures were evaluated by two separate, blinded, 
investigators. In addition to counting the number of mast cells, close proximity ( $<5 \mu \mathrm{m})$ of mast cells to a nerve ending and the number of degranulating mast cells was scored. ${ }^{5}$

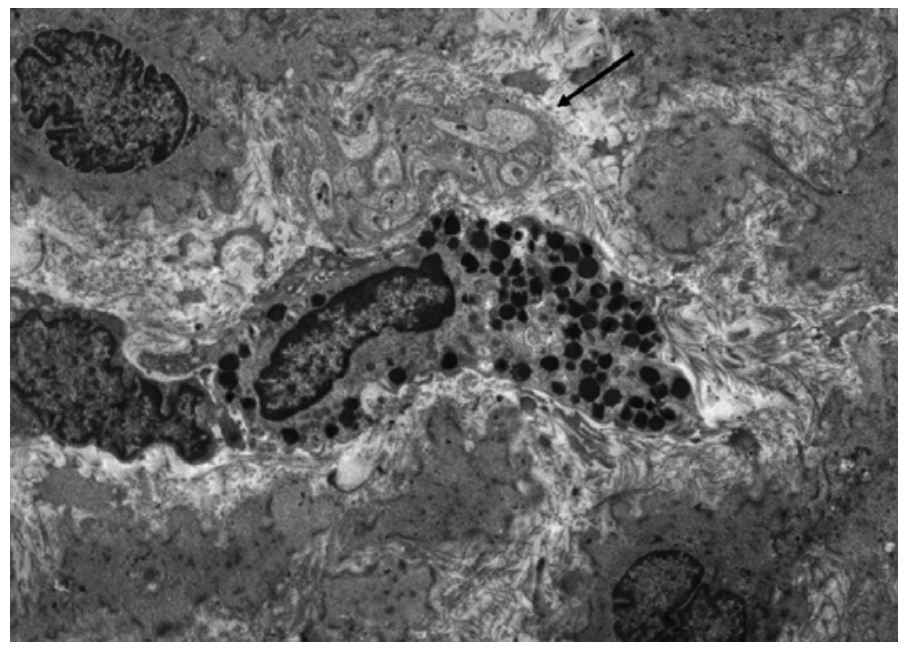

Figure 7.1 Mast cell with Electron Microscopy: Electron microscopic image of mast cell in proximity with nerve ending (arrow) in sigmoid mucosa of a healthy volunteer. Magnification 5000x.

\section{Data analysis and statistics}

For barostat data the mean volume in the balloon during each pressure level was calculated. Compliance $(\mathrm{ml} / \mathrm{mmHg})$ was defined as the increase in balloon volume between the two consecutive pressure levels at the steepest part of the pressurevolume curve, divided by two. For each distension step of each individual subject the highest perception score was used of either urge or discomfort or pain.

Differences in perception during stepwise isobaric distensions was analyzed, using a Mixed Model analysis, corrected for multiple testing.

Light-microscopy mast cell counts (n/100 crypts) were averaged per participant over five pictures. Both the amount of mast cells at a distance of $<5 \mu \mathrm{m}$ from nerve endings and the amount of degranulating mast cells (scored using electron microscopy) are presented as percentages of the total amount of mast cells, counted per copper grid.

Correlations between mast cell parameters and sensitivity parameters were tested using the Spearman's correlation coefficient. Multiple testing was corrected for, by using the Bonferroni correction. In addition, mast cell parameters were compared within the UCR group between the $50 \%$ with highest and $50 \%$ with lowest perception scores. 
SPSS 16.0 was used for statistical analysis. Data was tested for normality with the Kolmogorov-Smirnov test. In case of normal distribution, chi-square test and independent t-test were used to compare groups. Correlations were analyzed using the Pearson's correlation coefficient. In case of non-parametric distribution of data, equivalent non-parametric tests were used.

Data were expressed as mean ( \pm SEM) or number (percentage) when appropriate. The level of significance was set at $p<0.05$.

\section{Ethical considerations}

This human intervention study had been approved by the Leiden University Medical Center Ethics Committee (Leiden, The Netherlands), and conducted in full accordance with the principles of the Declaration of Helsinki. All particpants had given written informed consent.

\section{RESULTS}

\section{Patient characteristics}

Characteristics of the two groups are given in Table 7.1. None of the controls had abdominal complaints or a defecation disorder. In six of the controls a total of seventeen polyps (adenomatous and hyperplastic) were found and removed. None of the polyps had characteristics of advanced adenomas. In the controls no signs of macro- or microscopic inflammation were present.

Table 7.1 Clinical, endoscopic and histological characteristics of controls and UCR patients

\begin{tabular}{lcc}
\hline Characteristic & $\begin{array}{c}\text { Controls } \\
(\mathbf{n = 1 7})\end{array}$ & $\begin{array}{c}\text { UCR } \\
(\mathbf{n = 1 9})\end{array}$ \\
\hline Age (yrs) & $44 \pm 3$ & $50 \pm 3$ \\
Male/Female-ratio & $8 / 9$ & $10 / 9$ \\
Years after UC-diagnosis & $\mathrm{NA}$ & $17 \pm 2$ \\
Previous abdominal surgery (n) & 0 & 0 \\
Pancolitis & $\mathrm{NA}$ & $37 \%$ \\
Years between UC-diagnosis and establishment of pancolitis & & $2 \pm 1$ \\
Mayo-score & $0 \pm 0$ & $0 \pm 0$ \\
Microscopic inflammation (Truelove score $>1$ ) & $0 / 17$ & $0 / 19$ \\
5-ASA medication & $0 \%$ & $84 \%$ \\
Use of Immuno-suppressants & $0 \%$ & $21 \%$ \\
\hline
\end{tabular}




\section{Barostat Measurements}

\section{Compliance}

The compliance of the rectum did not significantly differ between UCR and controls: $28 \pm 4 \mathrm{ml} / \mathrm{mmHg}$ vs $21 \pm 2 \mathrm{ml} / \mathrm{mmHg}$ respectively.

\section{Perception}

All subjects tolerated the full distension range up to $40 \mathrm{mmHg}$.

As shown in Figure 7.2, perception during isobaric distensions was significantly higher in patients with UCR vs. controls ( $p<0.05$; mixed model analysis). Differences in perception were more pronounced in the pressure range from $32-40 \mathrm{mmHg}(55 \pm 6$ in controls vs. $70 \pm 4$ in UCR-patients; $p<0.05)$. In he UCR group eleven subjects $(58 \%)$ had perception scores (at distension from $32-40 \mathrm{mmHg}$ ) above the upper limit of the confidence interval for controls [51 mm-79 mm]. In UCR patients perception scores during distensions, ranging from $32-40 \mathrm{mmHg}$, correlated significantly with mean symptom scores, derived from the diaries $(r=0.69 ; p<0.05)$.

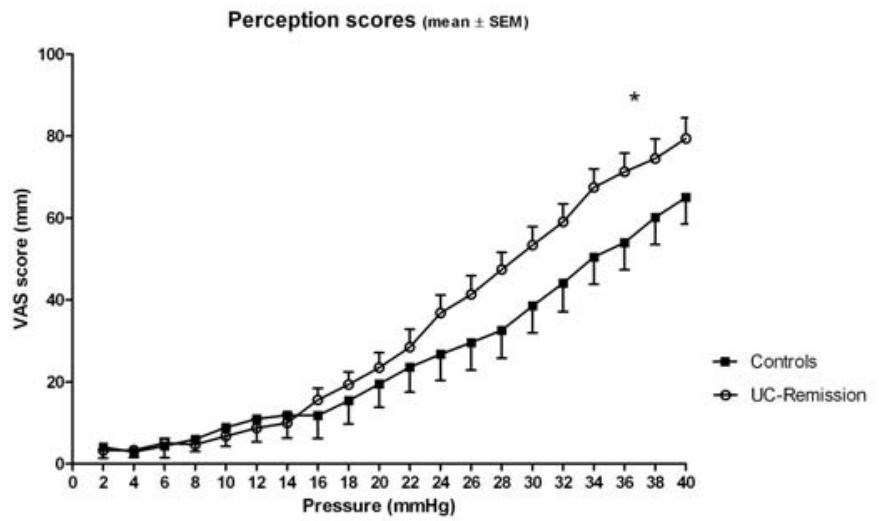

Figure 7.2 Visceroperception during isobaric distension. Visceroperception during isobaric rectal distension. Controls = control group; UC = Patient group with Ulcerative Colitis. Values are expressed as mean \pm SEM. ${ }^{*} \mathrm{p}<0.05$ for UC vs. Controls

\section{Mast cells}

The number of mucosal mast cells was significantly higher in the UCR group versus controls (Figure 7.3A, 7.3B and Table 7.2). Furthermore both the percentage of mast cells in proximity to nerve endings as well as the percentage of degranulating mast cells was also significantly higher in the UCR group versus controls. A significant but weak correlation was observed between the number of mucosal mast cells per 100 crypts 
and the mean perception during isobaric distensions, ranging from 32 to $40 \mathrm{mmHg}$ $(r=0.32 ; p<0.05)$ for both groups together.

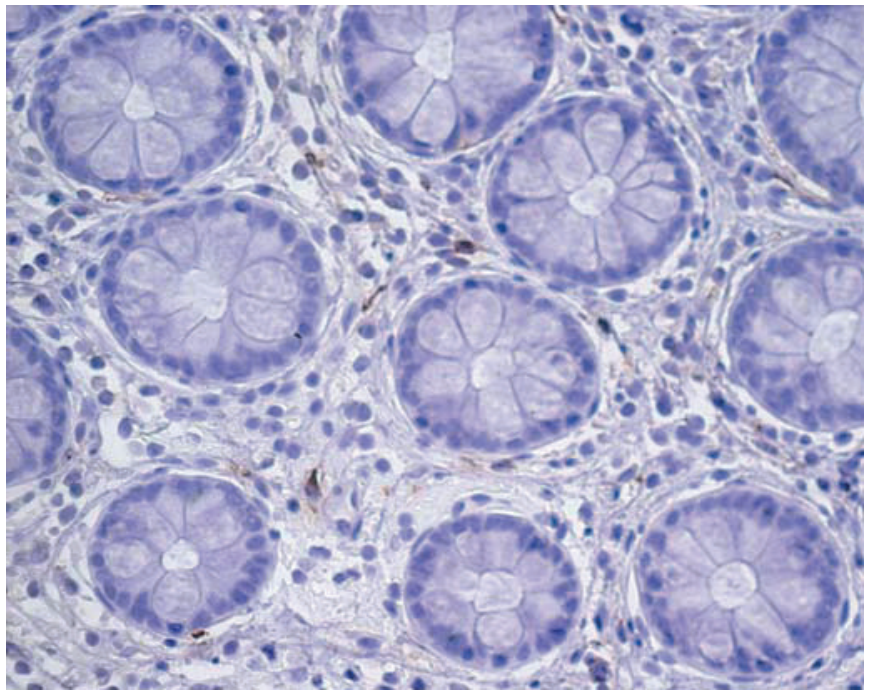

Figure 7.3A Tryptase stained mast cells in a control subject

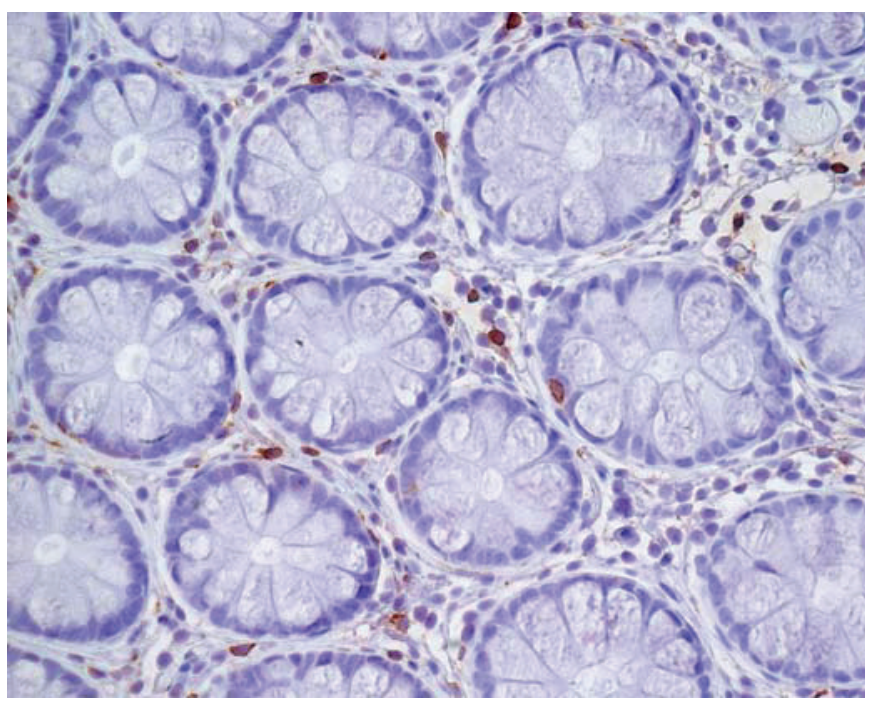

Figure 7.3B Mast cells, immunohistochemistry: Tryptase stained mast cells in an UCR subject. 
In the $50 \%$ UCR patients with $5 \%$ highest versus $50 \%$ with lowest perception scores, as measured by barostat, the number of mast cells per 100 crypts was significantly different: $273 \pm 23$ vs. $205 \pm 17$ per 100 crypts $(p<0.05$ ) respectively but no differences were observed in percentage mast cells in close proximity to nerve endings ( $59 \pm 7$ vs. $58 \pm 6 \%$ ) or percentage degranulating mast cells ( $37 \pm 10$ vs. $43 \pm 10 \%)$.

Table 7.2 Mast cell characteristics

\begin{tabular}{lcc}
\hline & $\begin{array}{c}\text { Controls } \\
(\mathbf{n = 1 7})\end{array}$ & $\begin{array}{c}\text { UCR } \\
(\mathbf{n}=\mathbf{1 9})\end{array}$ \\
\hline \# mast cells / 100 crypts & $163 \pm 18$ & $228 \pm 20^{*}$ \\
\% of mast cells in close proximity $(<5 \mu \mathrm{m})$ to nerve ending & $38 \pm 3$ & $58 \pm 4^{*}$ \\
\% of mast cells degranulating & $16 \pm 4$ & $40 \pm 7^{*}$ \\
\hline
\end{tabular}

$* \mathrm{p}<0.05$ UCR vs. controls

\section{Mediation analysis}

A mediation analysis was performed, following the method, described by Baron et al. ${ }^{20}$ in order to test whether the correlation between the perception scores during isobaric distensions $(32-40 \mathrm{mmHg}$ ) and the mean symptom score is mediated by the amount of mucosal mast cells. Although there was 1) a significant correlation between perception scores and mean symptoms scores and 2) a significant correlation between perception scores and the amount of mast cells, no significant correlation was observed between the amount of mast cells and mean symptom scores. Therefore it is unlikely, that the correlation between perception scores and mean symptom scores is mediated by the amount of mucosal mast cells.

\section{DISCUSSION}

In 1983 Isgar et al. ${ }^{21}$ have shown us, that in UCR patients the prevalence of symptoms suggestive of a 'motility disturbance' is increased in comparison with controls. Later these findings have been confirmed by several other studies. ${ }^{16}$ An association has been found between these symptoms and psychological factors, a decreased quality of life and increased health resource ultilization..$^{22,23,24}$ However, the mechanism, underlying this phenomenon remained incompletely understood.

In the present study we have observed that UCR patients are characterized by increased rectal sensitivity. Rectal sensitivity was found to be correlated with the amount of daily IBS-like abdominal symptoms. 
The UCR patients experienced significantly more perception of urge, discomfort or pain than controls during pressure distensions in the range from 32 to $40 \mathrm{mmHg}$. A weak but significant correlation was found between the number of mucosal mast cells and pain perception in the UCR group and UCR patients with highest perception scores for had a significantly higher number of mucosal mast cells per 100 crypts than UCR-patients with lower perception scores. To our knowledge, this is the first study to report on an association between mast cell count and visceroperception in UCR.

Barbara et al. have observed a correlation between abdominal symptoms in IBS patients and a close proximity of mast cells to colonic nerve endings. ${ }^{5}$ Furthermore the amount of both tryptase and histamine was found to be increased in colonic mucosa of IBS patients. In a rat model of IBS, the amount of degranulating mast cells was positively associated with visceral hypersensitivity. ${ }^{25}$ We hypothesize that the pathophysiological mechanisms underlying visceral hypersensitivity in patients with UCR resemble those of an IBS subgroup: patients with post-infectious type of IBS that have recovered from the acute inflammation with persistence of mast cells that are in closer proximity to nerve endings. This hypothesis is based on our observation that mast cells in UCR patients are found in larger quantities compared to controls, more frequently show signs of degranulation and more frequently are found in proximity to nerve endings.

Mast cells are inflammatory type cells, containing granules with serotonin, proteinases (i.e. tryptase, chymase, carboxypeptidase), histamine, anti-coagulants and several chemotactic factors. Of the mediators secreted by mast cells, tryptase and histamine are of special interest, with respect to visceral sensitivity. Proteinase activated receptors (PAR), especially PAR- 2 and PAR-4 are activated by luminal proteases and increase colonic permeability. These receptors are also activated by mast cells release of tryptase and histamine. ${ }^{26,27}$ Activation of PAR affects visceral hypersensitivity. PAR receptors are found to be overexpressed in colonic biopsies of UC patients. ${ }^{26}$ Tryptase has been shown to activate PAR receptors expressed on primary afferent nerves to initiate visceral hyperalgesia. ${ }^{28}$ Histamine is also known to activate enteric and extrinsic neurons. ${ }^{29}$ The sensitization of afferent nerve terminals results in an increased response to non- painful and painful stimuli. Within this process, the close proximity between mast cells and the endings of sensory neurons results in an amplifying loop. It is likely, that the association between visceroperception and the presence of mast cells in close proximity to nerve endings in patients with UCR, as observed in this study, can be explained by this mechanism. Nevertheless it should be underlined, that the correlation between viscero perception and mucosal mast cell quantity in this study although significant, is rather weak. Therefore it is likely, that several other factors also 
contribute to visceral hypersensitivity in patients with UCR, for example psychological factors as described by Simren et al. ${ }^{26}$

\section{CONCLUSION}

Our findings indicate that patients with UCR are characterized by 1) visceral hypersensitivity to rectal distension, 2) a number of mast cells in the mucosa, activated mast cells and close proximity of mast cells to colonic nerve endings, that are significantly increased and 3) a correlation between rectal hypersensitivity and abdominal, IBS-like symptoms and number of mast cells. 


\section{REFERENCES}

1. Longstreth GF, Thompson WG, Chey WD, Houghton LA, Mearin F, Spiller RC. Functional bowel disorders. Gastroenterology. 2006;130:1480-91.

2. van der Veek PP, Van Rood YR, Masclee AA. Symptom severity but not psychopathology predicts visceral hypersensitivity in irritable bowel syndrome. Clin Gastroenterol Hepatol. 2008;6:321-8.

3. Kanazawa M, Palsson OS, Thiwan SI, Turner MJ, van Tilburg MA, Gangarosa LM, Chitkara DK, Fukudo S, Drossman DA, Whitehead WE. Contributions of pain sensitivity and colonic motility to IBS symptom severity and predominant bowel habits. Am J Gastroenterol. 2008; 103:2550-61.

4. Azpiroz F, Bouin M, Camilleri M, Mayer EA, Poitras P, Serra J, Spiller RC. Mechanisms of hypersensitivity in IBS and functional disorders. Neurogastroenterol Motil. 2007;19:62-88

5. Barbara G, Stanghellini V, De Giorgio R, Cremon C, Cottrell GS, Santini D, Pasquinelli G, Morselli-Labate AM, Grady EF, Bunnett NW, Collins SM, Corinaldesi R. Activated mast cells in proximity to colonic nerves correlate with abdominal pain in irritable bowel syndrome. Gastroenterology. 2004;126: 693-702.

6. Barbara G, Wang B, Stanghellini V, de Giorgio R, Cremon C, Di Nardo G, Trevisani M, Campi B, Geppetti P, Tonini M, Bunnett NW, Grundy D, Corinaldesi R. Mast cell-dependent excitation of visceralnociceptive sensory neurons in irritable bowel syndrome. Gastroenterology. 2007; 132:26-37.

7. Dunlop SP, Jenkins D, Spiller RC. Distinctive clinical, psychological, and histological features of postinfective irritable bowel syndrome. Am J Gastroenterol. 2003;98:1578-83.

8. Cremon C, Gargano L, Morselli-Labate AM, Santini D, Cogliandro RF, De Giorgio R, Stanghellini V, Corinaldesi R, Barbara G. Mucosal immune activation in irritable bowel syndrome: gender-dependence and association with digestive symptoms. Am J Gastroenterol. 2009;104:392-400.

9. Parry S, Forgacs I. Intestinal infection and irritable bowel syndrome. Eur J Gastroenterol Hepatol. 2005;17:5-9.

10. Rodriguez LA, Ruigomez A. Increased risk of irritable bowel syndrome after bacterial gastroenteritis: cohort study. BMJ. 1999;318:565-6.

11. Spiller RC. Postinfectious irritable bowel syndrome. Gastroenterology. 2003;124:1662-71.

12. Podolsky DK. Inflammatory bowel disease. N Engl J Med. 2002;347:417-29.

13. He SH. Key role of mast cells and their major secretory products in inflammatory bowel disease. World J Gastroenterol. 2004;10:309-18.

14. Seo M, Okada M, Maeda K, Oh K. Correlation between endoscopic severity and the clinical activity index in ulcerative colitis. Am J Gastroenterol. 1998;93:2124-9.

15. Chang L, Munakata J, Mayer EA, Schmulson MJ, Johnson TD, Bernstein CN, Saba L, Naliboff B, Anton PA, Matin K. Perceptual responses in patients with inflammatory and functional bowel disease. Gut. 2000;47:497-505.

16. Minderhoud IM, Oldenburg B, Wismeijer JA, van Berge Henegouwen GP, Smout AJ. IBS-like symptoms in patients with inflammatory bowel disease in remission; relationships with quality of life and coping behavior. Dig Dis Sci. 2004;49:469-47.

17. Keohane J, O'Mahony C, O'Mahony L, O'Mahony S, Quigley EM, Shanahan F. Irritable bowel syndrometype symptoms in patients with inflammatory bowel disease: a real association or reflection of occult inflammation ? Am J Gastroenterol. 2010;105:1788, 1789-94.

18. Schroeder KW, Tremaine WJ, Ilstrup DM. Coated oral 5-aminosalicylic acid therapy for mildly to moderately active ulcerative colitis. A randomized study. N Engl J Med. 1987;317:1625-9.

19. van der Veek PP, Swenne CA, Vooren H, Schoneveld AL, Maestri R, Masclee AA. Viscerosensorycardiovascular reflexes: altered baroreflex sensitivity in irritable bowel syndrome. Am J Physiol Regul Integr Comp Physiol. 2005;289:R970-6.

20. Baron RM, Kenny DA. The moderator-mediator variable distinction in social psychological research: Conceptual, strategic and statistical considerations. J Pers Soc Psychol. 1986;51:1173-82.

21. Isgar B, Harman M, Kaye MD, Whorwell PJ. Symptoms of irritable bowel syndrom in ulcerative colitis in remission. Gut. 1983;24:190-2. 
22. Simrén M, Axelsson J, Gillberg R, Abrahamsson H, Svedlund J, Björnsson ES. Quality of life in inflammatory bowel disease in remission> the impact of IBS-like symptoms and associated psychological factors. Am J Gastroenterol. 2002;97:389-96.

23 Farrokhyar F, Marshall JK, Easterbrook B, Irvine EJ. Functional gastrointestinal disorders and mood disorders in patients with inactive inflammatory bowel disease: prevalence and impact on health. Inflamm Bowel Dis. 2006;12:38-46.

24 Ansari R, Attari F, Razjouyan H. Ulcerative colitis and irritable bowel syndrome: relationships with quality of life. Eur J Gastroenterol Hepatol. 2008;20:46-50.

25. La JH, Kim TW, Sung TS, Kim HJ, Kim JY, Yang IS. Role of mucosal mast cells in visceral hypersensitivity in a rat model of irritable bowel syndrome. J Vet Science (Suwon-si, Korea). 2004;5:319-24.

26. Bueno L. Protease activated receptor 2: a new target for IBS treatment. European Rev Med Pharm Sci. 2008;12 Suppl 1:95-102.

27. Dabek M, Ferrier L, Roka R, Gecse K, Annahazi A, Moreau J, Escourrou J, Cartier C, Chaumaz G, Leveque M, Ait-Belgnaoui A, Wittmann T, Theodorou V, Bueno L. Luminal cathepsin g and protease-activated receptor 4: a duet involved in alterations of the colonic epithelial barrier in ulcerative colitis. Am J Path. 2009;175:207-14.

28. Sharkey KA. Visceral sensation and colitis: inflammation and hypersensitivity do not always go hand in hand. Neurogastroenterol Motil. 2006;18:87-90.

29. Bueno L, Fioramonti J, Delvaux M, Frexinos J. Mediators and pharmacology of visceral sensitivity: from basic to clinical investigations. Gastroenterology. 1997;112:1714-43. 


\title{
CHAPTER 8
}

\author{
General discussion
}


Chapter 8 


\section{GENERAL DISCUSSION}

Irritable Bowel Syndrome (IBS) is a highly prevalent functional gastrointestinal (GI) disorder with a female predominance and heterogeneous phenotype. The disorder is characterized by altered bowel habits and abdominal pain in the absence of a clear organic cause. The pathophysiology is still poorly understood and thereby IBS remains a challenge to handle in daily clinical practice. In the current thesis we aimed to study psychosocial, central and intestinal factors as well as patients characteristics that may affect symptom scores in patient with IBS.

In chapter $\mathbf{2}$ of this thesis, we found that psychological factors as well as dysfunctional cognitions significantly affect symptom severity and quality of life (QoL) in IBS patients. IBS symptoms did improve significantly upon treatment with a probiotic when compared to placebo (chapters $\mathbf{3}$ and $\mathbf{4}$ ), but this effect was only seen at the end of the follow-up period (i.e. 8 weeks after the end of treatment) and only in the male population. These findings could not be explained by baseline differences in symptom scores, psychological or lifestyle factors, nor by medication use. Analyses with regard to the epithelial barrier, immune markers and visceral perception did not reveal differences between the probiotic and placebo treated patients, apart from a small although significant decrease in urge perception in a subgroup of the probiotic treated patients. Further analyses in a large IBS cohort (chapter 5), showed decreased 5-HIAA and 5-HIAA/5-HT ratio in IBS patients compared to healthy controls, in which female patients had lower concentrations than male patients. No influence was found for symptoms, anxiety and/or depression nor for medication use on plasma 5-HT, 5-HIAA or their ratio in IBS patients or subgroups with linear regression analysis. In chapter 6 we further explored possible gender differences in IBS patients, showing that female IBS patients exhibit a different disease phenotype than male IBS patients. Furthermore, female IBS patients have significantly lower fecal short chain fatty acid (SCFA) levels compared to male IBS patients. Body Mass Index (BMI) was a significant contributor, however, not influencing the significance in the gender difference, possibly pointing to a role of altered microbial activity in the supposed difference in pathophysiology between female and male IBS patients.

\section{Gender difference}

In an 8 week placebo controlled intervention study with a commercially available probiotic product, we found a clear gender difference in therapy responsiveness after the follow-up period, in which the male population showed a significant benefit of probiotic treatment compared to placebo and in which only the female population showed a clear placebo effect (chapter 3). The gender differences in treatment and 
placebo response could not be explained by psychosocial factors or execution of the study.

In general, placebo responses are found to be high in many IBS trials and may vary between $16 \%$ and $71 \% .{ }^{1}$ Data regarding factors that affect the placebo response (i.e. the frequency of intervention, the number of trial visits and the type of treatment given) are not conclusive. ${ }^{1-3}$ Data on the influence of gender on placebo response are inconsistent, ${ }^{4-7}$ in which several studies suggest even a stronger placebo response in males. Studies in which information was given by female research nurses showed that females and males react differently to the support given by the opposite gender, and only males reacted favorably. This was not supported by our findings. Others hypothesize that men may be less willing to consider themselves "ill" and more willing to believe in the efficacy of treatment. The high female placebo effect could also be influenced by differences in cognitive function or psychosocial comorbidity, but data on psychosocial comorbidity were not available for the patients studied in chapter 3 . It has to be taken into account that the natural history of IBS, with its fluctuating course of disease, affects the placebo response separately from a true placebo effect of a certain treatment. In addition, regression of symptoms towards mean severity may occur, since studies tend to include patients with a high(er) initial symptom severity, after which a second measurement of the symptoms may reveal less pronounced symptom severity. The characteristic feature of IBS is that some weeks are worse than others. In case that patients have been selected for a study in the worst week of their spectrum, they are almost predestined to improve thereafter. ${ }^{8}$ However, this does not explain the observed gender difference.

A high placebo response is typical for IBS and studies in IBS and should be accounted for in power calculation and study design. In addition, a considerably high dropout rate is often reported in IBS trials and therefore intention-to-treat analyses should be performed, as was applied in our probiotic trial. Although the placebo response in females could have masked a probiotic effect, we observed a pronounced and statistically significant effect in males. We did not find differences in other patient characteristics such as medication use, comorbidity or dysfunctional cognitions that could explain this gender difference in therapeutic response. A more in-depth characterization of the phenotype profiles of IBS patients participating in studies, certainly including extensive analysis of psychosocial factors and psychopathology, can help in explaining and understanding the placebo effect. Unfortunately, no data were available regarding microbiota composition in males versus females and changes in this microbiota composition under influence of the probiotic intervention. We believe that the intestinal microbiota may be a missing link in the pathophysiology of IBS and possible gender differences, since chapter 6 on gender differences and biomarkers, showed a significant lower concentration of fecal SCFAS in female compared to male IBS patients. In addition, the study on serotonin metabolism in chapter $\mathbf{5}$ also revealed 
a gender difference. The female IBS population had significantly lower 5-HIAA concentrations compared to the male IBS population, without any relation with anxiety and/or depression or SSRI use. The reason for this gender difference in serotonin metabolism is not clear. A link between sex hormones and serotonin metabolism has been proposed, but not convincingly proven in the literature. ${ }^{9}$ However, evidence is accumulating on a relationship between serotonin metabolism and gut microbiota composition and microbial diversity. ${ }^{10} \mathrm{~A}$ proposed link between sex hormones and microbiota, which has been suggested as an explanation for the female predominance in auto-immune disease may also hold true for IBS. The model to explain the link between sex hormones and microbiota consist of various concepts:

- Sex hormones regulate microbial activity either through immune or metabolic mechanisms

- Microbes are regulators of hormonal metabolism

- Both microbiota and hormones contribute in an additive fashion to effector mechanisms. ${ }^{11}$

\section{Microbiota: the missing link ?}

Both the Maastricht-IBS cohort patients (chapters $\mathbf{5}$ and 6) as well as the participants in the randomized controlled trial on probiotic treatment (chapter 3) handed in fecal samples. The fecal samples of the large Maastricht-IBS cohort will certainly be analyzed with respect to microbial composition in the near future. It is very interesting to compare baseline samples within the well-characterized Maastricht-IBS cohort (i.e $\mathrm{n}=400$ IBS and 200 controls) to assess differences between gender, IBS subtypes, subjects with versus without psychiatric comorbidity and differences between IBS patients and healthy controls. Furthermore, analysis of the functional capacity as well as the production of metabolites i.e. SCFA in combination with dietary analysis which influences both these aspects is warranted. A combination of microbiome, SCFAs and diet analyses in IBS patients, followed prospectively with resampling over time, with evaluation of therapeutic interventions, may provide more detailed insight in the proposed underlying pathophysiologic mechanisms and may help to explain the observed gender differences.

\section{Concurrent psychopathology}

Psychopathology is known to be an important factor contributing to the development of IBS, but also in pertaining IBS symptoms. This is supported by our findings showing high percentages of IBS patients affected with anxiety and/or depression related symptoms. In general, almost two-third of all patients with self-reported depressive symptoms are not identified as such by the attending physician as suffering from psychiatric problems. Screening for psychopathology can easily be performed through 
adequate history taking and using patient questionnaires, and form the basis for additional therapeutic interventions. ${ }^{12,13}$ Although high percentages of concurrent psychopathology have been found in different patient cohorts described in this thesis, the exact role in the IBS pathophysiology has not been clarified fully till now. In our own tertiary center for referral of patients with complex functional gastrointestinal disorders (FGIDs), positive results have been obtained with an integrated medicalpsychiatric outpatient care model showing significant improvement in gastrointestinal and psychiatric symptoms as well as quality of life after 6 months of treatment. ${ }^{14}$

\section{IBS subtypes: relevance of IBS-M?}

Hypotheses regarding the multifactorial etiology in IBS are generally acknowledged and may contribute to the differences between IBS subtypes. The use of IBS subtyping according to predominant bowel habits, as stated in the Rome Criteria, is however of limited value in clinical practice. Furthermore, important symptoms such as bloating are not taken into account. Several studies investigating pathophysiological factors or interventions affecting IBS symptoms focus on differences between subtypes, often comparing patients with diarrhea (IBS-D) versus those with constipation (IBS-C). The IBS-M subtype with mixed stool patterns has been neglected due to the relative difficulty to characterize this subtype with varying stool consistencies over time. ${ }^{15}$ Nevertheless, IBS-M appears to be the most common subtype of IBS. ${ }^{16}$ The study on serotonin metabolism in chapter $\mathbf{5}$ showed clear differences for the IBS-M subtype versus other subtypes, in which the 5-HIAA/5-HT ratio was significantly lower compared to healthy controls and IBS-D patients, suggesting that IBS-M is worth exploring in future IBS studies.

We postulate that IBS-M should be considered a separate entity in IBS, possibly with a different pathophysiological background in comparison to IBS-D and IBS-C. Future studies should therefore make comparisons between all subtypes including sufficient numbers of patients. A large well-characterized patient group is included in the Maastricht-IBS cohort and could possibly be used to shed more light on the characteristics of the IBS-M subtype.

\section{The Maastricht-IBS Cohort}

In this thesis, two studies have been conducted using patients included in the Maastricht-IBS Cohort. This cohort currently includes over 500 IBS patients, who have been extensively phenotyped with collection of fecal, blood and exhaled air samples. Subgroups underwent assessments for visceral perception and/or intestinal permeability. Analyses regarding microbiota composition, metabolomics in exhaled air, host genetics and diet are currently ongoing. Possibly these data, combined with the data presented in this thesis, may provide leads for further studies gaining more 
detailed insight in the pathophysiology and identify groups of IBS patients for specific treatments. Since IBS is a very heterogeneous condition with frequent medication use, associated comorbidity and a multifactorial pathophysiology, large population based cohorts are needed to assess genotype-phenotype interactions and to elucidate the pathogenesis of IBS and relevant subgroups thereof. Therefore, standardized phenotyping of the IBS population is necessary to enable pan-European co-operations, since IBS is not only heterogeneous but also influenced by lifestyle factors and geographic differences throughout the world.

\section{How to proceed in clinical practice?}

Up to $40 \%$ of patients visiting the outpatient clinic of the gastroenterologist suffers from a functional GI disorder. Lack of understanding on underlying explanations for IBS is a handicap in clinical practice, hindering diagnosis, communication, and management. ${ }^{17}$ Patients worry about having a serious disease, partly caused by lack of understanding of their illness, ${ }^{18}$ but also due to limited information and frustration about the explanation by the physician. ${ }^{19-21}$ Dissatisfaction of IBS patients regarding their treatment and interaction with their treating physician is common and has an impact on disease outcome. ${ }^{22}$ Both education of patients and efforts should be undertaken in regaining control of a patient's condition and on treatment options (i.e. patient empowerment), which may contribute to improve patient satisfaction and lead to less symptomatology with a higher quality of life.

A recent study ${ }^{17}$ has provided suggestions on how to explain IBS and its causes to patients:

- The brain sends signals in such a way that they are over-interpreted by the bowel.

- The bowel receives signals over-sensitively.

- The bowel processes signals over-sensitively and this affects bowel function.

- The function of the bowel is affected by the autonomic and enteric nervous system.

- The bowel sends signals in such a way that they are over-interpreted by the brain.

- The brain receives or processes signals too sensitively.

- The brain misinterprets normal signals from the body as signs of imbalance or disease.

- Food, bacteria, or substances found in the gut can sometimes cause the gut to malfunction and trigger symptoms.

Furthermore, the WGO Guideline for IBS (2009) provides tips on how to handle the symptoms and concerns of the IBS patients:

- Identify and explore the patient's concerns. 
- A positive patient-physician relationship should be established, with the patient's symptoms and distress being accepted as real.

- Appreciate the impact of symptoms.

- Discuss patient's anxieties related to symptoms and possible diagnoses, with the aim being to eliminate unnecessary worries.

- Identify and help resolve stressful factors.

- Reduce avoidance behavior.

Steps have been undertaken towards shared decision making in IBS. These include detailed information on various therapeutic (effective) interventions with their potential benefit and risks, effort and time needed to be invested by patients. An example of such a program is the project called REDUCE IBS, initiated by the IBS patients association in the Netherlands (PDSB) and gastroenterologists (www.pdsb.nl). The treatment options are divided in groups: general information and explanation; without drugs (dietary interventions, probiotics, hypnotic therapy); drugs acting on the bowel (antibiotics, peppermint oil, spasmolytics); and drugs acting on the brain (tricyclic anti-depressants or SSRIs). The pilot project will provide information on regaining control of patients over their own condition and treatment options (i.e. patient empowerment).

In summary, gaining more insight in the pathophysiological mechanisms of IBS remains an important goal to identify subgroups of IBS patients that could benefit from targeted interventions. Furthermore, gender and comorbidity should be taken into account.

However, most benefit for patients and their health care providers can be obtained by taking the time to explain to the patient the complex multifactorial condition of IBS, and reassuring patients not having life- threatening diseases.

Furthermore, an important task for gastroenterologists is to stimulate selfempowerment, make sure that patients become in control of their disabling condition. 


\section{REFERENCES}

1. Patel SM, Stason WB, Legedza A, Ock SM, Kaptchuk TJ, Conboy L, et al. The placebo effect in irritable bowel syndrome trials: a meta-analysis. Neurogastroenterol Motil. 2005;17:332-40.

2. Dorn SD, Kaptchuk TJ, Park JB, Nguyen LT, Canenguez K, Nam BH, et al. A meta-analysis of the placebo response in complementary and alternative medicine trials of irritable bowel syndrome. Neurogastroenterol Motil. 2007;19:630-7.

3. Pitz $\mathrm{M}$, Cheang $\mathrm{M}$, Bernstein $\mathrm{CN}$. Defining the predictors of the placebo response in irritable bowel syndrome. Clin Gastroenterol Hepatol. 2005;3:237-47.

4. Camilleri M, Mayer EA, Drossman DA, Heath A, Dukes GE, McSorley D, et al. Improvement in pain and bowel function in female irritable bowel patients with alosetron, a 5-HT3 receptor antagonist. Aliment Pharmacol Ther. 1999;13:1149-59.

5. Flaten MA, Aslaksen PM, Finset A, Simonsen T, Johansen O. Cognitive and emotional factors in placebo analgesia. J Psychosom Res. 2006;61:81-9.

6. Kelley JM, Lembo AJ, Ablon JS, Villanueva JJ, Conboy LA, Levy R, Marci CD, Kerr CE, Kirsch I, Jacobson EE, Riess $\mathrm{H}$, Kaptchuk TJ. Patient and practitioner influences on the placebo effect in irritable bowel syndrome. Psychosom Med. 2009;71:789-97.

7. MacDonald AJ, Peden NR, Hayton R, Mallinson CN, Roberts D, Wormsley KG. Symptom relief and the placebo effect in the trial of an anti-peptic drug. Gut. 1981;22:323-6.

8. Shah E, Pimentel M. Placebo effect in clinical trial design for irritable bowel syndrome. J Neurogastroenterol Motil. 2014;20:163-70.

9. Houghton LA, Brown H, Atkinson W, Morris J, Fell C, Whorwell PJ, Lockhart S, Keevil B. 5hydroxytryptamine signalling in irritable bowel syndrome with diarrhoea: effects of gender and menstrual status. Aliment Pharmacol Ther. 2009;30:919-29.

10. O'Mahony SM, Clarke G, Borre YE, Dinan TG, Cryan JF. Serotonin, tryptophan metabolism and the braingut-microbiome axis. Behav Brain Res. 2015;277:32-48.

11. Yurkovetskiy L, Burrows M, Khan AA, Graham L, Volchkov P, Becker L, Antonopoulos D, Umesaki Y, Chervonsky AV. Gender bias in autoimmunity is influenced by microbiota. Immunity. 2013;39:400-12.

12. Meyer T, Klemme H, Herrmann C. Depression but not anxiety is a significant predictor of physicians' assessments of medical status in physically ill patients. Psychotherapy and psychosomatics. 2000; 69:147-54.

13. Pae CU, Masand PS, Ajwani N, Lee C, Patkar AA. Irritable bowel syndrome in psychiatric perspectives: a comprehensive review. Int J Clin Pract. 2007;61:1708-18.

14. Kruimel J, Leue C, Winkens B, Marcus D, Schoon S, Dellink R, et al. Integrated medical-psychiatric outpatient care in functional gastrointestinal disorders improves outcome: a pilot study. Eur J Gastroenterol Hepatol. 2015;27:721-7.

15. Su AM, Shih W, Presson AP, Chang L. Characterization of symptoms in irritable bowel syndrome with mixed bowel habit pattern. Neurogastroenterol Motil. 2014;26:36-45.

16. Lin S, Mooney PD, Kurien M, Aziz I, Leeds JS, Sanders DS. Prevalence, investigational pathways and diagnostic outcomes in differing irritable bowel syndrome subtypes. Eur J Gastroenterol Hepatol. 2014;26:1176-80.

17. Hungin AP, Becher A, Cayley B, Heidelbaugh JJ, Muris JW, Rubin G, Seifert B, Russell A, De Wit NJ. Irritable bowel syndrome: an integrated explanatory model for clinical practice. Neurogastroenterol Motil. 2015 Feb 20.

18. Faresjo A, Grodzinsky E, Hallert C, Timpka T. Patients with irritable bowel syndrome are more burdened by co-morbidity and worry about serious diseases than healthy controls--eight years follow-up of IBS patients in primary care. BMC Public Health. 2013;13:832.

19. Bijkerk CJ, de Wit NJ, Stalman WA, Knottnerus JA, Hoes AW, Muris JW. Irritable bowel syndrome in primary care: the patients' and doctors' views on symptoms, etiology and management. Can J Gastroenterol. 2003;17:363-8.

20. Stenner PH, Dancey CP, Watts S. The understanding of their illness amongst people with irritable bowel syndrome: a Q methodological study. Soc Sci Med. 2000;51:439-52. 
21. Casiday RE, Hungin AP, Cornford CS, de Wit NJ, Blell MT. Patients' explanatory models for irritable bowel syndrome: symptoms and treatment more important than explaining aetiology. Fam Pract. 2009;26:40-7.

22. Dhaliwal SK, Hunt RH. Doctor-patient interaction for irritable bowel syndrome in primary care: a systematic perspective. Eur J Gastroenterol Hepatol. 2004;16:1161-6. 



\section{SUMMARY}

Irritable Bowel Syndrome (IBS) is a highly prevalent functional gastrointestinal (GI) disorder with a female predominance and heterogeneous phenotype. It contains different subtypes based on predominant bowel habits (i.e diarrhea, constipation).The pathophysiology is still poorly understood and symptom scores in these patients can be affected by a variety of factors and have a major impact on quality of life (QoL). In the current thesis we aimed to study psychosocial, central and intestinal factors as well as patients characteristics that may affect symptom scores in patients with IBS. Furthermore, a probiotic intervention trial was performed.

Chapter 1 provides an overview on the epidemiology and clinical characteristics of IBS, the suggested pathophysiological mechanisms and probiotic treatment in IBS. In addition, specific information of the probiotic strain Lactobacillus casei Shirota (LCS, Yakult ${ }^{\circledR}$ ) has been given, as this strain is used in two studies presented in this thesis.

Chapter $\mathbf{2}$ focuses on the impact of various psychological factors on QoL and symptom severity. Psychological factors (such as anxiety and depression symptoms) are frequently reported in patients with IBS. The aim of this study was to explore the relevance of psychological factors including dysfunctional cognitions on QoL and symptom severity in a large heterogeneous group of IBS patients. We have shown that psychological factors influence symptom severity and QoL in patients with IBS. Patients who suffer from possible anxiety disorders or depression had more severe symptoms, a worse physical and mental QoL and higher dysfunctional cognition scores. Dysfunctional cognitions independently influence physical and mental QoL, but also have a significant impact on symptom severity. Recognizing possible anxiety and depression disorders as well as dysfunctional cognitions in IBS patients can be an important step in symptom relieve and improving quality of life in this difficult to treat patient group. Furthermore, it may help to reduce the burden for health care and economic costs.

In chapter 3 we performed a randomized, double-blind, placebo-controlled intervention study with a commercially available probiotic product containing LcS. It has been previously shown that probiotics affect intestinal microbiota and immune function by interacting with host immune competent cells of the intestinal mucosa, secreting bacterial products and competing with other bacteria. Probiotics have therefore been suggested as a treatment for IBS and meta-analyses point to a beneficial result. The probiotic strain LCS is known to survive adequately throughout the GI tract and was previously found to positively influence chronic obstipation. This placebo controlled randomized study, with intention to treat analyses, aimed to assess 
the effect of LCS on the symptoms and QoL of patients with IBS. No significant difference in improvement of symptom scores between probiotic and placebo treated IBS patients was found after an 8 week intervention. However, we did find a significant difference in several individual symptom scores and the total day score in favour of the probiotic treatment after subjects finished the intervention and the follow-up period, i.e. week 16. The beneficial effect of the intake of LcS was most profound in the male population, while the female population showed a marked placebo effect. The underlying mechanisms for the gender difference observed in this study are unclear. The fact that an effect of LCS was observed at week 16 but not at week 8 indicates that not only the duration of the intervention period is important, but also the duration of follow-up after the intervention.

During the placebo controlled intervention study we performed additional side studies that allowed us to explore the effect of the intervention on underlying pathophysiological mechanisms of IBS, of which the results are described in chapter 4. These pathophysiological factors associated with IBS (i.e. visceral perception, intestinal barrier function and activation of the immune system) may be modified or altered by probiotic strains and/or eventual alterations in gut microbiota composition. Aim of this explorative study was to study potential pathophysiological mechanisms involved in the beneficial effect of LCS in the intervention trial we have performed in IBS patients. We found no differences in stimulated plasma cytokine levels, fecal calprotectin, mast cell numbers or tight junction expression in sigmoid biopsies. Only within the probiotic group a significant decrease in urge perception was found at high barostat pressures after treatment, but no differences were observed between both treatment groups. This exploratory study could not provide clear leads towards the possible mechanism of action of LcS. However, it should be noted that there were several methodological limitations and small patient groups in this study.

In addition to the factors evaluated in chapter 2 and 4, an important role has been claimed for dysregulations along the brain-gut axis in IBS pathophysiology. In chapter $\mathbf{5}$, the role of serotonin (5-hydroxytryptamine, 5-HT) metabolism was explored in a large group of well-characterized IBS patients participating in the Maastricht-IBS cohort. $5-\mathrm{HT}$, as a (neuro)transmitter not only modulates physiological and behavioral processes in the brain but also is a key factor in the regulation of secretion, motility and perception in the gut. Previous studies exploring 5-HT metabolism in IBS, in which plasma levels of 5-HIAA, the principle metabolite of 5-HT, and 5-HIAA/5-HT ratio were measured to reflect the turnover of $5-\mathrm{HT}$, have found contradicting results. We hypothesized that 1) plasma 5-HT and 5-HIAA concentrations are different in IBS patients compared to healthy controls (HC), 2) that this depends on IBS subtype, 3 ) is related to more severe abdominal symptoms, anxiety and depression. We observed a significant decrease in 5-HIAA concentrations and in 5-HIAA/5-HT ratio in IBS patients 
compared to $\mathrm{HCs}$. However, no alterations were observed in $5-\mathrm{HT}$ concentrations between IBS and HC. All IBS subtypes showed lower 5-HIAA levels compared to HC, being most pronounced in the IBS-M subgroup. The $5-\mathrm{HIAA} / 5-\mathrm{HT}$ ratio was significantly lower in IBS-M compared to HC and IBS-D. Linear regression showed a possible influence of gender on 5-HIAA levels, in which the female IBS population has lower 5HIAA levels. No further influence was found for symptoms, anxiety and/or depression nor for medication use on plasma 5-HT, 5-HIAA or their ratio in IBS patients or subgroups with linear regression analysis. Future research should focus on assessment of serotonin metabolism at the intestinal level, possibly combined with plasma measurements, of 5-HT and 5-HIAA, over time, with a specific focus on the IBS-M subtype.

IBS has a clear female predominance and symptom scores may differ between genders. As we observed gender difference in response to LcS (chapter 3 ) and with regard to 5-HT metabolism (chapter 5), we hypothesized that the phenotype differences in female versus male IBS patients relate to a different pathophysiological background. A previously tested detailed biomarkers set, representing various pathophysiological mechanisms in the Maastricht-IBS cohort, was used to screen for gender differences within the IBS population and explore the question of differences in pathophysiological background between IBS males and females in chapter 6 . We observed a significant decrease in short chain fatty acid (SCFA) concentrations in female IBS patients compared to male IBS patients, which was not present in healthy controls and remained significant in a linear regression model. Body Mass Index (BMI) was a significant contributor to SCFA concentrations but did not change the significant difference in SCFA concentration between female and male IBS patients. We would strongly recommend further gender specific investigation of both SCFA and microbiota in large groups of IBS patients, taking into account the dietary intake, BMI and the association with symptom severity.

Visceral hypersensitivity is an important hallmark observed in about half of IBS patients. Previous studies have shown that this could be associated with increased mast cell number and release of mast cell mediators. However it is not clear whether this finding is specific for patients with IBS or to (low grade) chronic inflammation in general. Ulcerative colitis (UC) is a chronic inflammatory bowel disease characterized by periods of remissions and exacerbations. A substantial subset of patients that are in remission report symptoms in absence of any endoscopic sign of disease activity, which resemble that of patients with IBS. We speculated that the previous inflammatory process of UC has resulted in visceral hypersensitivity, which persisted even though the inflammatory infiltrate has regressed and gut architecture has been restored. While inflammatory cells disappear, mast cells remain present in mucosal tissue when the inflammatory 
process has gone into remission. We hypothesized that hypersensitivity to rectal distension is present in a substantial percentage of patients with UC in remission, with at mucosal level a higher number of mast cells in proximity to nerve endings, as is found in IBS. Our findings in chapter $\mathbf{7}$ indicate that patients with UC in remission (UCR) are characterized by 1) visceral hypersensitivity to rectal distension, 2) a number of mast cells in the mucosa, activated mast cells and in close proximity of mast cells to colonic nerve endings, that were significantly increased and 3) found a correlation between rectal hypersensitivity and abdominal. IBS-like symptoms and number of mast cells in these patients. The future challenge for this group of UCR patients is to distinguish persistent inflammation from true remission with IBS complaints.

Chapter 8 provides a general discussion of the implications of the results in this thesis in relation to the current literature, daily clinical practice and in perspective to future research. 
SAMENVATTING 


\section{SAMENVATTING}

Prikkelbare Darm Syndroom (Irritable Bowel Syndrome, IBS) is een veel voorkomende functionele gastro-intestinale aandoening met een heterogeen fenotype, die bij vrouwen tweemaal zo vaak voorkomt als bij mannen.

Het wordt gekenmerkt door verschillende subtypen, gebaseerd op het overheersende stoelgang patroon (zoals diarree of obstipatie). De effectiviteit van beschikbare behandelingen is beperkt, mogelijke ook omdat de pathofysiologie van IBS zo divers is en we te maken hebben met vele oorzakelijke factoren. IBS symptomen hebben een grote impact op de kwaliteit van leven (Quality of Life, QoL) van patiënten. In dit proefschrift hebben we de bijdrage van psychosociale, centrale en perifere factoren alsook patiënt karakteristieken bestudeerd bij patiënten met IBS, alsmede de invloed van deze factoren op symptomen en QoL.

In Hoofdstuk 1 is een overzicht gegeven van de epidemiologie, klinische kenmerken, mogelijke pathofysiologische mechanismen en behandeling (met probiotica) van patiënten met IBS. Aanvullend wordt er specifieke informatie gegeven over het probioticum Lactobacillus casei Shirota (LCS, Yakult ${ }^{\circledR}$ ) dat werd onderzocht in dit proefschrift.

Hoofdstuk 2 gaat in op de impact van verschillende psychologische factoren op QoL en ernst van de symptomen bij IBS. Psychologische factoren (zoals angst en depressieve klachten) worden vaak gerapporteerd bij patiënten met IBS. Het doel van onze studie was om te onderzoeken of psychologische factoren, inclusief dysfunctionele cognities, een relevante impact hebben op ernst van symptomen en op QoL bij IBS patiënten. Patiënten die mogelijk een angststoornis of depressie hebben, vertoonden hogere symptoom scores, een slechtere fysieke en mentale score van QoL en hogere dysfunctionele cognitie scores. Deze dysfunctionele cognities beïnvloeden de fysieke en mentale QoL onafhankelijk van andere psychologische factoren en ze hebben een significante impact op de ernst van de symptomen. Het herkennen en behandelen van een mogelijke onderliggende/bijkomende angst of depressieve stoornis, maar ook van dysfunctionele cognities bij IBS patiënten kan een belangrijke stap zijn in het verlichten van de symptomen en verbeteren van kwaliteit van leven in deze moeilijk te behandelen patiëntengroep. Dit kan leiden tot aanzienlijke kosten reductie in de zorg van deze grote groep patiënten met IBS.

In hoofdstuk 3 hebben we een dubbelblinde gerandomiseerde placebogecontroleerde interventie studie uitgevoegd met een commercieel verkrijgbaar probioticum, LcS. Het is eerder aangetoond dat probiotica de intestinale microbiota en immuunfunctie gunstig kunnen beïnvloeden door een interactie aan te gaan met gastheer immuun 
competente cellen in de intestinale mucosa, secretie van bacteriële producten en competitie met andere bacteriën. Probiotica worden om die reden wel gesuggereerd als een behandelingsoptie voor patiënten met IBS. Uit meta-analyses kan echter niet meer dan een beperkt gunstig effect worden aangetoond.

Het probioticum species LCS overleeft aantoonbaar de passage door het maagdarmstelsel en heeft een positief effect op symptomen van chronische obstipatie. De placebo gecontroleerde, gerandomiseerde studie met intention-to-treat analyse had als doel om het effect van LcS op symptomen en QoL van IBS patiënten te onderzoeken. Er konden geen significante verschillen of verbeteringen van symptoomscores of QoL in de probiotica ten opzichte van de placebo behandelde patiënten worden aangetoond na een 8 weken durende interventie. We vonden echter wel een significant verschil in verschillende symptoomscores waarbij binnen de met probiotica behandelde groep een duidelijk voordeel te zien was van de behandeling welke niet werd gezien in de placebo behandelde groep na 8 weken interventie en vervolgens na 8 weken follow-up (week 16). Het gunstige effect van LcS inname was alleen significant in de mannelijke patiëntenpopulatie, terwijl bij de vrouwelijke patiëntenpopulatie een opvallend sterk placebo effect werd gezien. Het onderliggende mechanisme voor dit geslachtsverschil in deze studie is niet duidelijk. Het feit dat er een effect wordt gezien van LcS op week 16 geeft aan dat niet alleen de duur van de interventie periode, maar ook de follow-up belangrijk is.

Gedurende de hierboven beschreven interventie studie hebben we additionele studies uitgevoerd om het onderliggende pathofysiologische mechanisme van het effect van de probiotica behandeling te exploreren. De resultaten van deze additionele studies worden in hoofdstuk 4 beschreven. De pathofysiologische factoren die geassocieerd worden met IBS, zoals viscerale perceptie, intestinale barrière functie en activatie van het immuun systeem, kunnen direct worden beïnvloed of veranderd door probiotica en/of veranderingen in compositie van de microbiota ten gevolge van probioticagebruik. Het doel van deze exploratieve studie was om te onderzoeken welke pathofysiologische mechanismen betrokken waren bij het gunstige effect wat we hebben gevonden tijdens/na het gebruik van LcS bij IBS patiënten. We vonden geen verschillen in plasma cytokine spiegels, fecaal calprotectine, mestcel aantallen of expressie van 'tight junction' eiwitten in sigmoid biopten van deze patiënten. Binnen de probiotica groep werd een significante afname gezien van urge (aandrang) perceptie bij hoge barostat drukken na 8 weken behandeling, maar er werden geen verschillen tussen de beide behandelgroepen gevonden. Samenvattend gaf deze exploratieve studie geen duidelijke aanknopingspunt welk pathofysiologisch mechanisme het effect van LcS kan verklaren. Echter, het moet worden opgemerkt dat de patiënten aantallen in deze mechanistische studies klein waren en we een aantal factoren niet met zekerheid kunnen uitsluiten. 
Bij IBS is er sprake van een dysregulatie van de 'brain-gut axis' (darm-hersen-as). In hoofdstuk 5 wordt de rol van het serotonine (5-hydroxytryptamine, 5-HT) metabolisme onderzocht in een grote groep goed gekarakteriseerde IBS patiënten geïncludeerd in het Maastricht-IBS cohort. 5-HT is een (neuro) transmitter welke niet alleen fysiologische en gedragsmatige processen in het brein moduleert maar ook een sleutelpositie inneemt in de regulatie van secretie, motiliteit en perceptie van de darm. Eerdere studies naar 5-HT metabolisme in IBS, waarbij ook gekeken is naar plasma niveaus van 5-HIAA (de voornaamste metaboliet van $5-\mathrm{HT}$ ) en de 5-HIAA/5-HT ratio, hebben tegengestelde resultaten opgeleverd. Onze hypothesen waren 1) dat er sprake is van veranderde concentraties van $5-\mathrm{HT}$ en 5 -HIAA in IBS patiënten in vergelijking met gezonde controles, 2) dat deze verandering verschilt tussen IBS subtypes, en 3 ) gerelateerd is aan ernstigere abdominale symptoomscores en aan de aanwezigheid van angst- en depressieklachten. We vonden een significante afname in 5-HIAA en $5-\mathrm{HIAA} / 5 \mathrm{HT}$ ratio in de IBS patiënten ten opzichte van de gezonde controles. Er werden echter geen verschillen gevonden in de $5-\mathrm{HT}$ concentraties tussen IBS patiënten en gezonde controles. Alle IBS subtypes toonden een significant lagere 5-HIAA concentratie ten opzichte van gezonde controles, en deze was het meest uitgesproken in de IBS-M (mixed, gemengde type) groep. De 5-HIAA/5-HT ratio was ook significant lager in IBS-M vergeleken met gezonde controles en vergeleken met de IBS-D (diarree) subgroep. Lineaire regressie analyse toonde een mogelijke invloed van geslacht op de 5-HIAA concentraties, waarbij de vrouwelijke populatie een lager 5-HIAA concentratie had. In deze multivariate analyse werd geen effect gevonden van symptoomscores, angst- en/of depressieklachten of van medicatiegebruik op 5-HT, 5-HIAA of de ratio in IBS patiënten of subtypes. Toekomstige studies zouden meer moeten focussen op het bestuderen van serotonine metabolisme op darm niveau, mogelijk in combinatie met plasma metingen van 5-HT en 5-HIAA, over de tijd, met een speciale aandacht voor het IBS-M subtype.

IBS heeft een duidelijke vrouwelijke predominantie qua prevalentie en de symptomen kunnen verschillen tussen de geslachten. Omdat we een geslachtsverschil hebben geobserveerd in de behandeling met LCS (hoofdstuk 3) en bij de analyse van het 5-HT metabolisme in plasma (hoofdstuk 5), was onze hypothese dat de fenotype verschillen tussen vrouwen en mannen met IBS gerelateerd kunnen zijn aan verschillen in pathofysiologische mechanismen. Een eerder in het Maastricht-IBS cohort geteste biomarker set, als representatie voor verschillende pathofysiologische mechanismen, werd gebruikt om te screenen naar geslachtsverschillen binnen de IBS populatie. De vraag of er sprake kan zijn van verschillende pathofysiologische mechanismen tussen vrouwen en mannen met IBS werd geëxploreerd in hoofdstuk 6. We observeerden een significante afname in fecale korte-keten vetzuren (short chain fatty acid, SCFA) concentraties in vrouwelijke ten opzichte van mannelijke IBS patiënten. Deze afname 
bleef significant in een lineair regressie model en werd niet gezien in gezonde controles. Body Mass Index (BMI) had een significante bijdrage aan de SCFA concentraties, maar het geslachtsverschil bleef significant. We raden sterk aan om in de toekomst verdere geslacht specifieke analyses van zowel SCFA als microbiota te doen in grote groepen IBS patiënten, rekening houden met de dieetgewoonten, BMI en de associatie met symptomen.

Viscerale hypersensitiviteit is een belangrijk kenmerk van IBS en wordt gevonden bij ruim de helft van de IBS patiënten. Viscerale perceptie wordt gemeten middels een rectaal barostat onderzoek. Eerdere studies hebben aangetoond dat viscerale hypersensitiviteit geassocieerd is met verhoogde aantallen mestcellen en een toegenomen vrijkomen van mestcel mediatoren. Het is echter onduidelijk of deze bevindingen specifiek zijn voor IBS patiënten of gelden voor (laaggradige) chronische inflammatie in het algemeen. Colitis ulcerosa (CU) is een chronische inflammatoire darmziekte die wordt gekarakteriseerd door periodes van remissie en exacerbaties. Een groot deel van de CU patiënten die in remissie zijn, blijven symptomen houden in afwezigheid van endoscopische ziekte activiteit. In dit opzicht lijken CU patiënten in remissie op IBS patiënten. We speculeerden dat het voorheen inflammatoire proces van $\mathrm{CU}$ een trigger was die in een latere fase heeft geresulteerd laaggradige 'ongoing' inflammatie met sensitisatie resulterend in viscerale hypersensitiviteit. Onze hypothese was dat hypersensitiviteit bij rectale distensie aanwezig is bij een substantieel deel van de patiënten met $\mathrm{CU}$ in remissie, waarbij in de mucosa een hoger aantal mestcellen wordt gevonden, dichter bij darm-zenuwuiteinden gelegen, zoals ook in IBS eerder is aangetoond. Onze bevindingen in hoofdstuk 7 geven aan dat patiënten met $\mathrm{CU}$ in remissie worden gekarakteriseerd door 1) viscerale hypersensitiviteit bij rectale distensie, 2) een verhoogd aantal mestcellen in de mucosa dichtbij colon zenuwuiteinden en 3 ) een correlatie tussen rectale hypersensitiviteit en abdominale, IBS-gelijkende symptomen en het aantal mestcellen. De toekomstige uitdaging voor medici is om bij deze patiënten met $\mathrm{CU}$ in remissie onderscheid te kunnen maken tussen blijvende inflammatie en klinische remissie in patiënten met IBS-gelijkende symptomen.

Hoofdstuk 8 behandelt in een kort overzicht de implicaties van de resultaten zoals gepresenteerd in dit proefschrift in relatie met de huidige literatuur, dagelijkse praktijk en perspectieven voor toekomstig onderzoek. 



\section{VALORISATION ADDENDUM}

The gut is considered a gateway to many diseases and disorders not only within the gastrointestinal tract but also in other organs or at a systemic level. In the past decade more information has become available with respect to Irritable Bowel Syndrome (IBS). In this thesis, we have evaluated clinical characteristics and potential underlying pathophysiological mechanisms, such as psychosocial, central nervous system and intestinal factors, in patients with IBS in order to gain more insight in this heterogeneous condition.

IBS is a highly prevalent chronic disorder, which is increasingly found in Western countries. The condition is characterized by chronic, recurrent abdominal pain or discomfort associated with alterations in the pattern of defecation, in absence of an organic cause. IBS affects $15-20 \%$ of women and $5-20 \%$ of men in the Netherlands and it is assumed that at least $20 \%$ of the general population is affected at some time during life. Despite the high prevalence and the negative impact of the disorder on quality of life, only a limited number of effective therapeutic entities are available for IBS patients and subgroups of IBS.

Previous studies have focused mainly on symptom improvement in IBS patients, but more recently, many studies have been performed to clarify the pathophysiology of IBS. When underlying pathophysiological mechanisms are better understood, this may open the way to new therapies and to optimize existing therapies. This is a challenging task due to the heterogeneity in presentation of IBS and its multifactorial etiology. Up to now, focusing on further insight in the pathophysiology has not yet led to major breakthroughs or novel therapeutic approaches. Gaining more insight in the pathophysiological mechanisms of IBS remains an important goal and may help to identify subgroups of IBS patients that could benefit from targeted interventions.

Due to the fact that IBS is a chronic disorder, the lack of effective therapies and the relatively high prevalence of IBS, direct healthcare related costs as well as indirect costs related to work-absenteeism are considerable. ${ }^{1}$ IBS patients more frequently utilize healthcare facilities compared to healthy subjects from the general population ${ }^{2}$ and they have a two to three fold higher consumption of medication compared to the general population. Furthermore, about one-third of the IBS patients also suffer from psychiatric comorbidity, requiring pharmacological and/or psychological interventions. An increased awareness for psychosocial context and co-morbidities is warranted, since almost two-third of all patients with self-reported depressive symptoms are not identified by the attending physician. ${ }^{3,4}$ Screening of patients for quality of life, anxiety, depression and dysfunctional cognitions can be performed rather easily through patient questionnaires and is the basis and justification for additional evidence based 
therapeutic interventions. ${ }^{5-7}$ In this thesis we have pointed not only to a pronounced effect of dysfunctional cognitions on quality of life, but also of anxiety and depression, emphasizing the importance of screening for psychiatric complaints in IBS patients and treating them when present.

Patients with IBS actively seek for nutrients, medical of nutritional products and life style adjustments in order to be able to reduce symptoms and improve their quality of life. We have explored the role of a commercially available probiotic product on IBS symptoms in this thesis. No definite answer with respect to the role this of probiotic on IBS symptoms has been provided by us. Also in other studies, the efficacy of probiotics in IBS has been questioned. Based on our data several questions remain to be answered. First, the reason for the difference in response between males and females. Second the timing of the maximum response to the probiotic product. In our study an optimum was reached eight weeks after cessation of the product intake. Third, the mechanisms of action of the potentially beneficial probiotic product. So far, results of probiotic interventions in IBS have been rather disappointing. On the other hand, the role of gut microbiota and gut metabolism in pathogenesis of various gut and systemic disorders is of utmost relevance.

Since IBS has a clear female predominance and symptom scores may differ according to gender, we hypothesize that the phenotype differences in female versus male IBS patients relates to a different pathophysiological background. An important role has been claimed for dysregulations along the brain-gut axis in IBS pathophysiology. We have explored the role of serotonin (5-hydroxytryptamine, 5-HT) metabolism and observed a significant decrease in 5-HIAA concentrations and in 5-HIAA/5-HT ratio in IBS patients compared to healthy controls, with a possible role of gender in the 5-HIAA levels and serotonin metabolism. The question why female IBS patients have lower 5-HIAA plasma levels has not yet been found and warrants further research. We have also observed a significant decrease in short chain fatty acid (SFCA) concentrations in female IBS patients compared to male IBS patients. Based on our observations and findings we strongly recommend further gender specific investigation of the brain-gutaxis, SCFAs and microbiota, taking into account the dietary intake, BMI and the association with symptom severity.

The increasing knowledge about IBS contributes to a better understanding of the condition, not only for patients, but also for their treating physicians. Dissatisfaction of IBS patients regarding their treatment and the interaction with their treating physician is common and has a clear impact on disease outcome. This is to a large extent caused by lack of knowledge and lack of concept to explain to the patient what IBS is and how to manage IBS symptoms. Taking time to explain the complex multifactorial background of IBS to a patient, to acknowledge their symptoms and impact on daily life, and also to reassure patients that no life-threatening diseases is involved, is veryimportant. Furthermore, general practitioners and gastroenterologists should provide patients 
with tools for self-management, becoming more in control over their condition and their symptoms. Further research in IBS is needed before more targeted therapies can be provided. We consider the findings in this thesis as a step forward in a better understanding of IBS and the development of therapeutic strategies for all IBS patients. 


\section{REFERENCES}

1. Inadomi JM, Fennerty MB, Bjorkman D. Systematic review: the economic impact of irritable bowel syndrome. Aliment Pharmacol Ther. 2003;18:671-82.

2. Williams RE, Black CL, Kim HY, Andrews EB, Mangel AW, Buda JJ, et al. Determinants of healthcareseeking behaviour among subjects with irritable bowel syndrome. Aliment Pharmacol Ther. 20061; 23:1667-75.

3. Meyer T, Klemme H, Herrmann C. Depression but not anxiety is a significant predictor of physicians' assessments of medical status in physically ill patients. Psychother Psychosom. 2000;69:147-54.

4. Kroenke K, Jackson JL, Chamberlin J. Depressive and anxiety disorders in patients presenting with physical complaints: clinical predictors and outcome. Am J Med. 1997;103:339-47.

5. Ford AC, Talley NJ, Schoenfeld PS, Quigley EM, Moayyedi P. Efficacy of Antidepressants and Psychological Therapies in Irritable Bowel Syndrome: Systematic Review and Meta-analysis. Gut. 2009; 58:367-78.

6. Pae CU, Masand PS, Ajwani N, Lee C, Patkar AA. Irritable bowel syndrome in psychiatric perspectives: a comprehensive review. Int J Clin Pract. 2007;61:1708-18.

7. Zijdenbos IL, de Wit NJ, van der Heijden GJ, Rubin G, Quartero AO. Psychological treatments for the management of irritable bowel syndrome. Cochrane database of systematic reviews (Online). 2009(1):CD006442. 



\section{DANKWOORD}

Het verschijnen van dit proefschrift valt samen met de afronding van mijn opleiding tot MDL-arts. Dit was initieel niet zo gepland, maar het is een mooie samenkomst van twee mijlpalen. Er komt een einde aan 16 jaar studie, coschappen, onderzoek en opleiding, de top van de berg is bereikt. Nu ga ik op zoek naar de volgende bergtop om te beklimmen en een hobby. Als je zoveel jaar bezig bent geweest, wordt het dankwoord automatisch een lang verhaal. Ik zal proberen me in te houden, maar vooral om geen mensen te vergeten.

Zonder patiënten is er geen wetenschappelijk onderzoek, dus allereerst gaat mijn dank uit naar alle IBS patiënten die hebben meegewerkt aan de onderzoeken in dit proefschrift. Niet alleen hebben jullie de oplossing van de puzzel voor alle IBS patiënten een stukje dichterbij gebracht, maar dankzij jullie ben ik absoluut een betere dokter geworden.

Ik ben veel dank verschuldigd aan mijn promotor, professor Ad Masclee. Beste Ad, door jouw verhuizing naar het bourgondische zuiden ben ik ook in het Maastrichtse beland. Bedankt dat je me toen de tijd hebt gegeven om de beslissing voor mijn verhuizing te nemen. Het schrijven van dit boekje heeft veel geduld van je gevergd, maar ik heb me altijd gesteund gevoeld. Toen er bij mij weer ruimte kwam om het wetenschappelijke werk op te pakken, kreeg ik daarvoor de gelegenheid tijdens het laatste jaar van mijn opleiding, ik ben je erg dankbaar hiervoor. Het stuk wat je op 1 april nakeek bevatte een opmerking in de kantlijn waar ik erg om heb moeten lachen: "Kwestie van smaak: ik zou * bij vrouwen zetten. Wellicht heb je daar ander gender opinie over ......" . Na 11 jaar samenwerking ben je stukken minder onvoorspelbaar voor me geworden, maar grappen in de kantlijn waren toch nog nieuw voor me. Door jouw begeleiding ben ik gevormd als wetenschapper, als MDL-arts en als bestuurder. Mede dankzij onze productieve en goede samenwerking de afgelopen jaren ben ik er van overtuigd dat MaagDarmLeverziekten het vak is waar ik thuis hoor.

Tijdens mijn periode in het Diaconessenhuis in Leiden werd ik begeleid door dr. Cees Clemens, mijn copromotor. Beste Cees, jouw eeuwige optimisme heeft ervoor gezorgd dat ik de (nogal eens) optredende onderzoeksfrustratie naast me neer kon leggen en vol goede moed door kon gaan met ons project. Bijna dagelijks klopte je op mijn deur met nieuwe patiënten, maar vooral ook met nieuwe ideeën, die we ook nog mee konden nemen in het onderzoek. Je bent een ontzettend aardige en empathische dokter, daar heb ik veel van geleerd. Ik ben blij dat je me ook bent blijven begeleiden toen ik naar de andere kant van het land verkaste. Bedankt voor je geduld in dit lange 
proces en je begrip voor de veranderde inhoud van het boekje. We komen elkaar gelukkig nog geregeld tegen in het MDL-wereldje!

Toen ik eenmaal in Maastricht belandde, kreeg mijn tweede copromotor, dr. Daisy Jonkers, een veel prominentere rol in mijn proefschrift "berg beklimming". Lieve Daisy, zonder jouw fantastische begeleiding was dit boekje er nu niet geweest. Jouw deur stond werkelijk altijd open voor overleg, voor het aanhoren van mijn gezeur, voor steun in moeilijke periodes maar vooral ook voor gezelligheid! Presentaties, artikelen en logistieke plannen werden door jou van grondig en kritisch commentaar voorzien, aan jouw kennis heb ik ontzettend veel gehad. Je bent niet alleen een hele goede wetenschapper en fijne copromotor, maar ook nog eens een ontzettend leuk mens. Ik had het nooit gered zonder jou. Heel veel dank voor alles en ik hoop je nog vaak te zien en te spreken in de toekomst.

Ik wil alle leden van de beoordelingscommissie, professor Muris (voorzitter), dr. Strik, dr. Weijenborg en professor Witteman, bedanken voor de tijd en moeite die ze hebben genomen om mijn proefschrift door te lezen en te beoordelen.

Een ziekenhuis waar weinig wetenschappelijk onderzoek wordt gedaan opzadelen met een groot project waar vele afdelingen bij nodig waren, het was nogal wat. Veel medewerkers van het Diaconessenhuis Leiden ben ik dankbaar. De maatschap Interne$\mathrm{MDL}$, de afdeling endoscopie, de polikliniek, alle collega's van verpleegafdeling $2 \mathrm{~B}$, de receptie, de afdeling fysiotherapie, het klinisch chemisch laboratorium, de medische microbiologie, de pathologie, de technische dienst, de goederenontvangst en alle artsassistenten waar ik mee heb samengewerkt, bedankt voor jullie hulp en medewerking om dit project op te zetten en tot een goed einde te brengen.

Bart van der Linden, zonder jou deed de barostat het nu nog niet. Johan Kuyvenhoven en Michiel Alleman, bedankt voor jullie hulp bij het werven van patiënten in jullie ziekenhuizen.

Tijdens het probiotica project werkten we samen met de Universiteit van Antwerpen. Vanessa Vankerckhoven, jouw promotie zal ik nooit vergeten, ik heb bewondering voor hoe je daar stond. Professor Herman Goossens, bedankt voor het constructieve overleg tijdens de projectmeetings. Christine Lammens en Sabine LaChapelle, bedankt voor het werk in het laboratorium. Christopher Goossens en Michael Lavendomme, bedankt voor de ritjes op en neer van Leiden en Maastricht naar Antwerpen.

De probiotica trial werd verricht met Yakult ${ }^{\circledR}$, en vanuit dit bedrijf hebben een aantal mensen me bijgestaan. Jia Zhao and Kaori Suzuki, the project managers, thank you for the constructive dialogues and understanding the delays you had to deal with. Danielle 
van der Linde, Hikari Beck and Kenji Oishi, thank you for the support in the practical execution of the trial.

Na 2 jaar in het vertrouwde Diaconessenhuis belandde ik in Maastricht ineens in een grote onderzoeksgroep en dat was heerlijk. Ik wil iedereen bedanken dat jullie me zo snel hebben opgenomen in de groep, voor alle gezelligheid, de leuke borrels, de stapavondjes, de congressen, de lunches en nog veel meer. Esther Schaepkens, bedankt voor al je werk in het lab, je hebt me enorm veel werk uit handen genomen. Mariëlle Bouwens, Daisy Jonkers, Karen Koning en Eveline Rondagh, ons tripje naar New York en Chicago was in 1 woord fantastisch! Steven Vanhoutvin; dat je niets naar mijn hoofd mocht gooien vond je maar niks, maar onze vrijdagmiddag Limburgse muziekfeestjes met Henrike Hamer bevorderden mijn integratie in Maastricht behoorlijk. Zlatan Mujagic, dank je wel voor de fijne en constructieve samenwerking tijdens mijn inhaalrace begin 2015. Zonder jouw hulp waren er 2 hoofdstukken minder geweest in dit boekje.

Daniel Keszthleyi en Samefko Ludidi, heren, illuster duo, het was fantastisch samenwerken maar vooral ook feesten met jullie, met als onbetwist hoogtepunt ons tripje in de oranje cabrio aan de West Coast in Californië, samen met Mark van Avezaat. Daniel, professor K., bedankt voor de gezelligheid en voor je eeuwige gemopper! Je constructieve bijdrage aan de laatste fase van dit boekje heeft ervoor gezorgd dat ik zelf ook echt begrijp hoe het zit met serotonine (een beetje dan...). Samef, ik heb er bewondering voor hoe je al jouw talenten samen hebt laten komen in je florerende bedrijf. Je danskwaliteiten zijn daarnaast ongeëvenaard en je bent gewoon een schat van een man! Karen Koning, lieve Ka'tje: zonder jou was Maastricht nooit zo leuk geweest en had ik me niet zo snel thuis gevoeld. Wat een fijne vriendin heb ik overgehouden aan mijn onderzoekstijd in het Maastrichtse. Bedankt voor alles!

Eind 2009 begon ik met de MDL opleiding, waarvan ik 3 jaar in het Atrium MC te Heerlen doorbracht. Ik heb meer dan goede herinneringen aan mijn tijd in het Heerlense; de hectiek en het harde werken, de hechte groep assistenten, de maatschap interne-MDL, de MDL verpleegkundigen, de polikliniekmedewerkers, de geweldige endoscopie afdeling en vooral ook de Heerlense patiënten-populatie, ik vond het fantastisch.

Ik zwom daar als groentje op de verpleegafdeling samen met Joëlle Suijkerbuijk, zonder jou was ik niet meer boven komen drijven. Ik respecteer je om je zeer gedegen vakkennis, je hart voor de patiënt, maar vooral waardeer ik je als ontzettend lieve vriendin. Samen met Myriam Chalabi vormen wij een top trio! Myriam, zelden heb ik zo'n goede dokter meegemaakt als jij, maar ik was vooral blij dat ik iemand trof waar coassistenten ook wel eens bang voor zijn. Stiekem zijn we ontzettend lief hoor! Jij 
floreert nu in het AvL, het geluk straalt van je af en ik ben erg blij voor je dat het zo goed gaat daar.

Alle collega AIOS MDL waar ik mee heb mogen werken tijdens mijn opleiding: Michel Aquarius, Paul Bours, Renske Deutz, Maarten van Dijk, Frank Govaert, Jeoffrey Haans, Chantal Hoge, Reggy Jaspers, Daniel Keszthelyi, Sander de Kort, Paulien Liedorp, Tamara Munnecom, Helena Pilate, Jos Ramaker, Linda Roberts-Bos, Eveline Rondagh, Bram Schaap, Gerben Schouten, Corinne Spooren, Karen Steenhuisen en Jef Verbeek; bedankt voor het lachen, luisteren, sparren, met me mee zeuren, de steun tijdens moeilijkere tijden, de borrels en voor alle gezelligheid! Zonder jullie was de opleiding stukken minder leuk geweest. Ik zal altijd met veel plezier terugdenken aan het Kippenhok, en de periode met vrijwel alleen mannelijke collega's staat in mijn geheugen gegrift, vooral de ochtenden.....

Chantal Hoge, een speciaal woord voor jou. Lieve Ch, van collega semi-arts in het Diaconessenhuis tot collega AIOS MDL in het MUMC+ én het Atrium MC, tot nog even "mijn baas" in het MUMC+, maar bovenal een zeer gewaardeerde vriendin. Veel respect heb ik voor je doorzettingsvermogen en de keuzes die je hebt gemaakt. Helaas gaan we nu toch echt in verschillende regio's aan de slag, maar ons fijne contact zal blijven, daar ben ik van overtuigd. En een tripje Barcelona moet er zeker weer eens van komen!

Elly Mares en Mietsie Tijssens, dames, dank voor de gezellige praatjes, het luisterend oor, het regelen van afspraken in de drukbezette agenda van de prof en het afhandelen van allerlei administratieve zaken. Daarnaast al het personeel van de polikliniek, endoscopie afdeling en de verpleegkundig specialisten in het MUMC, bedankt voor de fijne samenwerking. Tiny Wouters, bedankt voor je hulp met de lay-out en praktische zaken in de laatste fase van de totstandkoming van dit proefschrift.

Gedurende al die jaren ben ik door vele MDL-artsen opgeleid, jullie hebben mij gemaakt tot de MDL-arts die ik nu ben. Veel dank ben ik verschuldigd aan Minke Bakker, Marc de Bièvre, José Conchillo, Wiet Crobach, Cees van Deursen, Jelle Goedhard, Burkhard Hamacher, Wim Hameeteman, Peter Jansen, Ger Koek, Joanna Kruimel, Yolande Keulemans, Annick van Nunen, Liekele Oostenbrug, Marieke Pierik, Rogier de Ridder, Sylvia Sanduleanu, Jan-Willem Straathof en Anne Witte. Ik hoop jullie nog vaak tegen te komen op de verschillende MDL bijeenkomsten in het land.

Yolande Keulemans, Lieve dok, jij bent, zoals collega van Dijk zou zeggen, een "rolvoorbeeld" voor mij geweest. Mijn zaalstage in het MUMC had ik zonder jouw supervisie niet overleefd. Daarnaast ben je gewoon een fijn mens, die ook de moeilijke keuzes niet schuwt. Ik hoop je nog vaak te zien en te spreken. 
Ik ben enorm trots om 1 van de oprichters te mogen zijn van het Leidse (bio)medische gilde Pluizig \& Blauw, dat nog altijd groeit en bloeit. Een aantal van jullie hebben nog meegewerkt als gezonde controles aan mijn onderzoek, bedankt daarvoor. Sytse van Beek, Marlies van Dalen en Ellen Strijbos, bedankt voor het rondrijden in Cees zijn brakke Golf, jullie zorgden ervoor dat de Yakultjes bij de patiënten kwamen, aan de hand van de door mij zorgvuldig opgestelde (maar niet altijd handige) routes. Marlies, jij hebt ook nog eindeloos veel data voor me ingevoerd, zonder jou had ik het nooit gered toentertijd, ontzettend bedankt!

Pluizig en Blauw meiden worden ouder en daarmee Furry \& Grey. Lieve lieve meiden, wat ben ik blij dat ik jullie heb getroffen in het Leidse. Chantal, Charlotte, Emma, Fabienne, Judith, Mariëlle, Marlies, Tatiana en Yvonne, met jullie ben ik volwassen geworden en hoop ik ook bejaard te worden. Bedankt voor alle mooie weekendjes weg, de vele feestjes en etentjes, het eindeloze gebel en inmiddels ge-app, de enorme hoeveelheid kinderen waar ik suikertante voor kan spelen en voor jullie onvoorwaardelijke vriendschap.

Mariëlle Eefting-Koper, lieve Jellie, wij zijn echt vanaf de eerste minuut dat we in Leiden arriveerden vriendinnen. Hoewel we op papier een wat onwaarschijnlijke combinatie lijken, matchen we heel goed. Inmiddels ben je zo goed als klaar als interventie cardioloog en heb je een prachtig gezin gesticht met Matthijs. Jullie hebben het vermogen om me altijd welkom te laten voelen bij jullie thuis, jullie zijn een ontzettend warm en open stel. Jullie prachtige huwelijk, met de pasgeboren Wessel, staat als getuige in mijn geheugen gegrift, en ik ben erg gelukkig dat we met zijn allen in dezelfde regio zullen wonen en werken de komende jaren. Ik zal niet bij jullie intrekken, maar kom wel zeer regelmatig een hapje mee eten, goed?

Fabienne Roossien, lieve Fab, chica! Jouw positieve kijk op het leven en naar de mens, je vermogen om altijd het goede te zien, staat soms in schril contrast met mijn wat tot pessimisme neigende visie, maar is juist daarom zeer waardevol voor mij. Je bent een onvoorwaardelijke vriendin sinds het prille begin van onze studententijd in Leiden, we hebben wat gefeest samen, en pinnen kunnen we nog steeds als de beste;-). Je bent stoer en ontzettend stabiel, een steun en toeverlaat niet alleen voor mij maar voor je vele vriendinnen, maar ook voor alle patiënten die op jouw SEH hun leven aan je toevertrouwen. Samen met je man Niek heb je 2 prachtige meiden op de wereld gezet en ik hoop nog heel lang te mogen meegenieten van jullie geluk. Gaan jullie nog eens terug naar Aruba? Want dan kom ik graag weer een weekje logeren....

Judith van Veldhoven-Rath, lieve Juud, jij was ooit een beetje bang voor mij...... gelukkig is het goed gekomen! Het is nooit stil met jou, je bent druk, bezig met van alles tegelijk 
en altijd actief. Je barst van de ambitie, zowel op het gebied van werk als op persoonlijk vlak, waar je fijne huwelijk met Peter en je florerende gezin een prachtig resultaat van zijn. Je kan ook erg twijfelen over dingen, je spart graag over hoe je zaken wil aanpakken en als het zo uitkomt hebben we elkaar 3x/dag aan de telefoon totdat we eruit zijn. Bij jou en Peet ben ik altijd welkom, je bent er gewoon, als het goed gaat, maar vooral ook toen ik het moeilijk had. Jullie hebben 2 prachtige meiden gekregen waar ik helemaal gek op ben en die ik kan zien opgroeien, zeker nu ik weer meer in de buurt kom wonen. Jij staat als paranimf naast me vandaag omdat jij een wetenschappelijke ambitie en vooral ook talent hebt wat vanuit je tenen komt, zoveel wetenschap als jij gedaan hebt tijdens je volledig perifere opleiding tot neuroloog, dat doen weinigen je na. Ik ben er van overtuigd dat je een geweldige carrière tegemoet gaat! Bedankt dat je naast me staat bij mijn verdediging, en in mijn leven.

Peter Thijssen, lieve broer, jij weet als geen ander hoe lastig de berg van het promoveren te beklimmen is. Uiteraard sta jij als paranimf naast mij vandaag, van ons tweeën ben jij de rasechte wetenschapper. Jij begreep maar weinig van mijn Leidse studentenleven, ik heb helemaal niks van jouw sportiviteit in me, maar hoe ouder we worden, hoe beter we elkaar begrijpen en hoe meer we aan elkaar hebben. Inmiddels weten we helaas ook dat samen een afschuwelijke tijd doormaken onze band alleen maar heeft versterkt. Ik ben super trots op je, hoe je in het leven staat, je scherpe humor, je loyaliteit naar je vrienden, je bereidheid om altijd te helpen en zaken op je te nemen die ieder ander zou laten liggen als iemand het moeilijk heeft. Inmiddels heb je een hartstikke leuke en lieve vriendin getroffen in Kirsten, ik ben heel blij met mijn schoonzus. Maak er wat moois van samen!

Lieve mama, samen met papa heb je mij, en Peter, altijd gesteund maar nooit gepusht. Jullie waren er altijd, een warm, gelukkig en ontzettend stabiel thuis. Toen papa wegviel, kwam er een oerkracht in jou boven. Je hebt gestreden voor de beste zorg voor papa en vooral heel veel onvoorwaardelijke liefde aan hem gegeven. Ik ben zo ontzettend trots op hoe je dit hebt gedaan. Ik lijk in veel opzichten op papa, maar 1 ding is zeker, mijn klinische blik heb ik van jou, een onmisbare eigenschap in mijn vak. $\mathrm{Jij}$ hebt het vaak eerder dan ik in de gaten dat er iets mis is met iemand. Maar stiekem lijk ik nog veel meer op jou hoor. Van koken worden we allebei niet blij, van lekker eten dan weer wel! Daarnaast delen we onze liefde voor mooie schoenen, kleding en makeup en kunnen we dus ook heel goed samen shoppen. Commentaar leveren op van alles en iedereen zijn we ook behoorlijk bedreven in, mijn weinige subtiele opmerkingen heb ik dus ook niet van een vreemde. Lieve mama, bedankt voor alles, ik ben heel blij dat ik straks weer een stuk dichterbij je zit. Want je weet, Limburg is mooi, maar je wil er ook wel weer eens weg!

Papa, gelukkig weet ik dat je trots zou zijn op mama, Peter en mij. 



\section{CURRICULUM VITAE}

Annemieke Yvonne Thijssen was born on October $1^{\text {st }} 1981$ in Leidschendam, the Netherlands. After finishing her secondary education in 1999, she started her medical education at Leiden University. During her studies she was a fulltime board member of the Leiden Medical Students' Association (M.F.L.S.) for one year. In 2004, she fulfilled her scientific project at the department of Gastroenterology and Hepatology at the Leiden University Medical Centre (LUMC) under supervision of Ad Masclee. After graduating from medical school in October 2006, she started working at the department of Internal Medicine at the Diaconessenhuis Leiden. She started her research project leading to this thesis in March of 2007. In September 2008, she moved to Maastricht to continue her research project at the Maastricht University Medical Centre+ (MUMC+). In December 2009, she started her residency in Gastroenterology at the Atrium Medical Center Heerlen and MUMC+. In March 2012, she began as boardmember of the Gastroenterology trainee association (NVMDL i.o.), of which she was the chair from September 2013 until March 2015. She is an active member of the Committee of Quality and the "Scientific agenda" project at this moment, both part of the Dutch Gastroenterology and Hepatology association (NVMDL). She will finish her residency with a special focus on digestive oncology in November 2015 and will start working as a Gastroenterologist at the Albert Schweitzer Hospital in Dordrecht at December $1^{\text {st }}$. 